Nevada

Environmental

Restoration

Project

Streamlined Approach for

Environmental Restoration

(SAFER) Plan for Corrective

Action Unit 544: Cellars, Mud Pits,

and Oil Spills

Nevada Test Site, Nevada

Controlled Copy No.:

Revision No.: 0

July 2010

Approved for public release; further dissemination unlimited.

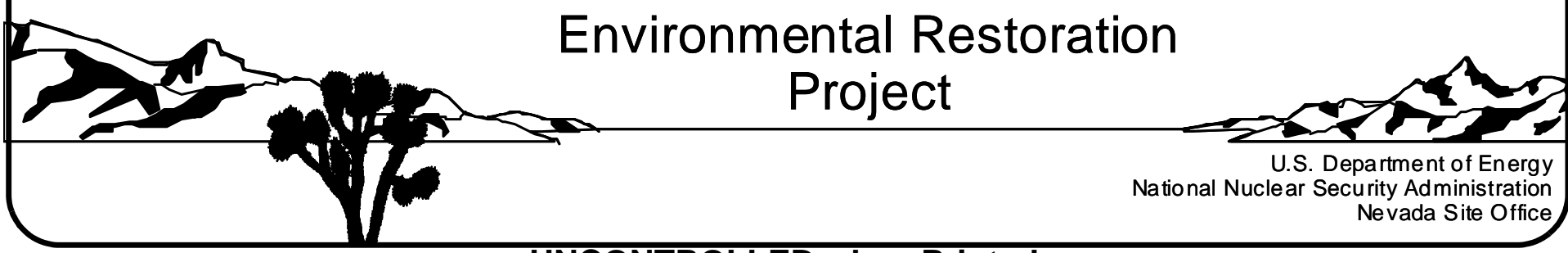


Available for sale to the public from:

U.S. Department of Commerce

National Technical Information Service

5301 Shawnee Road

Alexandria, VA 22312

Telephone: 800.553.6847

Fax: 703.605.6900

E-mail: orders@ntis.gov

Online Ordering: http://www.ntis.gov/help/ordermethods.aspx

Available electronically at http://www.osti.gov/bridge

Available for a processing fee to U.S. Department of Energy and its contractors, in paper, from:

U.S. Department of Energy

Office of Scientific and Technical Information

P.O. Box 62

Oak Ridge, TN 37831-0062

Phone: 865.576.8401

Fax: 865.576.5728

Email: reports@adonis.osti.gov

Reference herein to any specific commercial product, process, or service by trade name, trademark, manufacturer, or otherwise, does not necessarily constitute or imply its endorsement, recommendation, or favoring by the United States Government or any agency thereof or its contractors or subcontractors. 


\title{
STREAMLINED APPROACH FOR ENVIRONMENTAL RESTORATION (SAFER) PLAN FOR CORRECTIVE ACTION UNIT 544: CELLARS, MUD PITS, AND OIL SPILLS NEVADA TEST SITE, NEVADA
}

\author{
U.S. Department of Energy \\ National Nuclear Security Administration \\ Nevada Site Office \\ Las Vegas, Nevada
}

Controlled Copy No.:

Revision No.: 0

July 2010

Approved for public release; further dissemination unlimited.

Reviewed and determined to be UNCLASSIFIED.
Derivative Classifier: $\frac{\text { Joseph P. Johnston/NNES CO }}{\text { (Name/personal identifier and position title) }}$
Signature: $/$ /S/Joseph P. Johnston
Date: $6 / 30 / 2010$


STREAMLINED APPROACH FOR ENVIRONMENTAL RESTORATION (SAFER) PLAN FOR CORRECTIVE ACTION UNIT 544:

CELLARS, MUD PITS, AND OIL SPILLS

NEVADA TEST SITE, NEVADA

Approved by: /s/Kevin J. Cabble

Date: 6/30/2010

Kevin J. Cabble

Federal Sub-Project Director

Industrial Sites Sub-Project

Approved by: /s/Robert F. Boehlecke

Date: 6/30/2010

Robert F. Boehlecke

Federal Project Director

Environmental Restoration Project 


\section{Table of Contents}

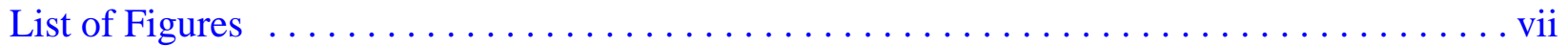

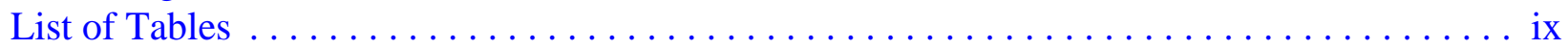

List of Acronyms and Abbreviations . . . . . . . . . . . . . . . . . .

Executive Summary . . . . . . . . . . . . . . . . . . . . . . . . ES-1

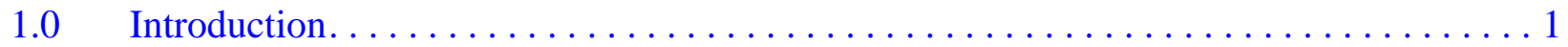

1.1 SAFER Process Description . . . . . . . . . . . . . . . . . 4

1.2 Summary of Corrective Actions and Closures . . . . . . . . . . . . . 5

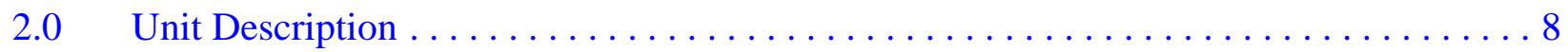

2.1 Mud Pit/Cellar CASs Located in Radiologically Controlled Areas . . . . . . . . 12

2.1.1 CAS 02-37-08, Cellar \& Mud Pit. . . . . . . . . . . . . . . . . 12

2.1.1.1 History and Process Knowledge . . . . . . . . . . . 14

2.1.1.2 Available Characterization Information . . . . . . . . . 14

2.1.2 CAS 02-37-09, Cellar \& Mud Pit. . . . . . . . . . . . . . 14

2.1.2.1 History and Process Knowledge . . . . . . . . . . . 16

2.1.2.2 Available Characterization Information . . . . . . . . . 16

2.1.3 CAS 09-09-46, U-9itsx20 PS \#1A Mud Pit . . . . . . . . . . . . . 16

2.1.3.1 History and Process Knowledge . . . . . . . . . . 17

2.1.3.2 Available Characterization Information . . . . . . . . . . 17

2.2 Oil/Waste Spill CASs Located in Non-radiologically Controlled Areas . . . . . . 19

2.2.1 CAS 19-25-01, Oil Spill. . . . . . . . . . . . . . . . . . 19

2.2.1.1 History and Process Knowledge . . . . . . . . . . . 19

2.2.1.2 Available Characterization Information . . . . . . . . . . 19

2.2.2 CAS 19-99-06, Waste Spill . . . . . . . . . . . . . . . . . 21

2.2.2.1 History and Process Knowledge . . . . . . . . . . 21

2.2.2.2 Available Characterization Information . . . . . . . . . 21

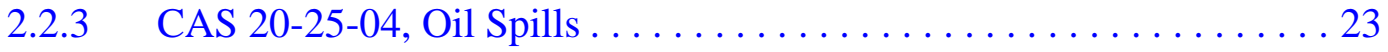

2.2.3.1 History and Process Knowledge ................. 23

2.2.3.2 Available Characterization Information . . . . . . . . . . . 23

2.2.4 CAS 20-25-05, Oil Spills . . . . . . . . . . . . . . . . . . . 23

2.2.4.1 History and Process Knowledge . . . . . . . . . . . 25

2.2.4.2 Available Characterization Information ............ 25

2.3 Mud Pit CASs Located in Non-radiologically Controlled Areas . . . . . . . . . . . 25

2.3.1 CAS 02-37-08, Cellar \& Mud Pit. . . . . . . . . . . . . . . . . 25

2.3.1.1 History and Process Knowledge . . . . . . . . . . 27

2.3.1.2 Available Characterization Information . . . . . . . . . . 27

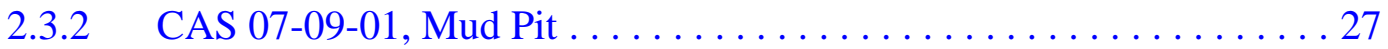

2.3.2.1 History and Process Knowledge . . . . . . . . . . 27

2.3.2.2 Available Characterization Information . . . . . . . . . 29 


\section{Table of Contents (Continued)}

2.3.3 CAS 10-09-01, Mud Pit .......................... 29

2.3.3.1 History and Process Knowledge .................. 29

2.3.3.2 Available Characterization Information .............. 31

2.3.4 CAS 12-09-03, Mud Pit ........................ 31

2.3.4.1 History and Process Knowledge .................. 31

2.3.4.2 Available Characterization Information ................ 31

2.3.5 CAS 19-09-01, Mud Pits (2) ....................... 31

2.3.5.1 History and Process Knowledge ................ 33

2.3.5.2 Available Characterization Information .............. 33

2.3.6 CAS 19-09-03, Mud Pit ......................... 33

2.3.6.1 History and Process Knowledge .................. 33

2.3.6.2 Available Characterization Information ............. 36

2.3.7 CAS 19-09-04, Mud Pit ......................... 36

2.3.7.1 History and Process Knowledge ................. 36

2.3.7.2 Available Characterization Information ............. 36

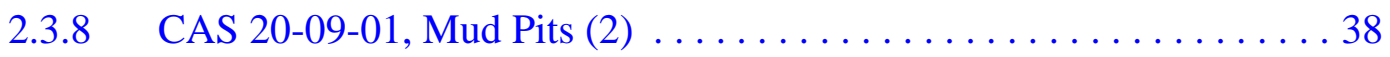

2.3.8.1 History and Process Knowledge ............... 38

2.3.8.2 Available Characterization Information ............. 38

2.3.9 CAS 20-09-02, Mud Pit ........................ 38

2.3.9.1 History and Process Knowledge ............... 40

2.3.9.2 Available Characterization Information ............. 40

2.3.10 CAS 20-09-03, Mud Pit ........................ 40

2.3.10.1 History and Process Knowledge $\ldots \ldots \ldots \ldots \ldots \ldots \ldots . . \ldots 40$

2.3.10.2 Available Characterization Information ............. 42

2.3.11 CAS 20-09-04, Mud Pits (2) ..................... 42

2.3.11.1 History and Process Knowledge $\ldots \ldots \ldots \ldots \ldots \ldots \ldots . . . \ldots 2$

2.3.11.2 Available Characterization Information .............. 42

2.3.12 CAS 20-09-06, Mud Pit ......................... 43

2.3.12.1 History and Process Knowledge ............... 43

2.3.12.2 Available Characterization Information ............... 43

2.3.13 CAS 20-09-07, Mud Pit ......................... 43

2.3.13.1 History and Process Knowledge ................. 45

2.3.13.2 Available Characterization Information . . . . . . . . . . . 45

2.3.14 CAS 20-09-10, Mud Pit ........................ 45

2.3.14.1 History and Process Knowledge ................. 48

2.3.14.2 Available Characterization Information ............. 48

2.4 Summary of Mud Pit CASs Located in Non-radiologically

Controlled Areas................................... 48 


\section{Table of Contents (Continued)}

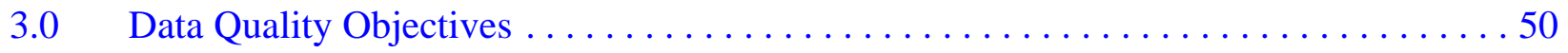

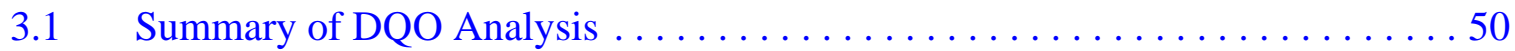

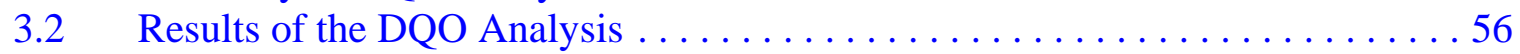

3.2.1 Action Level Determination and Basis.................. 56

3.2.1.1 Chemical PALs ......................... 57

3.2.1.2 Radionuclide PALs . . . . . . . . . . . . . . . . . . . 59

3.2.2 Hypothesis Test . . . . . . . . . . . . . . . . . . . . . . 59

3.2.3 Statistical Model............................ 59

3.2.4 Design Description/Option.......................6 60

3.2.4.1 Judgmental Sampling . . . . . . . . . . . . . . . . . 60

3.2.4.2 Probabilistic Sampling ....................6 61

3.2.5 Conceptual Site Model and Drawing ................... 61

$4.0 \quad$ Field Activities and Closure Objectives . . . . . . . . . . . . . . . . . 65

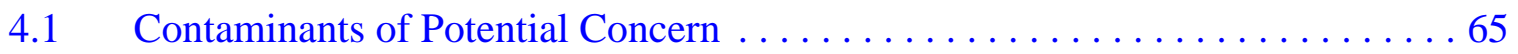

4.1.1 Radionuclides...........................66

4.1.2 Volatile and Semivolatile Organic Compounds.............66 66

4.1.3 Resource Conservation and Recovery Act Metals.............. 66

4.1.4 Polychlorinated Biphenyls . . . . . . . . . . . . . . . . . 67

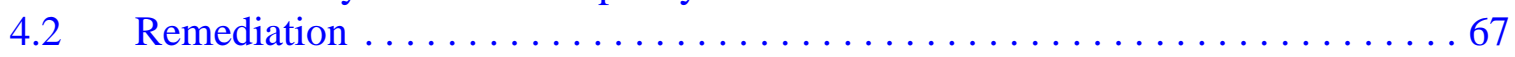

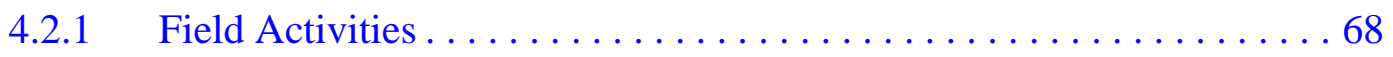

4.2.1.1 Site Preparation Activities $\ldots \ldots \ldots \ldots \ldots \ldots \ldots . \ldots 68$

4.2.1.2 Cellars .............................68

4.2.1.3 Oil and Waste Spills $\ldots \ldots \ldots \ldots \ldots \ldots \ldots \ldots$

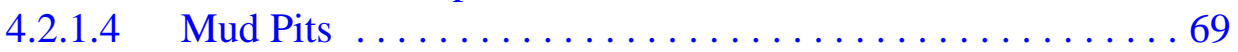

$4.3 \quad$ Verification.......................................... 71

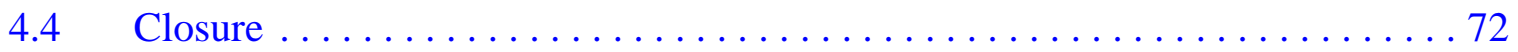

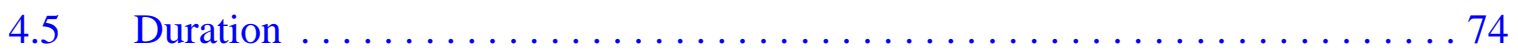

$5.0 \quad$ Reports and Records Availability ............................. 75

6.0 Investigation/Remediation Waste Management ................... 76

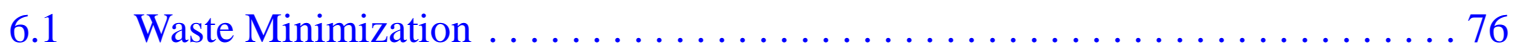

6.2 Potential Waste Streams . . . . . . . . . . . . . . . . . . . . . . . . 77

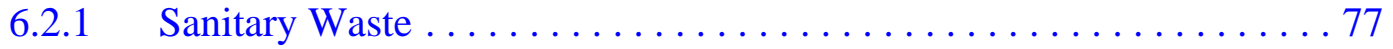

6.2.2 Low-Level Radioactive Waste . . . . . . . . . . . . . . . . . . . . . . 78

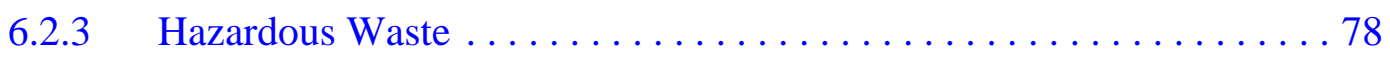

6.2 .4 Hydrocarbon Waste ............................. 79

6.2 .5 Mixed Low-Level Waste .......................... 79

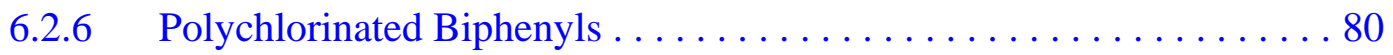




\section{Table of Contents (Continued)}

6.3 Management of Specific Waste Streams $\ldots \ldots \ldots \ldots \ldots \ldots \ldots \ldots \ldots$

6.3.1 Personal Protective Equipment. ..................... 80

6.3.2 Management of Decontamination Rinsate................ 81

6.3.3 Management of Soil and Drilling Mud ................ 81

6.3.4 Management of Debris .......................... 82

7.0 Quality Assurance/Quality Control $\ldots \ldots \ldots \ldots \ldots \ldots \ldots \ldots \ldots \ldots \ldots \ldots$

$7.1 \quad$ Sample Collection Activities . .......................... 83

7.2 Applicable Laboratory/Analytical Data Quality Indicators . . . . . . . . . . . . 84

$7.2 .1 \quad$ Precision....................................... 85

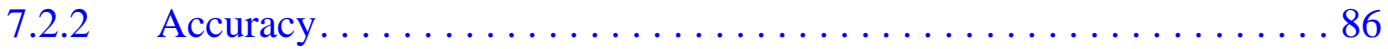

7.2.3 Representativeness ......................... 87

7.2 .4 Completeness ............................. 88

$7.2 .5 \quad$ Comparability ............................... 88

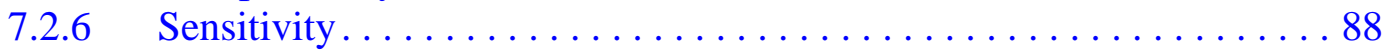

$8.0 \quad$ References............................................ 89

\section{Appendix A - Project Organization}

A.1.0 Project Organization ................................... A-1

\section{Appendix B - Data Quality Objective Process}

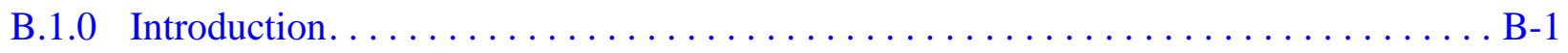

B.2.0 Step 1 - State the Problem........................... B

B.2.1 Planning Team Members $\ldots \ldots \ldots \ldots \ldots \ldots \ldots \ldots \ldots \ldots \ldots \ldots \ldots \ldots \ldots \ldots \ldots$

B.2.2 Conceptual Site Model .............................. B-3

B.2.2.1 Contaminant Release ......................... B-4

B.2.2.1.1 Mud Pits ............................. B

B.2.2.1.2 Cellars ............................. B-10

B.2.2.2 Potential Contaminants........................ B-11

B.2.2.3 Contaminant Characteristics.................... B-13

B.2.2.4 Site Characteristics......................... B-13

B.2.2.5 Migration Pathways and Transport Mechanisms............ B-14

B.2.2.6 Exposure Scenarios ........................ B-16

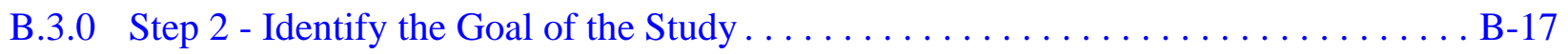

B.3.1 Decision Statements . . . . . . . . . . . . . . . . . . . . . . . 


\section{Table of Contents (Continued)}

B.3.2 Alternative Actions to the Decisions ..................... B-19

B.3.2.1 Alternative Actions to Decision I. .................... B-19

B.3.2.2 Alternative Actions to Decision II . . . . . . . . . . . . . B-19

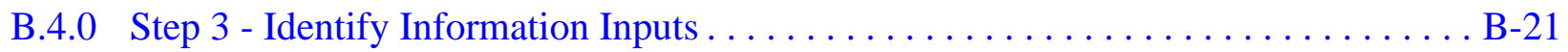

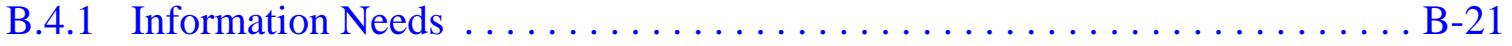

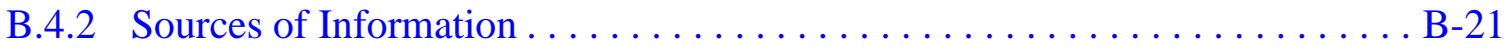

B.4.2.1 Sample Locations ......................... B-22

B.4.2.1.1 Judgmental Approach for Sample

Location Selection $\ldots \ldots \ldots \ldots \ldots \ldots \ldots \ldots \ldots$. B-22

B.4.2.1.2 Probabilistic Approach for Sample

Location Selection ..................... B-24

B.4.2.2 Analytical Methods .......................... B-24

B.5.0 Step 4 - Define the Boundaries of the Study $\ldots \ldots \ldots \ldots \ldots \ldots \ldots \ldots \ldots \ldots$ B-25

B.5.1 Target Populations of Interest. . . . . . . . . . . . . . .

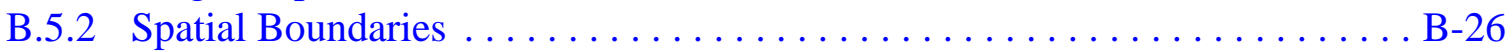

B.5.3 Practical Constraints . . . . . . . . . . . . . . . . . . . . . . . . .

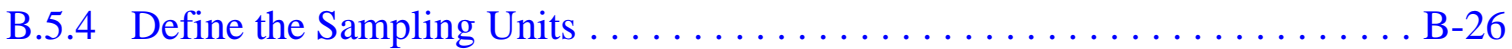

B.6.0 Step 5 - Develop the Analytic Approach $\ldots \ldots \ldots \ldots \ldots \ldots \ldots \ldots \ldots \ldots \ldots$ B-27

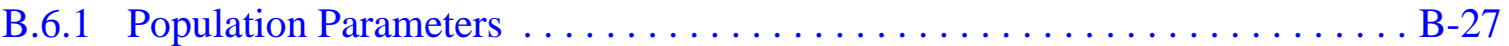

B.6.1.1 Judgmental Sampling Design................... B-27

B.6.1.2 Probabilistic Sampling Design .................... B-27

B.6.2 Action Levels . . . . . . . . . . . . . . . . . . . . . . . . B-28

B.6.2.1 Chemical PALs.............................. B-29

B.6.2.2 Radionuclide PALs.......................... B-30

B.6.3 Decision Rules . .............................. B-30

B.7.0 Step 6 - Specify Performance or Acceptance Criteria .................. B-32

B.7.1 Decision Hypotheses. . . . . . . . . . . . . . . . . . . . . . . . . . B-32

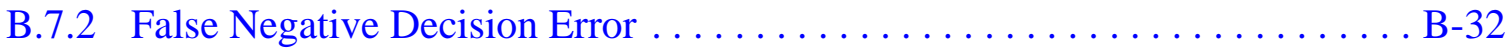

B.7.2.1 False Negative Decision Error for Judgmental Sampling . . . . . . . . B-33

B.7.2.2 False Negative Decision Error for Probabilistic Sampling ....... . B-35

B.7.3 False Positive Decision Error . . . . . . . . . . . . . . . . . . . B-36

B.8.0 Step 7 - Develop the Plan for Obtaining Data $\ldots \ldots \ldots \ldots \ldots \ldots \ldots \ldots \ldots$ B-38

B.8.1 Judgmental Sampling . . . . . . . . . . . . . . . . . . . . . . . B-39

B.8.1.1 Cellar Sampling Design ........................ B-39

B.8.1.2 Oil/Waste Spill Sampling Design................. B-42 


\section{Table of Contents (Continued)}

B.8.2 Probabilistic Sampling Design . . . . . . . . . . . . . . . . . . B-42

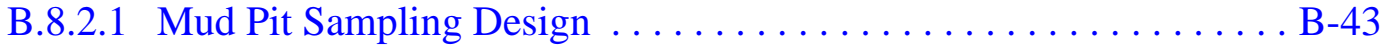

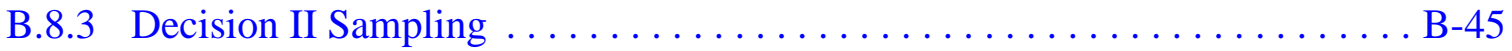

B.9.0 References.................................. B-47

\section{Appendix C - Probabilistic Sampling Plan}

C.1.0 Probabilistic Sampling Plan $\ldots \ldots \ldots \ldots \ldots \ldots \ldots \ldots \ldots \ldots \ldots \ldots \ldots$.1

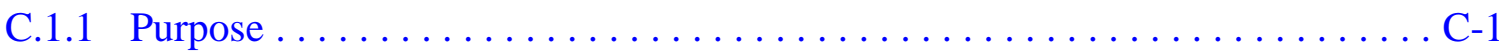

C.1.2 Methodology.................................

C.1.2.1 Computation of the Upper Confidence Limit. . . . . . . . . . . . . . . . C-2

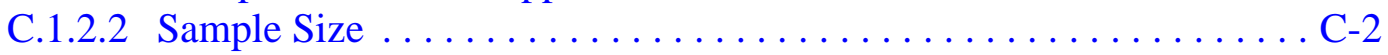

C.1.2.3 Sample Location Selection. ................... C-3

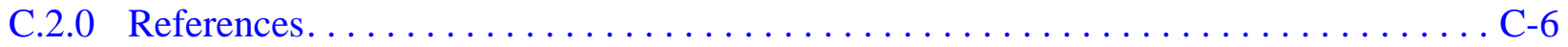

Appendix D - Nevada Division of Environmental Protection Comments 


\section{List of Figures}

Number

Title

Page

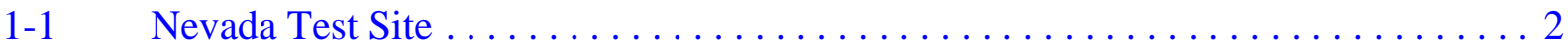

1-2 CAU 544, CAS Location Map $\ldots \ldots \ldots \ldots \ldots \ldots \ldots \ldots \ldots \ldots \ldots \ldots \ldots \ldots \ldots \ldots$

1-3 CAU 544 Closure Decision Process $\ldots \ldots \ldots \ldots \ldots \ldots \ldots \ldots \ldots \ldots \ldots \ldots \ldots \ldots \ldots$

2-1 CAS 02-37-08, Cellar \& Mud Pit, Location with Respect to

Surrounding Roads and Other Physical Features ................... 13

2-2 CAS 02-37-09, Cellar \& Mud Pit, Location with Respect to

Surrounding Roads and Other Physical Features $\ldots \ldots \ldots \ldots \ldots \ldots \ldots \ldots \ldots$

2-3 CAS 09-09-46, U-9itsx20 PS \#1A Mud Pit, Location with

Respect to Surrounding Roads and Other Physical Features .............. 18

2-4 CAS 19-25-01, Oil Spill, Location with Respect to

Surrounding Roads and Other Physical Features .................... 20

2-5 CAS 19-99-06, Waste Spill, Location with Respect to

Surrounding Roads and Other Physical Features $\ldots \ldots \ldots \ldots \ldots \ldots \ldots \ldots . \ldots 22$

2-6 CAS 20-25-04, Oil Spills, Location with Respect to

Surrounding Roads and Other Physical Features ................... 24

2-7 CAS 20-25-05, Oil Spills, Location with Respect to

Surrounding Roads and Other Physical Features .................. 26

2-8 CAS 07-09-01, Mud Pit, Location with Respect to

Surrounding Roads and Other Physical Features $\ldots \ldots \ldots \ldots \ldots \ldots \ldots \ldots . \ldots . \ldots$

2-9 CAS 10-09-01, Mud Pit, Location with Respect to

Surrounding Roads and Other Physical Features .................... 30

2-10 CAS 12-09-03, Mud Pit, Location with Respect to

Surrounding Roads and Other Physical Features ................... 32

2-11 CAS 19-09-01, Mud Pits (2), Location with Respect to

Surrounding Roads and Other Physical Features .................... 34

2-12 CAS 19-09-03, Mud Pit, Location with Respect to

Surrounding Roads and Other Physical Features .................... 35 


\section{List of Figures (Continued)}

Number

Title

Page

2-13 CAS 19-09-04, Mud Pit, Location with Respect to

Surrounding Roads and Other Physical Features

2-14 CAS 20-09-01, Mud Pits (2), and CAS 20-09-02, Mud Pit,

Locations with Respect to Surrounding Roads and

Other Physical Features.

2-15 CAS 20-09-03, Mud Pit, and CAS 20-09-04, Mud Pits (2)

Locations with Respect to Surrounding Roads and

Other Physical Features.

2-16 CAS 20-09-06, Mud Pit, Location with Respect to

Surrounding Roads and Other Physical Features . . . . . . . . . . . . . 44

2-17 CAS 20-09-07, Mud Pit, Location with Respect to

Surrounding Roads and Other Physical Features ............... 46

2-18 CAS 20-09-10, Mud Pit, Location with Respect to

Surrounding Roads and Other Physical Features . . . . . . . . . . . . 47

3-1 Risk-Based Corrective Action Decision Process $\ldots \ldots \ldots \ldots \ldots \ldots$

3-2 Conceptual Site Model Diagram for CAU $544 \ldots \ldots \ldots \ldots \ldots \ldots \ldots \ldots$

3-3 CAU 544 Conceptual Site Model . . . . . . . . . . . . . . . . . . 64

4-1 Example of Sample Locations at Mud Pits $\ldots \ldots \ldots \ldots \ldots \ldots \ldots \ldots$

B.2-1 Conceptual Site Model for CAU 544 CASs $\ldots \ldots \ldots \ldots \ldots \ldots \ldots \ldots \ldots$. . . . . .

B.3-1 SAFER Closure Decision Process for CAU 544 CASs . . . . . . . . . . . . B-18

B.8-1 Proposed Sample Locations at Cellars $\ldots \ldots \ldots \ldots \ldots \ldots \ldots \ldots \ldots \ldots \ldots$ B-41

B.8-2 Proposed Sample Locations at Mud Pits. . . . . . . . . . . . . . B-44

C.1-1 CAS 02-37-09, Sample Locations and Coordinates ................ C-4

C.1-2 CAS 09-09-46, Sample Locations and Coordinates ............... C-5 


\section{List of Tables}

Number

Title

Page

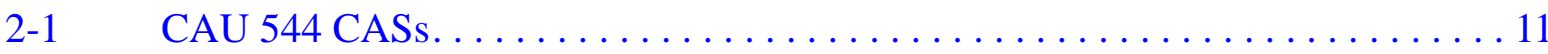

2-2 Summary of Mud Pits Recommended for NFA ................. 48

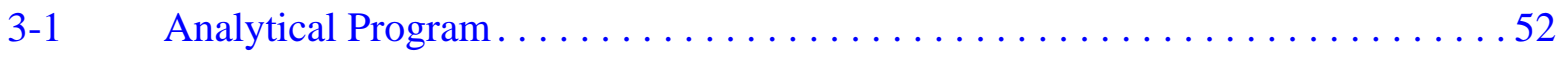

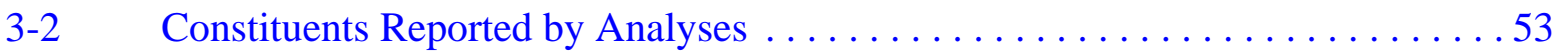

3-4 Analytical Requirements for Radionuclides for CAU $544 \ldots \ldots \ldots \ldots \ldots . \ldots 54$

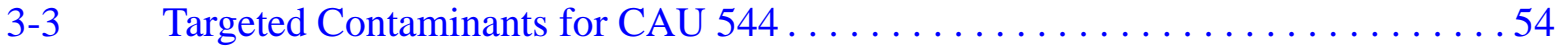

3-5 Analytical Requirements for Chemical COPCs for CAU $544 \ldots \ldots \ldots \ldots 55$

4-1 Sampling Approach for CAU 544 CASs . . . . . . . . . . . . . . . . . 73

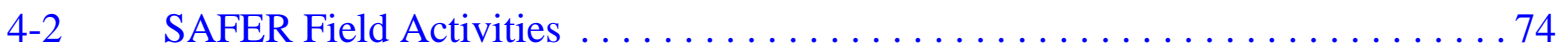

7-1 Laboratory and Analytical Performance Criteria for CAU 544 DQIs . . . . . . . . 84

B.2-1 Conceptual Site Model Description of Elements for Each

CAS Feature in CAU $544 \ldots \ldots \ldots \ldots \ldots \ldots \ldots \ldots \ldots \ldots \ldots \ldots \ldots \ldots \ldots$

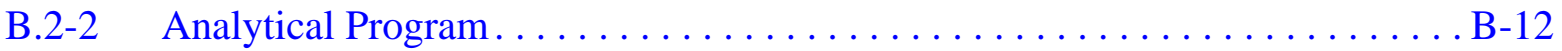

B.2-3 Targeted Contaminants for CAU $544 \ldots \ldots \ldots \ldots \ldots \ldots \ldots \ldots \ldots \ldots$ B-12

B.2-4 Land Use and Exposure Scenarios . . . . . . . . . . . . . . . . .

B.5-1 Spatial Boundaries of CAU 544 CASs...................... B-26

B.8-1 Summary of Sampling Approach and Data Evaluation ............... B-38 


\section{List of Acronyms and Abbreviations}

Ac

Am

ASTM

bgs

BMP

BOP

CAA

CAI

CAS

CAU

CFR

Co

COC

COPC

cps

CR

Cs

CSM

DoD

DOE

DOT

dpm

DQI

DQO

DRO

EPA
Actinium

Americium

American Society for Testing and Materials

Below ground surface

Borehole Management Project

Blowout preventer

Corrective action alternative

Corrective action investigation

Corrective action site

Corrective action unit

Code of Federal Regulations

Cobalt

Contaminant of concern

Contaminant of potential concern

Counts per second

Closure report

Cesium

Conceptual site model

U.S. Department of Defense

U.S. Department of Energy

U.S. Department of Transportation

Disintegrations per minute

Data quality indicator

Data quality objective

Diesel-range organics

U.S. Environmental Protection Agency 


\section{List of Acronyms and Abbreviations (Continued)}

\begin{tabular}{|c|c|}
\hline $\mathrm{Eu}$ & Europium \\
\hline FAL & Final action level \\
\hline FFACO & Federal Facility Agreement and Consent Order \\
\hline FSR & Field-screening result \\
\hline $\mathrm{ft}$ & Foot \\
\hline $\mathrm{ft}^{2}$ & Square foot \\
\hline GPS & Global Positioning System \\
\hline HWAA & Hazardous waste accumulation area \\
\hline IDW & Investigation-derived waste \\
\hline in. & Inch \\
\hline $\mathrm{K}$ & Potassium \\
\hline LANL & Los Alamos National Laboratory \\
\hline LCS & Laboratory control sample \\
\hline LLNL & Lawrence Livermore National Laboratory \\
\hline MDC & Minimum detectable concentration \\
\hline $\mathrm{mg} / \mathrm{kg}$ & Milligrams per kilogram \\
\hline mi & Mile \\
\hline MLLW & Mixed low-level waste \\
\hline $\mathrm{mrem} / \mathrm{yr}$ & Millirem per year \\
\hline MS & Matrix spike \\
\hline MSD & Matrix spike duplicate \\
\hline NAC & Nevada Administrative Code \\
\hline NAD & North American Datum \\
\hline $\mathrm{Nb}$ & Niobium \\
\hline NCRP & National Council on Radiation Protection and Measurements \\
\hline ND & Normalized difference \\
\hline
\end{tabular}




\section{List of Acronyms and Abbreviations (Continued)}

\begin{tabular}{|c|c|}
\hline NDEP & Nevada Division of Environmental Protection \\
\hline NFA & No further action \\
\hline NNES & Navarro Nevada Environmental Services, LLC \\
\hline NNSA/NSO & $\begin{array}{l}\text { U.S. Department of Energy, National Nuclear Security Administration } \\
\text { Nevada Site Office }\end{array}$ \\
\hline NTS & Nevada Test Site \\
\hline NTSWAC & Nevada Test Site Waste Acceptance Criteria \\
\hline PAL & Preliminary action level \\
\hline $\mathrm{Pb}$ & Lead \\
\hline PCB & Polychlorinated biphenyl \\
\hline PPE & Personal protective equipment \\
\hline PSM & Potential source material \\
\hline $\mathrm{Pu}$ & Plutonium \\
\hline QA & Quality assurance \\
\hline QAPP & Quality Assurance Project Plan \\
\hline QC & Quality control \\
\hline RadCon & Radiological Control \\
\hline RBCA & Risk-based corrective action \\
\hline RBCSR & Risk-Based Closure Strategy Report \\
\hline RBSL & Risk-based screening level \\
\hline RCA & Radiologically controlled area \\
\hline RCRA & Resource Conservation and Recovery Act \\
\hline REOP & Real Estate/Operations Permit \\
\hline RL & Reporting limit \\
\hline RMA & Radioactive material area \\
\hline ROTC & Record of Technical Change \\
\hline RPD & Relative percent difference \\
\hline
\end{tabular}




\section{List of Acronyms and Abbreviations (Continued)}

RSL Regional screening level

SAFER Streamlined Approach for Environmental Restoration

SAIC Science Applications International Corporation

SDWS Safe Drinking Water Standards

Sr Strontium

SS Site Supervisor

SSTL Site-specific target level

SVOC Semivolatile organic compound

TCLP Toxicity characteristic leaching procedure

Th Thorium

Tl Thallium

TPH Total petroleum hydrocarbons

TSCA Toxic Substances Control Act

U Uranium

UCL Upper confidence limit

UGTA Underground Test Area

UR Use restriction

URMA Underground radioactive material area

UTM Universal Transverse Mercator

VOC Volatile organic compound

VSP Visual Sample Plan

yd Yard

\% R Percent recovery 


\section{Executive Summary}

This Streamlined Approach for Environmental Restoration (SAFER) Plan addresses the actions needed to achieve closure for Corrective Action Unit (CAU) 544, Cellars, Mud Pits, and Oil Spills, identified in the Federal Facility Agreement and Consent Order (FFACO). Corrective Action Unit 544 comprises the following 20 corrective action sites (CASs) located in Areas 2, 7, 9, 10, 12, 19, and 20 of the Nevada Test Site (NTS):

- 02-37-08, Cellar \& Mud Pit

- 02-37-09, Cellar \& Mud Pit

- 07-09-01, Mud Pit

- 09-09-46, U-9itsx20 PS \#1A Mud Pit

- 10-09-01, Mud Pit

- 12-09-03, Mud Pit

- 19-09-01, Mud Pits (2)

- 19-09-03, Mud Pit

- 19-09-04, Mud Pit

- 19-25-01, Oil Spill

- 19-99-06, Waste Spill

- 20-09-01, Mud Pits (2)

- 20-09-02, Mud Pit

- 20-09-03, Mud Pit

- 20-09-04, Mud Pits (2)

- 20-09-06, Mud Pit

- 20-09-07, Mud Pit

- 20-09-10, Mud Pit

- 20-25-04, Oil Spills

- 20-25-05, Oil Spills

This plan provides the methodology for field activities needed to gather the necessary information for closing each CAS. There is sufficient information and process knowledge from historical documentation and investigations of similar sites regarding the expected nature and extent of potential contaminants to recommend closure of CAU 544 using the SAFER process. Using the approach approved for previous mud pit investigations (CAUs 530-535), 14 mud pits have been identified that

- $\quad$ are either a single mud pit or a system of mud pits,

- are not located in a radiologically posted area, and

- have no evident biasing factors based on visual inspections. 
These 14 mud pits are recommended for no further action (NFA), and further field investigations will not be conducted.

For the sites that do not meet the previously approved closure criteria, additional information will be obtained by conducting a field investigation before selecting the appropriate corrective action for each CAS. The results of the field investigation will support a defensible recommendation for closure of the remaining CASs in CAU 544. This will be presented in a closure report (CR) that will be prepared and submitted to the Nevada Division of Environmental Protection (NDEP) for review and approval.

The sites will be investigated based on the data quality objectives (DQOs) developed on April 27, 2010, by representatives of NDEP and the U.S. Department of Energy (DOE), National Nuclear Security Administration Nevada Site Office (NNSA/NSO). The DQO process was used to identify and define the type, amount, and quality of data needed to determine and implement appropriate corrective actions for each CAS in CAU 544.

The DQO process developed for this CAU identified the following expected closure options: (1) investigation and confirmation that no contamination exists above the final action levels (FALs) leading to an NFA declaration, (2) characterization of the nature and extent of contamination leading to closure in place with use restrictions, (3) clean closure by remediation and verification, (4) closure in place with use restrictions with no investigation if CASs are in crater areas that have been determined to be unsafe to enter, or (5) NFA if the mud pit CAS meets the criteria established during the CAUs 530-535 SAFER investigation.

The following summarizes the SAFER activities that will support the closure of CAU 544:

- Perform visual inspection of all CASs.

- Perform site preparation activities (e.g., utilities clearances, construction of temporary site exclusion zones).

- Removal of easily managed, nonhazardous, and nonradioactive debris, including vegetation (e.g., tumbleweeds), at various CASs that interfere with sampling, if required to inspect soil surface or collect soil sample. 
- Collect environmental samples from designated target populations (e.g., mud pits, cellars, stained soil) to confirm or disprove the presence of contaminants of concern (COCs) as necessary to supplement existing information.

- If no COCs are present at a CAS, establish NFA as the corrective action.

- If COCs exist, collect environmental samples from designated target populations (e.g., clean soil adjacent to contaminated soil) and submit for laboratory analyses to define the extent of COC contamination.

- If a COC is present at a CAS, either

- Establish clean closure as the corrective action. The material to be remediated will be removed, disposed of as waste, and verification samples will be collected from remaining soil, or

- Establish closure in place as the corrective action and implement the appropriate use restrictions.

- Confirm the preferred closure option is sufficient to protect human health and the environment.

This SAFER Plan has been developed in accordance with the FFACO that was agreed to by the State of Nevada; DOE, Environmental Management; U.S. Department of Defense; and DOE, Legacy Management. Under the FFACO, this SAFER Plan will be submitted to NDEP for approval. Fieldwork will be conducted following approval of the plan. 


\subsection{Introduction}

This Streamlined Approach for Environmental Restoration (SAFER) Plan addresses the actions necessary for the closure of Corrective Action Unit (CAU) 544: Cellars, Mud Pits, and Oil Spills, Nevada Test Site (NTS), Nevada. It has been developed in accordance with the Federal Facility Agreement and Consent Order (FFACO) that was agreed to by the State of Nevada; U.S. Department of Energy (DOE), Environmental Management; U.S. Department of Defense; and DOE, Legacy Management (FFACO, 1996; as amended March 2010).

A SAFER may be performed when the following criteria are met:

- Conceptual corrective actions are clearly identified (although some degree of investigation may be necessary to select a specific corrective action before completion of the Corrective Action Investigation [CAI]).

- Uncertainty of the nature and extent of potential contamination, and of the corrective action chosen, must be limited to an acceptable level of risk.

- $\quad$ Decision points and criteria for making data quality objective (DQO) decisions are defined.

The purpose of the CAI will be to document and verify the adequacy of existing information; to confirm the decision for either clean closure, closure in place, or no further action (NFA); and to provide sufficient data to implement the corrective action. The actual corrective action selected will be based on characterization activities implemented under this SAFER Plan. This SAFER Plan identifies decision points developed in cooperation with the Nevada Division of Environmental Protection (NDEP), where the DOE, National Nuclear Security Administration Nevada Site Office (NNSA/NSO) will reach consensus with NDEP before beginning the next phase of work.

Corrective Action Sites (CASs) within CAU 544 are located in Areas 2, 7, 9, 10, 12, 19, and 20 of the NTS, which is approximately 65 miles (mi) northwest of Las Vegas, Nevada (Figure 1-1). Corrective Action Unit 544 includes 20 CASs, which may be located in potential crater areas, and are shown on Figure 1-2 and listed below:

- 02-37-08, Cellar \& Mud Pit

- 02-37-09, Cellar \& Mud Pit

- 07-09-01, Mud Pit 


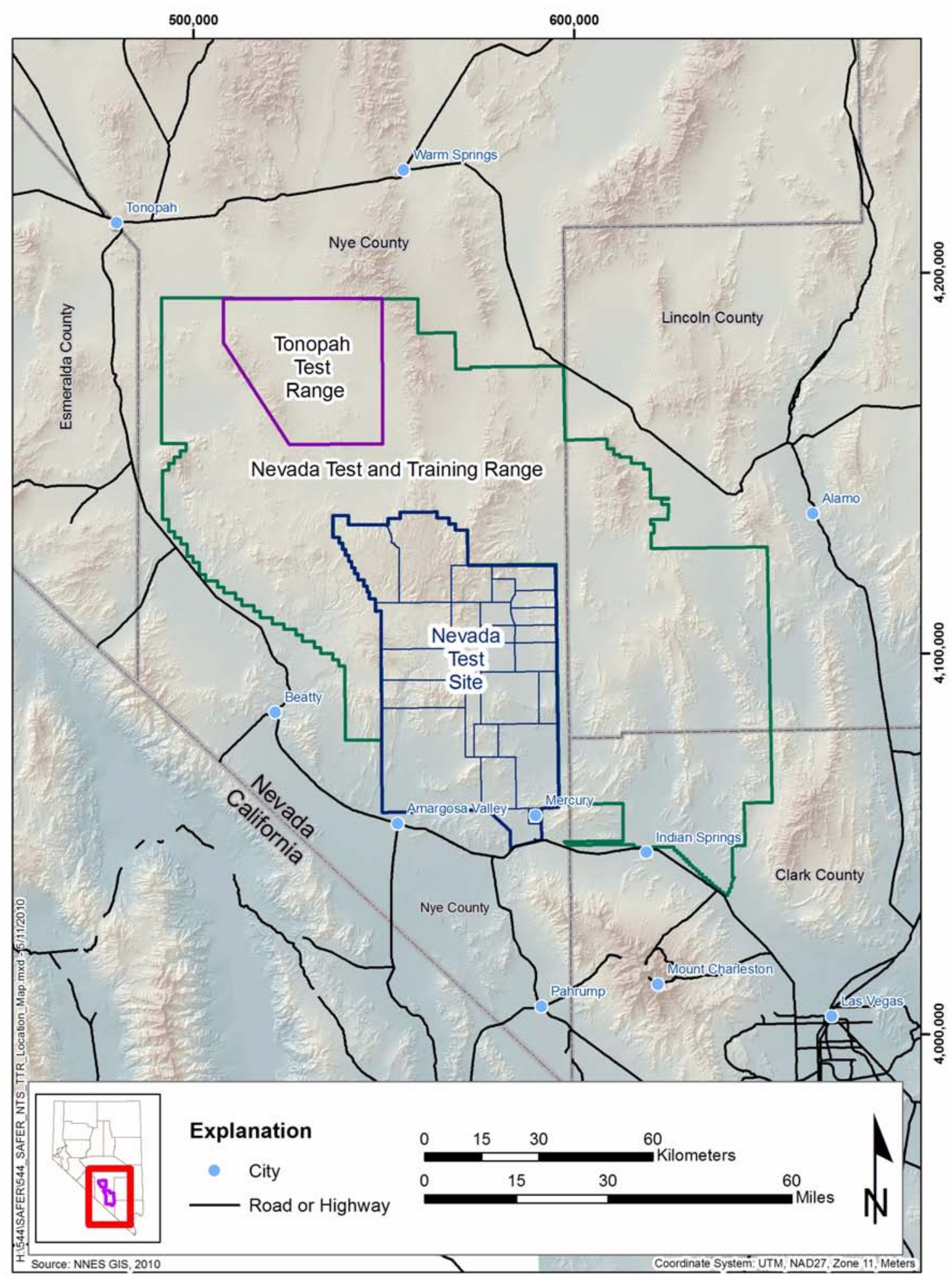

Figure 1-1

Nevada Test Site 


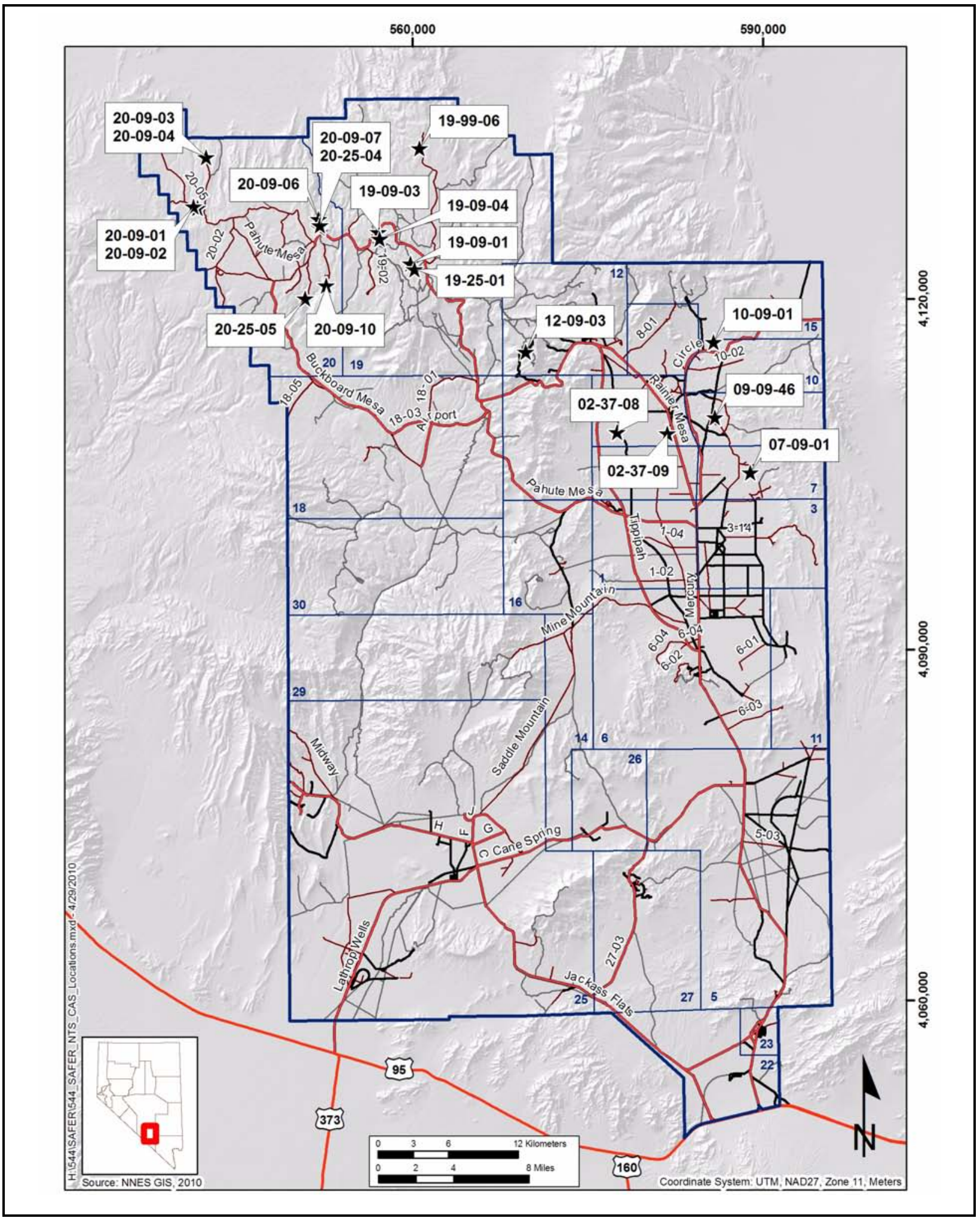

Figure 1-2

CAU 544, CAS Location Map 
- 09-09-46, U-9itsx20 PS \#1A Mud Pit

- 10-09-01, Mud Pit

- 12-09-03, Mud Pit

- 19-09-01, Mud Pits (2)

- 19-09-03, Mud Pit

- 19-09-04, Mud Pit

- 19-25-01, Oil Spill

- 19-99-06, Waste Spill

- 20-09-01, Mud Pits (2)

- 20-09-02, Mud Pit

- 20-09-03, Mud Pit

- 20-09-04, Mud Pits (2)

- 20-09-06, Mud Pit

- 20-09-07, Mud Pit

- 20-09-10, Mud Pit

- 20-25-04, Oil Spills

- 20-25-05, Oil Spills

The CAU is composed of 4 oil/waste spill CASs, 14 mud pit CASs, and 2 cellar and mud pit CASs. There is sufficient information and process knowledge from historical documentation and investigations of other similar sites (i.e., the expected nature and extent of contaminants of potential concern [COPCs]) to recommend closure of CAU 544 using the SAFER process (FFACO, 1996; as amended March 2010). The SAFER process was successfully applied to CAUs 177, 355, 356, 358, and 530-535, which included both mud pits and associated cellars. The Mud Pit Risk-Based Closure Strategy Report (RBCSR) (NNSA/NSO, 2004a) presented sufficient information relating to process knowledge of mud pit operations that have not been affected radiologically and investigation results from similar mud pits to implement the SAFER process, and recommended NFA as the preferred closure alternative for CAUs 530-535. The RBCSR also presented criteria that, if met, would allow future mud pits to be closed without sampling.

\subsection{SAFER Process Description}

Corrective action units that may be closed using the SAFER process have conceptual corrective actions that are clearly identified. Consequently, corrective action alternatives (CAAs) can be chosen before completing a CAI, given anticipated investigation results.

The SAFER process combines elements of the DQO process and the observational approach to plan and conduct closure activities. The DQOs are used to identify the problem and define the type and 
quality of data needed to complete closure of each CAS. The purpose of the CAI phase is to verify the adequacy of existing information used to determine the chosen corrective action and to confirm that closure objectives were met.

Use of the SAFER process allows for technical decisions to be made based on incomplete but sufficient information, and the experience of the decision makers. Any uncertainties are addressed by documented assumptions that are verified by sampling and analysis, data evaluation, and onsite observations, as necessary. Closure activities may proceed simultaneously with site characterization as sufficient data are gathered to confirm or disprove the assumptions made during selection of the corrective action. If, at any time during the closure process, new information is discovered that indicates that closure activities should be revised, closure activities will be re-evaluated as appropriate.

\subsection{Summary of Corrective Actions and Closures}

The decision process for closure of CAU 544 is summarized in Figure 1-3. The process begins with the review of the site history and processes to determine whether the mud pits within the CAU 544 CASs meet the RBCSR criteria for NFA. For mud pits that meet these criteria, the recommendation is for NFA without additional sampling. For mud pits that do not meet the RBCSR criteria, and other CASs or CAS components, the process continues with the initial investigation in which the appropriate target populations within a mud pit, cellar, or oil or waste spill (defined in the DQO process, Appendix B) are sampled. The population of interest for a cellar or oil/waste spill is any location within the cellar or spill that is contaminated with any contaminant above a final action level (FAL) (judgmental sampling). For the mud pits, the population of interest is locations representative of site contamination (probabilistic sampling). If contaminants are detected at concentrations that are above the FALs and remediation can be accomplished, the nature and extent of contamination will be delineated by additional sampling. However, contingencies are built into the process in the event new information is identified which indicates that the selected closure option should be revised. The process ends with a recommendation of NFA for mud pits meeting the RBCSR criteria or closure of the site based on laboratory analytical results of the environmental samples and the preparation of a closure report (CR). Corrective action alternatives of closure in place and clean closure will be 


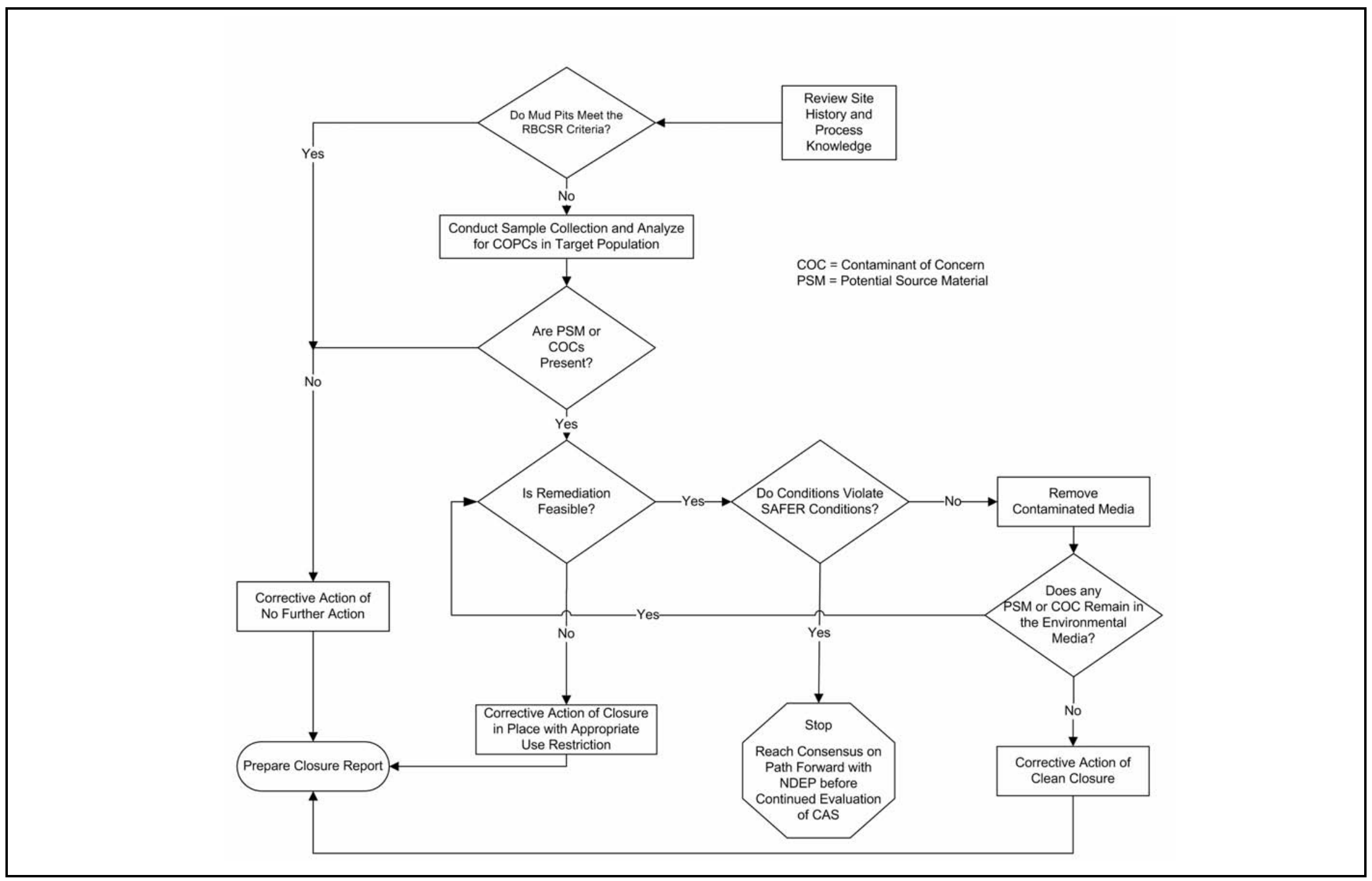

Figure 1-3

CAU 544 Closure Decision Process 
evaluated for each CAS with contaminants above FALs. If there are no contaminants of concern (COCs), then the CAS will be closed with NFA.

Decision points that require a consensus be reached between the NNSA/NSO and NDEP before continuing are indicated in Figure 1-3.

In addition to the previously discussed hold/decision points, work may be temporarily suspended until the issue can be satisfactorily resolved if any of the following unexpected conditions occur:

- Conditions outside the scope of work are encountered.

- Radiological screening yields results which require an upgrade in procedures to continue survey work in specific areas.

- Elevated levels of additional COCs are found that were not originally identified as being present at the sites.

- Unexpected conditions, including unexpected waste and/or contamination, are encountered.

- Out-of-scope work activities are required due to the detection of other COCs that would require re-evaluating a disposal pathway, such as with hazardous or low-level waste.

- Unsafe conditions or work practices.

The anticipated corrective action for most of the CASs in CAU 544 is NFA. It is believed that these CASs will meet risk-based corrective action (RBCA) criteria and result in there being no required corrective actions at many of these CASs. For individual mud pits, cellars, or oil/waste spills, there is also a contingency for a corrective action of closure in place with implementation of use restrictions (URs) if a COC is present and there is sufficient information to establish the boundaries of contamination. 


\subsection{Unit Description}

The CASs within CAU 544 are located within Areas 2, 7, 9, 10, 12, 19, and 20 of the NTS

(Figure 1-2) and are located in potential crater areas. The operational history, process knowledge, and existing information for each CAS is summarized in this section. Process knowledge for the CAU 544 CASs has been obtained through historical document reviews, engineering drawing and map reviews, and interviews with past and present NTS employees. Based on this CAS information, assumptions were made to formulate a conceptual site model (CSM) that describes the most probable scenario for the current conditions at each CAS. Section 3.2.5 provides additional information on the CSM developed for the CASs in CAU 544.

General process knowledge of the CASs and CSM assumptions related to the mud pit and cellar process that serve as the basis for this investigation are:

- Mud pits in CAU 544 are considered to have resulted from essentially the same process. This is supported by the similarities in drilling mud formulations, drilling practices, and contamination profiles for mud pits within the previously investigated mud pits located on the NTS and at offsite locations (NNSA/NSO, 2004a).

- The drilling process homogenized the drilling fluid in the mud pits. The drilling process involved circulating the drilling fluid through the borehole and mud pits. As a result, the drilling fluid was continuously mixed and homogenized throughout the borehole and recirculation pit. This suggests surface samples are representative of the mud throughout the depth of the mud pit. This has been confirmed through previous sampling activities (NNSA/NSO, 2006b).

- Radionuclides are the only COPCs for mud pits. During the development of the closure strategy for CAUs 530-535, sampling results from previous mud pit sampling activities were evaluated, and it was determined that the only COPC for mud pits that were not radiologically affected was total petroleum hydrocarbons (TPH)-diesel-range organics (DRO). In addition, the circulation of drilling fluids was stopped before the post-test drilling reached the depth potentially affected by the nuclear test in order to reduce the likelihood of bringing radioactive material to the surface and into the mud pits. This was confirmed during the CAUs 530-535 CAI. The evaluation of the data further indicated that the TPH-DRO did not pose an unacceptable risk to human health or the environment. For mud pits located in radiologically posted areas such as Contamination Areas or Radioactive Material Areas (RMAs), however, the potential for radionuclides exists within a mud pit. For mud pits in radiologically posted areas, the COPCs are limited to radionuclides. 
- The physical properties of the drilling mud are expected to adsorb potential contaminants and limit significant lateral or vertical migration. The drilling mud will have low permeability, porosity, and hydraulic conductivity due to the presence of bentonite. These physical properties, combined with the high evapotranspiration rates in the desert climate of the NTS, suggest no significant vertical migration is expected. This conclusion is supported by previous modeling efforts that report the immobility of TPH-DRO in drilling mud and the limited downward migration into underlying soil (DOE/NV, 1998; NNSA/NSO, 2004a). Lateral migration is expected to be minimal given the physical properties of the mud and the bermed construction of the mud pits, which limits potential stormwater run-on and runoff. However, compromises in the integrity of a berm may result in releases outside the mud pit. Given the limited potential for contaminant migration and groundwater levels of 500 to 2,800 feet (ft) below ground surface (bgs) at the NTS (USGS and DOE, 2009), contaminants associated with the NTS mud pits are not expected to have any impact on groundwater.

- Cellars in CAU 544 are considered to have resulted from essentially the same process. This is supported by the knowledge regarding the use and typical construction of a cellar. There are also documented similarities in post-test drilling practices, including reports from previously investigated cellars (CAUs 177, 355, and 358) (NNSA/NSO, 2003a and b).

- Chemical constituents and radionuclides are COPCs for cellars. Available information is insufficient to eliminate both chemical and radiological contamination as COPCs. The primary source of potential chemical contaminants is expected to be spills/leaks of drill rig fluids or decontamination of drilling equipment over the cellar cavity. Although the drilling mud was circulated throughout the mud pits, the potential exists for radiologically contaminated drilling mud to have spilled or leaked into the cellar cavity as a result of careless activities or a malfunction in the circulation system.

- Due to the typical construction of a cellar, no significant lateral or vertical migration of contaminants is expected. Any contaminants within the impacted media at the base of a cellar would be laterally bound by the corrugated metal casing that lines the cellar cavity. The potentially impacted media within a cellar is expected to be 10 to $12 \mathrm{ft}$ bgs, which is the depth of the cellar casing. The impacted media at the two cellar CASs (02-37-08 and 02-37-09) is known to be buried beneath fill material, further limiting vertical migration. Vertical migration of contaminants from infiltration of precipitation is expected to be insignificant. Some cellars have concrete bottoms (NNSA/NSO, 2003a and b), which would further prevent the downward migration of contaminants into the underlying soil.

- It is expected that backfilled cellars contain drill stemming left in place. Observations from open and backfilled cellars indicate that drill stemming from post-test borings were commonly left in place and were cut off approximately $1 \mathrm{ft}$ above the cellar floor or extended several feet out of the cellar above the ground surface. Sampling logistics, such as access to the cellar floor and sample locations, may be affected by the presence and orientation of drill stemming. 
The mud pits and cellars in CAU 544 were constructed for use during the drilling activities conducted at the NTS in support of the underground nuclear weapons testing program. The mud pits and cellars were constructed as part of Los Alamos National Laboratory (LANL) or Lawrence Livermore National Laboratory (LLNL) pretest and post-test drilling activities.

Both types of drilling operations involved the routine construction of earthen mud pits that were created for the separation of drill cuttings and the circulation of drilling fluids. Although LANL utilized drilling mud and LLNL used an air-foam mixture (Davis Mix), the drilling processes were essentially the same for both laboratories (NNSA/NSO, 2004a). Drilling fluids containing suspended cuttings would be deposited into the pit where the cuttings would settle out, and the drilling fluid would be circulated back to the borehole. Circulation of drilling fluids would cease when drilling approached the depth potentially affected by the nuclear test. This reduced the likelihood of contaminating the mud pits with radioactive material or releasing radioactive material to the surface. If the drill bit became stuck during drilling operations, diesel fuel was typically added to the fluid to lubricate the bit until it became mobile again and drilling could resume. Diesel fuel also changed the viscosity of the drilling mud, causing it to thicken and provide better lift for removing the cuttings (NNSA/NSO, 2005). Following post-test activities, the mud pits were commonly allowed to dry out, surveyed for radiation, and in some instances backfilled with native soils (NNSA/NSO, 2006a).

The main purpose of the cellar was to house the blowout preventer (BOP) equipment. The BOP was a device located at the post-test borehole that could seal off the annular space between the drill pipe and walls of the containment stack to prevent an uncontrolled escape of radioactive gases or liquids. For post-test drilling, the drill rig was set up at a predetermined distance, and the borehole was typically drilled at a 32-degree angle to the zone of interest after the test. The cellars typically consist of a 10-ft diameter corrugated metal pipe that lines a 10- to 12-ft-deep excavation. A concrete foundation around the perimeter of the cellar is often found at the ground surface. After completion of post-test sampling, the drill pipe was withdrawn, and an abandonment valve was installed and closed to seal off the hole (NNSA/NSO, 2006a). The boreholes associated with the cellars are under the control of the Borehole Management Project (BMP) and are not included in the scope of this CAU. 
The environmental media affected by a release will be defined for each feature because the sources of contamination, release points, and affected media are dependent on the separate mud pit and cellar processes. For a mud pit, the CAS is the direct release of drilling mud potentially impacted by radiological contamination. For a cellar, the CAS is soil within the base of the cellar potentially impacted by radiological or chemical contaminants from a release of drill rig fluids, decontamination rinsate, or drilling mud. For an oil/waste spill, the CAS is the direct release of the oil or waste substance into the environmental media.

The CASs in CAU 544 can be divided into the following three groups: (1) mud pit/cellar CASs located in radiologically controlled areas (RCAs), (2) oil/waste spill CASs located in non-RCAs, and (3) mud pit CASs located in non-RCAs. The CAU 544 CASs are listed in Table 2-1, along with the sections in which these CASs are described.

Table 2-1

CAU 544 CASs

(Page 1 of 2)

\begin{tabular}{||c|c|c|c||}
\hline CAS & Description & RCA/Non-RCA & Section \\
\hline \hline \multirow{2}{*}{$02-37-08$} & Cellar \& Mud Pit & Cellar - RCA & 2.1 .1 \\
\cline { 3 - 4 } & Cellar \& Mud Pit & Cellar and Mud Pit - RCA & 2.1 .2 \\
\hline $02-37-09$ & U-9itsx20 PS \#1A Mud Pit & RCA & 2.1 .3 \\
\hline $09-09-46$ & Oil Spill & Non-RCA & 2.2 .1 \\
\hline $19-25-01$ & Waste Spill & Non-RCA & 2.2 .2 \\
\hline $19-99-06$ & Oil Spills & Non-RCA & 2.2 .3 \\
\hline $20-25-04$ & Oil Spills & Non-RCA & 2.2 .4 \\
\hline $20-25-05$ & Mud Pit & Non-RCA & 2.3 .2 \\
\hline $07-09-01$ & Mud Pit & Non-RCA & 2.3 .3 \\
\hline $10-09-01$ & Mud Pit & Non-RCA & 2.3 .4 \\
\hline $12-09-03$ & Mud Pits (2) & Non-RCA & 2.3 .5 \\
\hline $19-09-01$ & Mud Pit & Non-RCA & 2.3 .6 \\
\hline $19-09-03$ & Mud Pit & Non-RCA & 2.3 .7 \\
\hline $19-09-04$ & & & \\
\hline
\end{tabular}


Table 2-1

CAU 544 CASs

(Page 2 of 2)

\begin{tabular}{||c|c|c|c||}
\hline $\begin{array}{c}\text { CAS } \\
\text { Number }\end{array}$ & Description & RCA/Non-RCA & Section \\
\hline \hline $20-09-01$ & Mud Pits (2) & Non-RCA & 2.3 .8 \\
\hline $20-09-02$ & Mud Pit & Non-RCA & 2.3 .9 \\
\hline $20-09-03$ & Mud Pit & Non-RCA & 2.3 .10 \\
\hline $20-09-04$ & Mud Pits (2) & Non-RCA & 2.3 .11 \\
\hline $20-09-06$ & Mud Pit & Non-RCA & 2.3 .12 \\
\hline $20-09-07$ & Mud Pit & Non-RCA & 2.3 .13 \\
\hline $20-09-10$ & Mud Pit & Non-RCA & 2.3 .14 \\
\hline
\end{tabular}

\subsection{Mud Pit/Cellar CASs Located in Radiologically Controlled Areas}

\subsubsection{CAS 02-37-08, Cellar \& Mud Pit}

Corrective Action Site 02-37-08 consists of potential environmental releases associated with a mud pit and cellar located in the vicinity of the U-2cn crater.

The cellar is located in an RCA, whereas the mud pit is located in a non-RCA. Because the CAS 02-37-08 cellar is located in an RCA, a description of this component of the CAS is provided in this section. Available characterization information provided in this section is limited to that information relating to the cellar. Information about the mud pit component of this CAS is presented in Section 2.3.1.

The cellar is backfilled with a dirt mound next to it and is located within a fenced area posted with “Underground Radioactive Material Area” (URMA) signs. The URMA posting is believed to be associated with the fact that the borehole extends into the cavity created by the Cruet test. The fenced area measures approximately 130 by $46 \mathrm{ft}$. No odor or staining was noticed, as observed from outside the perimeter of the fenced area, during the site visit conducted in March 2010. Figure 2-1 shows the CAS location with respect to the surrounding roads and other physical features. 


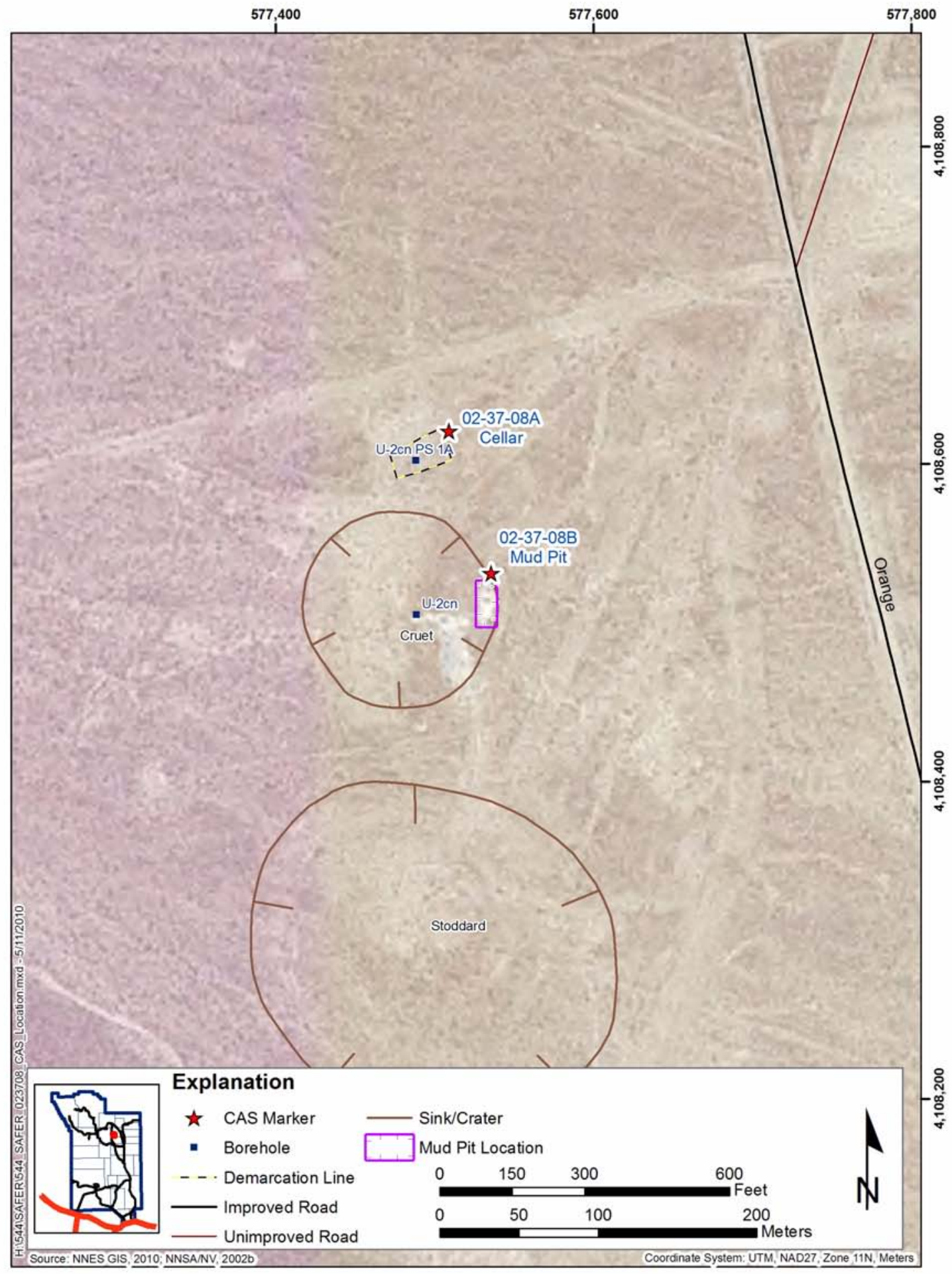

Figure 2-1

CAS 02-37-08, Cellar \& Mud Pit, Location with Respect to Surrounding Roads and Other Physical Features 


\subsubsection{History and Process Knowledge}

The mud pit and cellar are associated with post-test drilling of borehole U-2cn PS \#1A. Cruet was the associated underground weapons-related test that was conducted by LLNL on October 29, 1969, and resulted in the formation of $\mathrm{U}-2 \mathrm{cn}$ crater (DOE/NV, 2000). There was no reported detectable release of radioactivity to the atmosphere at the time of the test. The post-test borehole is scheduled for plug-back activities through the Underground Test Area (UGTA) BMP (Gustafson, 2010). No stability study has been conducted for the U-2cn crater.

\subsubsection{Available Characterization Information}

A radiological survey has been conducted at this CAS. The survey was part of a demarcation project for various cellars and/or mud pits. The cellar was surveyed on June 1, 1998. A review of the results indicates that the highest alpha and beta levels recorded in the field were 47 disintegrations per minute (dpm) alpha and $497 \mathrm{dpm}$ beta. A final dpm reading was taken after at least a 48-hour decay time. The highest final alpha and beta levels recorded were $4 \mathrm{dpm}$ alpha and $7 \mathrm{dpm}$ beta (DOE/NV, 1998). It is believed that the URMA posting is only associated with the fact that the borehole extends into the cavity created by the device used in the Cruet test.

No previous media sampling or geophysical surveys have been conducted for this CAS.

\subsubsection{CAS 02-37-09, Cellar \& Mud Pit}

Corrective Action Site 02-37-09 consists of potential environmental releases from a mud pit and cellar associated with the U2dc4a crater.

The cellar is backfilled and surrounded by a two-strand yellow wire fence. The mud pit is covered and is enclosed with barbed wire fencing. The entire fenced area is posted with URMA signs and measures approximately 100 by $20 \mathrm{ft}$. It appears that the mud pit was fenced and posted with URMA signs after the cellar was fenced and posted, because the type of wire used for the fence around the mud pit is different from the one used for the cellar. No odor or staining was observed from outside the perimeter of the fenced area (IT, 2001c). Figure 2-2 shows the CAS location with respect to the surrounding roads and other physical features. 


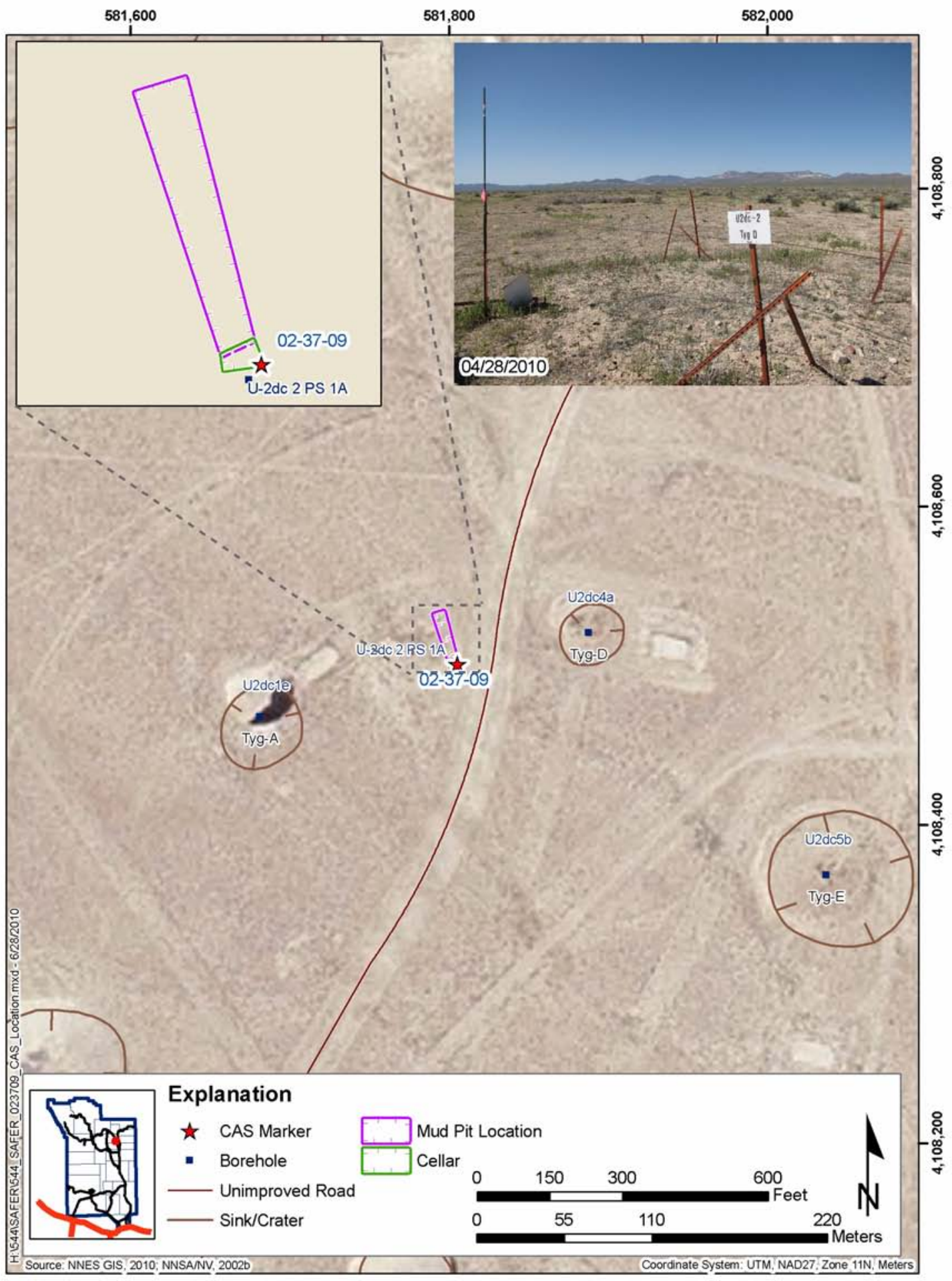

Figure 2-2

CAS 02-37-09, Cellar \& Mud Pit, Location with Respect to Surrounding Roads and Other Physical Features 


\subsubsection{History and Process Knowledge}

This CAS is associated with the post-test drilling of borehole U-2dc-2 PS \#1A to access the subsurface cavity at the U2dc4a crater. Tyg-D was the underground weapons-related test that was conducted by LLNL on December 12, 1968, and resulted in the formation of the U2dc4a crater. There was a release of radioactivity that was detected only on site (DOE/NV, 2000). No stability study has been conducted for the U2dc4a crater.

Drilling activities at U-2dc-2 PS \#1A began on December 22, 1968, and ended on April 19, 1973, at a total depth of $879 \mathrm{ft}$ with a diameter of $97 / 8$ inches (in.). The hole was plugged with cement from 450 to $9 \mathrm{ft}$ bgs and then abandoned (RSN, 1991).

\subsubsection{Available Characterization Information}

A radiological survey has been conducted at this CAS. The survey was part of a demarcation project for various cellars and/or mud pits. The cellar was surveyed on June 2, 1998. A review of the results indicates that the highest alpha and beta levels recorded at the field were $22 \mathrm{dpm}$ alpha and $0 \mathrm{dpm}$ beta. A final dpm reading was taken after at least a 48-hour decay time. The highest final alpha and beta levels recorded were $0 \mathrm{dpm}$ alpha and $12 \mathrm{dpm}$ beta (DOE/NV, 1998). It is believed that the URMA posting is only associated with the fact that the borehole extends into the cavity created by the device used in the Tyg-D test.

No previous sampling or geophysical surveys have been conducted for this CAS.

\subsubsection{CAS 09-09-46, U-9itsx20 PS \#1A Mud Pit}

Corrective Action Site 09-09-46 consists of potential releases to a mud pit of drilling mud/fluids used for post-test drilling at U-9itsx20. Hod-B (Red) was the associated underground weapons-related test that was conducted by LLNL on May 1, 1970, and resulted in the formation of U-9itsx20 crater (DOE/NV, 2000). The CAS is located on the eastern edge of the U-9itsx20 crater in Area 9 of the NTS.

The mud pit is located within the crater fence line between the crater and the fence. The mud pit and area within the crater are posted as a Contamination Area. The mud pit boundaries are not well 
defined, and sections of the mud pit appear to have been backfilled or graded over. The mud pit and graded area are oriented east-west on the eastern side of the crater and the open portion of the pit. The open portion of the pit contains dried mud and measures approximately 45 by $35 \mathrm{ft}$. The backfilled/graded portion of the mud pit measures approximately 125 by $50 \mathrm{ft}$. The sides of the mud pit are bermed. There is vegetation, including spiny and dry shrubs, within and around the site as observed during the March 2010 site visit. Figure 2-3 shows the CAS location with respect to the surrounding roads and other physical features.

\subsubsection{History and Process Knowledge}

The mud pit of this CAS is associated with post-test drilling of borehole U-9itsx20 PS \#1A. A stability study has not been conducted.

\subsubsection{Available Characterization Information}

No sampling, radiological surveys, or geophysical walkover surveys have been conducted at this CAS. However, a radiological land area survey was conducted in 2006 over the associated cellar at nearby CAU 177, CAS 09-23-09, and its results are reported in the preliminary assessment for CAU 544 (SNJV, 2007). Based on the Global Positioning System (GPS) coordinates provided in the report, it was determined that the radiological survey area did not overlap the CAS 09-09-46 mud pit boundary; however, results of the survey provide information regarding background radiation levels in the vicinity of the cellar/surveyed area. The mean gamma radiation measurement for the undisturbed background area outside the cellar survey boundary was determined to be 160 counts per second (cps) (SNJV, 2007).

A geophysical survey was conducted in June 2005 at the cellar (CAU 177, CAS 09-23-09) near CAS 09-09-46. Geophysical anomalies identified may overlay the CAS 09-09-46 boundary. No additional metallic piping or utilities appear to be present within the surveyed area (SNJV, 2007). 


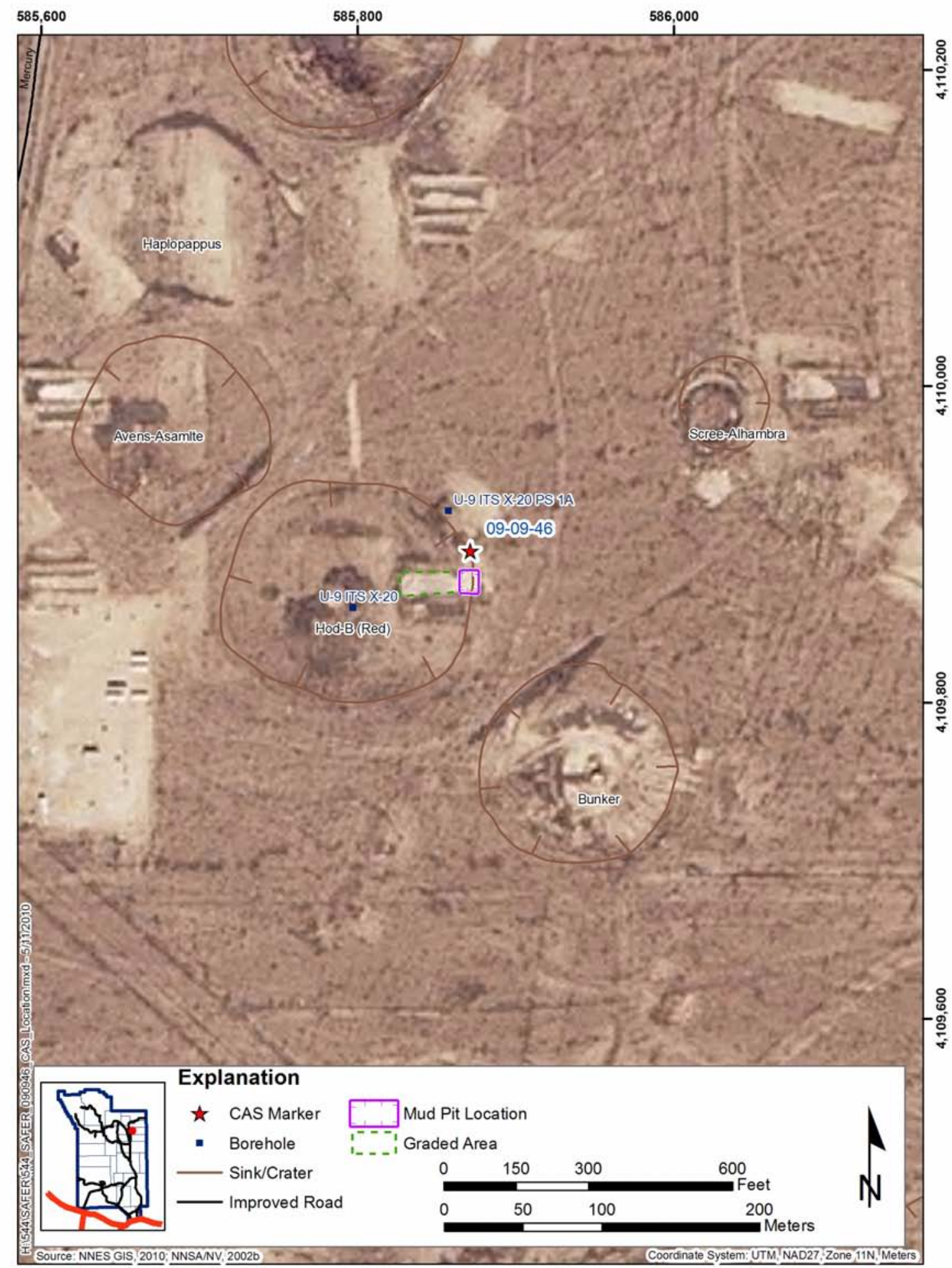

Figure 2-3

CAS 09-09-46, U-9itsx20 PS \#1A Mud Pit, Location with Respect to Surrounding Roads and Other Physical Features 


\subsection{Oil/Waste Spill CASs Located in Non-radiologically Controlled Areas}

\subsubsection{CAS 19-25-01, Oil Spill}

Corrective Action Site 19-25-01 consists of a suspected release of hydrocarbons to the soil associated with an oil spill.

The CAS is located in Area 19 of the NTS, approximately 1,800 ft southwest of the U-19ab (Towanda) crater. A preliminary assessment site visit in April 2002 confirmed the CAS consisted of a 15-ft diameter dark gray soil stain; it was also noted that there are two oil spills. One oil spill is outside the crater fence, while the other spill is inside the crater (IT, 2002c). It was observed during the site visit in April 2010 that there was no visible oil stain and that the ground was covered with pea gravel. The area has no radiological postings. Figure 2-4 shows the CAS location with respect to the surrounding roads and other physical features.

\subsubsection{History and Process Knowledge}

No documentation that identifies the date, type and volume of oil spilled, or depth of the contaminated soil was located. The oil spill located within the boundaries of the fenced potential crater area is not visible from outside the fence. The spill located outside the crater fence line was not observed during the site visit in April 2010. Therefore, the conditions of the soil stains are unknown. Exact dimensions of the spills are unknown at this time.

A stability study for the U-19ab crater was conducted by LANL; additional subsidence at the site is very unlikely (Aldrich, 2004). There are no radiological postings at the CAS.

\subsubsection{Available Characterization Information}

No sampling, radiological surveys, or geophysical walkover surveys have been conducted at this CAS. 


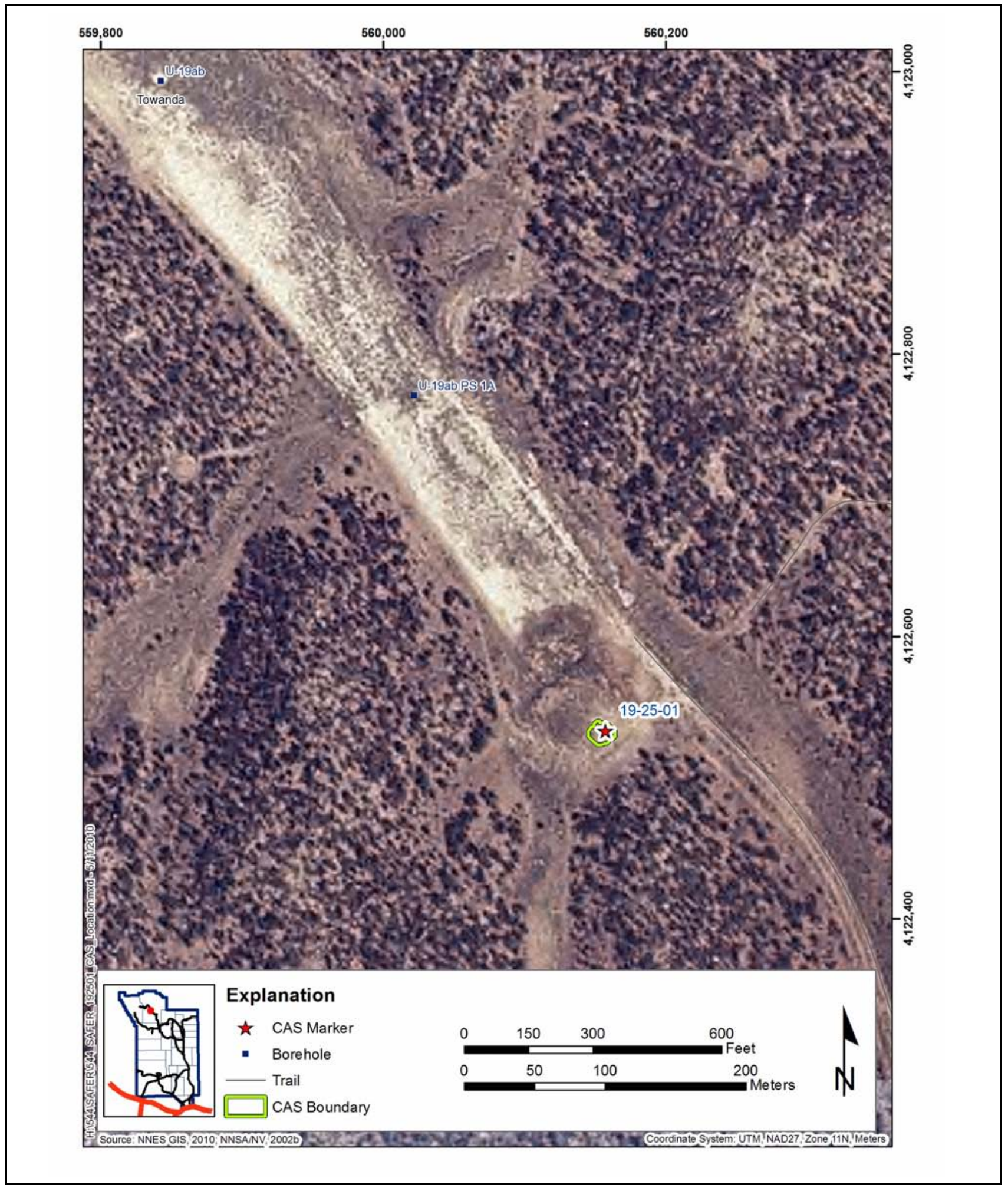

Figure 2-4

CAS 19-25-01, Oil Spill, Location with Respect to Surrounding Roads and Other Physical Features 


\subsubsection{CAS 19-99-06, Waste Spill}

Page 21 of 94

Corrective Action Site 19-99-06 is located in Area 19 of the NTS, east of U-19j emplacement hole. The environmental concern at CAS 19-99-06 consists of potential environmental release associated with several large spills of dry, light-gray grout.

The waste consists of dried bentonite drilling mud and cement grout. The cement grout measured 1/8 to 1 in. in thickness and is medium to dark gray in color. The CAS consists of one main spill that is approximately $10 \mathrm{ft}$ in diameter and several scattered small spills with indistinguishable boundaries. Vegetation at the spill is sparse compared to the surrounding areas. The soil at the site is composed of gravel, pebbles, and very coarse scattered pebbles, and appears to be non-native fill. The area has no radiological postings. Figure 2-5 shows the CAS location with respect to the surrounding roads and other physical features.

\subsubsection{History and Process Knowledge}

No documentation that identifies the date of the spill, and the volume and depth of contaminated soil was located. The waste spill is approximately $10 \mathrm{ft}$ in diameter. Due to the location of the spill, it is possible that it was related to the drilling operations associated with $\mathrm{U}-19 \mathrm{j}$, although no documentation was located to support this assumption. There are no radiological postings at the CAS (IT, 2002a).

\subsubsection{Available Characterization Information}

No walkover radiological surveys or geophysical surveys have been conducted at this CAS.

Two samples were collected at the waste spill on August 26, 1997. The samples were analyzed for volatile organic compounds (VOCs), semivolatile organic compounds (SVOCs), Resource Conservation and Recovery Act (RCRA) metals, and radionuclides. Arsenic was the only chemical of concern that exceeded the U.S. Environmental Protection Agency (EPA) generic soil screening level for ingestion. Several constituents (e.g., lead, barium, gross alpha/beta) exceeded instrument detection limits, but were below regulatory guidelines (Bordelois, 1998b). 


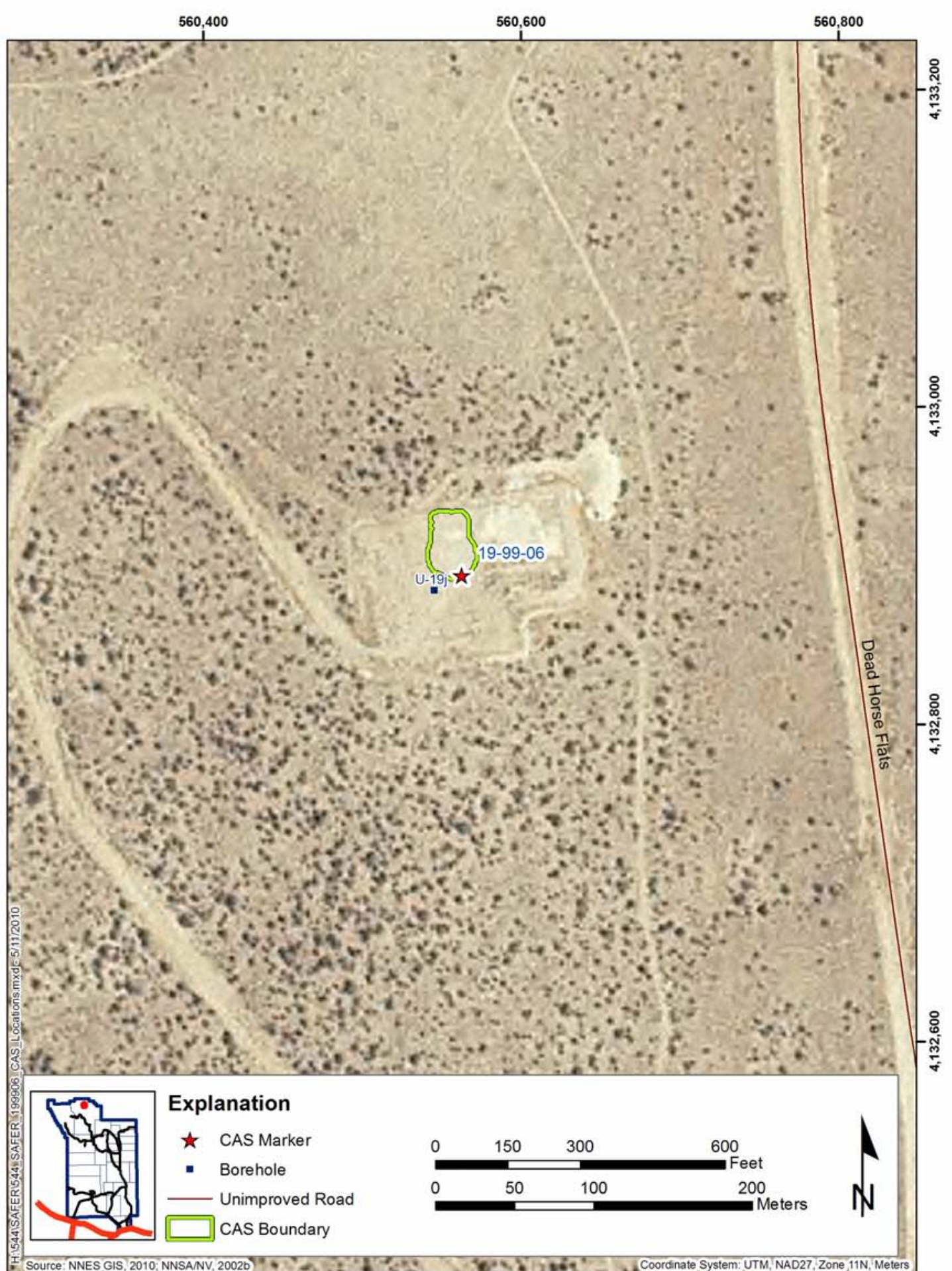

Figure 2-5

CAS 19-99-06, Waste Spill, Location with Respect to Surrounding Roads and Other Physical Features 


\subsubsection{CAS 20-25-04, Oil Spills}

Corrective Action Site 20-25-04 consists of potential releases of hydrocarbons to the soil near U-20aw.

The oil spills cover several square feet of soil (IT, 2002a). During a March 2010 site visit, the oil spills were not visible from outside the potential crater area fencing, and heavy vegetation covers the area. The area has no radiological postings. Figure 2-6 shows the CAS location with respect to the surrounding roads and other physical features.

\subsubsection{History and Process Knowledge}

No documentation was located indicating when the spills occurred, the type and volume of oil spilled, and depth of the contaminated soil. The oil spills are located within the boundaries of a fenced potential crater area and is not visible from outside the fence. Therefore, the current conditions, including the dimensions, of the spills are unknown. A previous field investigation described the site as consisting of several oil spills located on the northeast side of U-20aw ground zero (IT, 2002a). However, during the March 2010 site visit, the oil spills were not observed.

A crater stability study for the U-20aw crater was conducted by LLNL in 2003 (Pawloski, 2003). The study suggests that the crater is stable in its current configuration, but LLNL has less confidence than normal in making this statement.

\subsubsection{Available Characterization Information}

No sampling, radiological surveys, or geophysical walkover surveys have been conducted at this CAS.

\subsubsection{CAS 20-25-05, Oil Spills}

Corrective Action Site 20-25-05 consists of potential releases of hydrocarbons to the soil. The CAS consists of numerous oil spills. The spill areas varied from 1 to 10 square feet $\left(\mathrm{ft}^{2}\right)$. In previous field visits, the oil stains could not be located, and it is unknown whether they were remediated (IT, 2002a). The oil spills were not located during the most recent field visit in March 2010. The area is covered with pea gravel and overgrown with shrubs. The area has no radiological postings. 


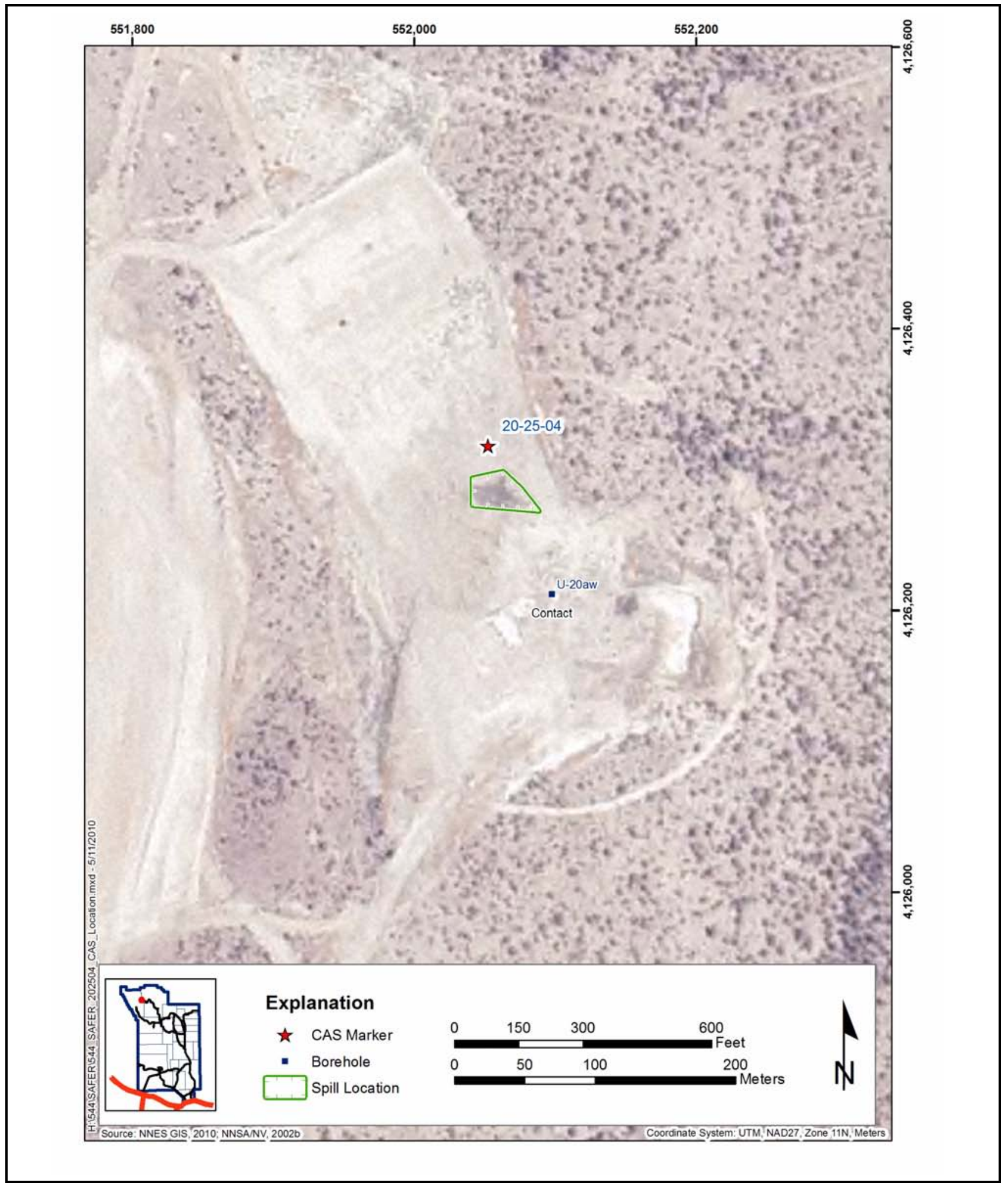

Figure 2-6

CAS 20-25-04, Oil Spills, Location with Respect to Surrounding Roads and Other Physical Features 
A cellar and post-test drill pipe are located directly east of the CAS marker. Figure 2-7 shows the CAS location with respect to the surrounding roads and other physical features.

\subsubsection{History and Process Knowledge}

According to the original site description, the site consists of stained soil located 340 degrees north and $150 \mathrm{ft}$ from the fence line at U-20be, in the area formerly used as the trailer park during the Hoya underground nuclear test. During previous site visits in August 2001 and March 2010, no evidence of stained soil was observed at the site, and the oil spills were not located. The spill site lies within an area that is graded and covered with non-native pea gravel (IT, 2002a). Vegetation also covers the area.

No documentation that identifies when the spills occurred was located; therefore, certain details about the site were not identified. These unknown items include the date on which the spills occurred, exact type and volume of oil/fuel spilled, and depth of the contaminated soil.

\subsubsection{Available Characterization Information}

No sampling, radiological surveys, or geophysical surveys have been conducted at this CAS.

\subsection{Mud Pit CASs Located in Non-radiologically Controlled Areas}

There are 13 mud pits within CAU 544 that are located in non-RCAs.

\subsubsection{CAS 02-37-08, Cellar \& Mud Pit}

As discussed in Section 2.1.1, the CAS 02-37-08 mud pit is located in a non-RCA in the vicinity of the U-2cn crater. The mud pit is uncovered and measures approximately 100 by $30 \mathrm{by} 10 \mathrm{ft}$. There is light gray dried drilling mud covering the bottom of the pit. Mud pit debris consists of a metal sign post, metal pipe, and some wood; vegetation is also growing in the mud pit. The mud pit is located approximately $270 \mathrm{ft}$ from the cellar and is located on the eastern edge of the crater (IT, 2001b). The fencing around the crater is gone; only the T-posts remain. The mud pit has no radiological postings. Figure 2-1 shows the CAS location with respect to the surrounding roads and other physical features. 


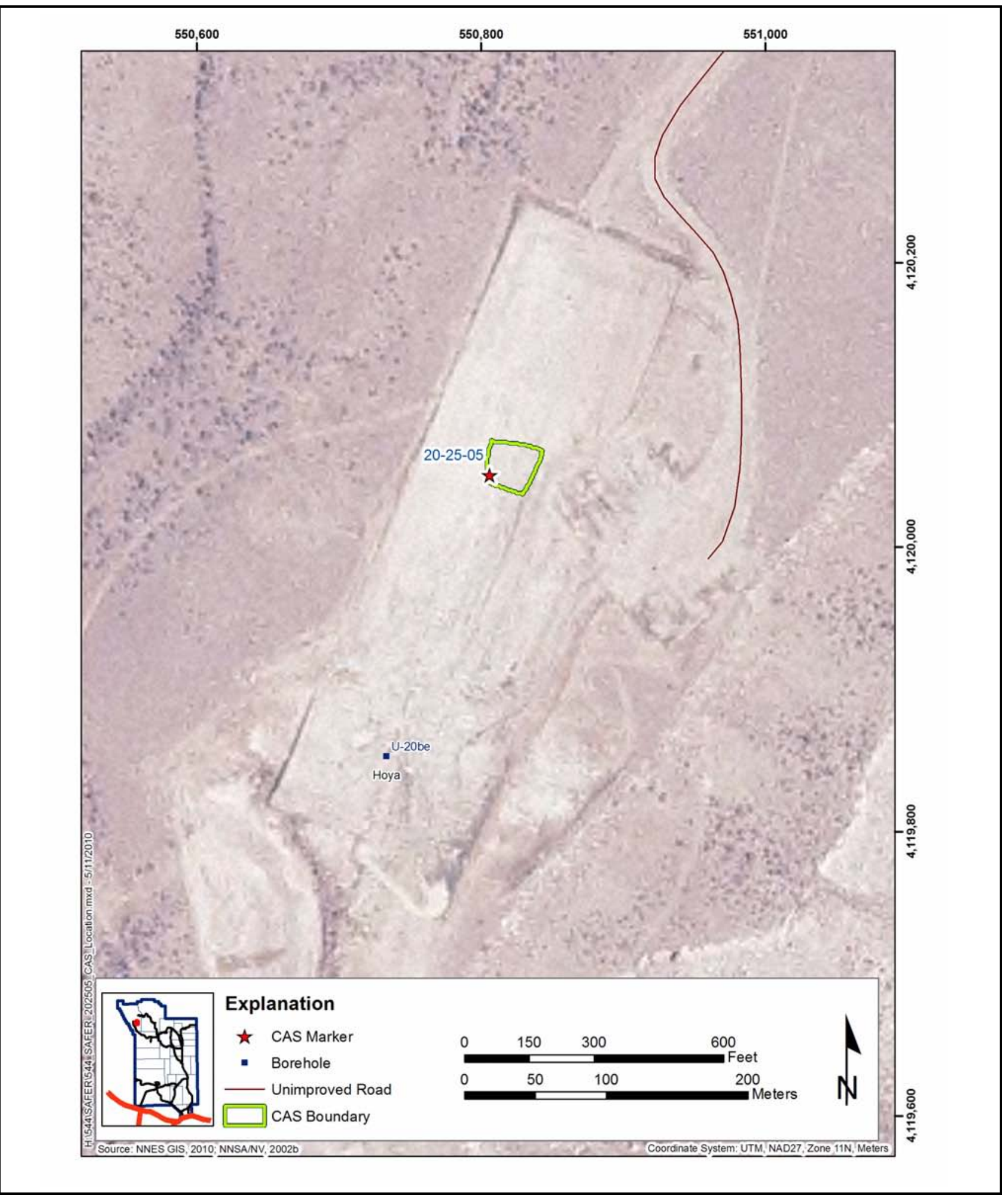

Figure 2-7

CAS 20-25-05, Oil Spills, Location with Respect to Surrounding Roads and Other Physical Features 


\subsubsection{History and Process Knowledge}

A description of the use and history of this CAS is presented in Section 2.1.1.1.

\subsubsection{Available Characterization Information}

Characterization information pertaining to this CAS is provided in Section 2.1.1.2. Characterization information specific to the mud pit portion of this CAS is scarce, but available data from other similar sites suggest that no significant sources of contamination are expected to be present.

No sampling, geophysical surveys, or radiological surveys have been conducted for this CAS.

\subsubsection{CAS 07-09-01, Mud Pit}

Corrective Action Site 07-09-01 consists of potential environmental releases associated with a mud pit located in the vicinity of the U-7bi crater.

The mud pit is located predominately within the fenced boundary of the U-7bi crater. Berms are built around the two-mud-pit system (return and suction) that slopes downgradient towards the crater. The dimensions of the return mud pit are approximately 140 by $115 \mathrm{by} 3 \mathrm{ft}$. The dimensions of the suction pit are approximately 150 by 10 by $0.5 \mathrm{ft}$. The mud pit is not backfilled and has an uneven layer of dried light gray mud covering the bottom. The interior of the mud pit is sparsely vegetated. The mud pit has no radiological postings. Figure 2-8 shows the CAS location with respect to the surrounding roads and other physical features.

\subsubsection{History and Process Knowledge}

This mud pit is believed to have supported activities associated with the Dolcetto Test, which was conducted by LANL on August 30, 1984, and resulted in the formation of the U-7bi crater (DOE/NV, 2000). There was no reported detectable release of radioactivity to the atmosphere. A stability study conducted by LANL resulted in a determination that additional surface subsidence is unlikely at U-7bi (Hawkins, 2005). 


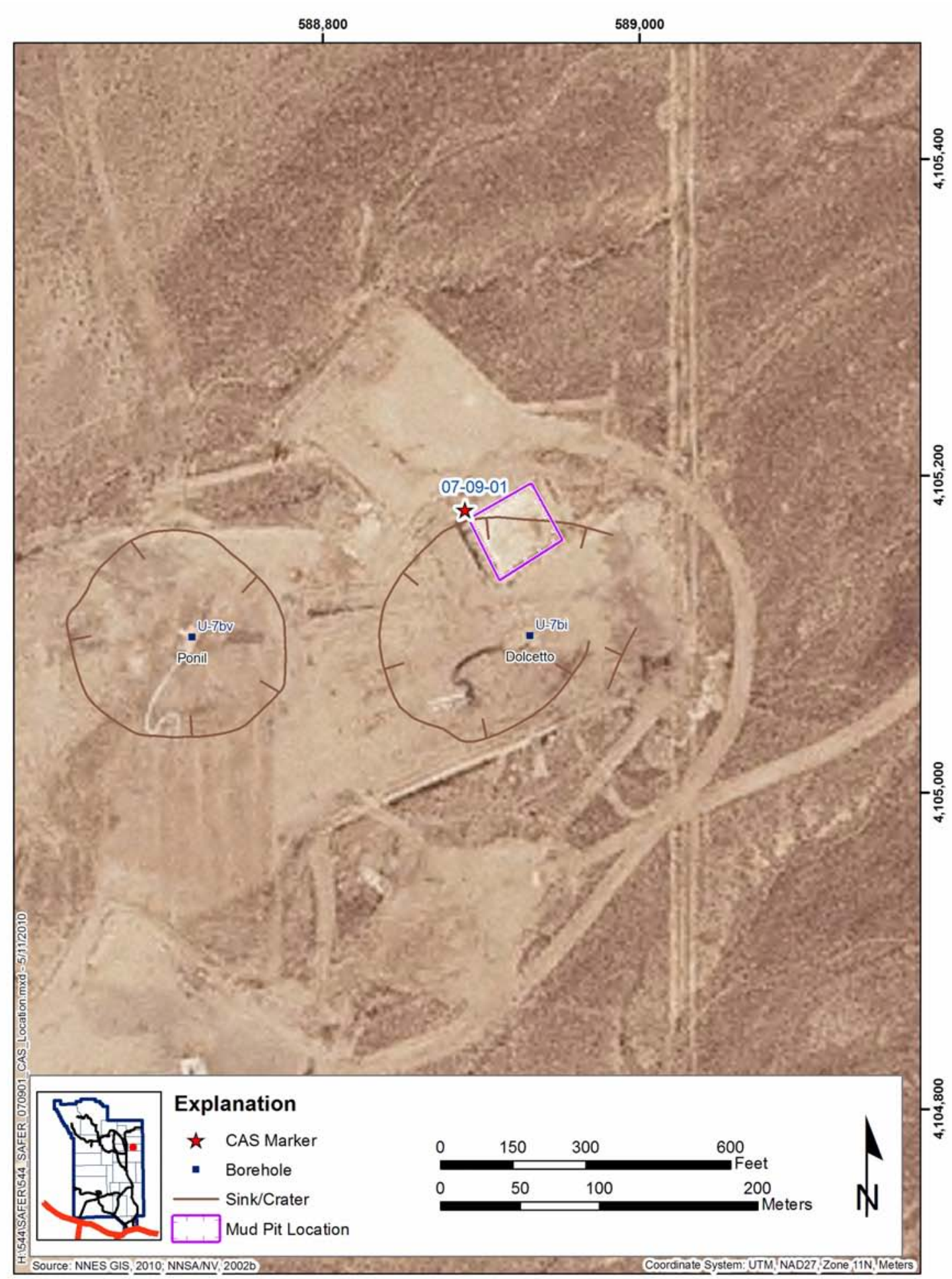

Figure 2-8

CAS 07-09-01, Mud Pit, Location with Respect to Surrounding Roads and Other Physical Features 


\subsubsection{Available Characterization Information}

One discrete soil sample was collected from the bottom of this mud pit on August 21, 1997, and analyzed for total RCRA metals, VOCs, SVOCs, TPH, and radionuclides. Chemical analytes at concentrations above instrument detection limits but below regulatory guidelines for RCRA metals included barium, chromium, and lead. Arsenic exceeded the EPA generic soil screening level for ingestion. Radionuclides present at concentrations above detection limits but below regulatory guidelines included the following: gross alpha, gross beta, lead-212, and potassium-40 (Bordelois, 1998a).

A radiological survey was conducted in the northwest corner of the mud pit by field personnel in August 1997. Results of the survey show radiological readings below the background detection limits. No geophysical surveys have been conducted at this CAS.

\subsubsection{CAS 10-09-01, Mud Pit}

Corrective Action Site 10-09-01 consists of environmental releases associated with a mud pit located in the vicinity of the $\mathrm{U}-10 \mathrm{cb}$ crater.

This site consists of a mud pit located approximately $50 \mathrm{ft}$ south of the U-10cb crater, within the U-10cb crater fence line in Area 10. The mud pit measures approximately 80 by $70 \mathrm{ft}$ and was constructed with 3-ft-high, 10-ft-wide berms. A significant amount of drill cuttings is located in the northwest corner and the center of the pit. Dried, light gray drilling mud is visible in the southeast corner of the mud pit. There is no vegetation in the mud pit, and the vegetation surrounding the mud pit is disturbed. The mud pit has no radiological postings. Figure 2-9 shows the CAS location with respect to the surrounding roads and other physical features.

\subsubsection{History and Process Knowledge}

Corrective Action Site 10-09-01 is associated with the drilling efforts accomplished for the Normanna test and the U-10cb emplacement hole. The Normanna test was conducted by LLNL on July 12, 1984 (DOE/NV, 2000). There was no reported detectable release of radioactivity to the atmosphere.

A stability study for the U-10cb crater conducted by LLNL resulted in the determination that the crater is stable in its current configuration (Pawloski, 2003). 


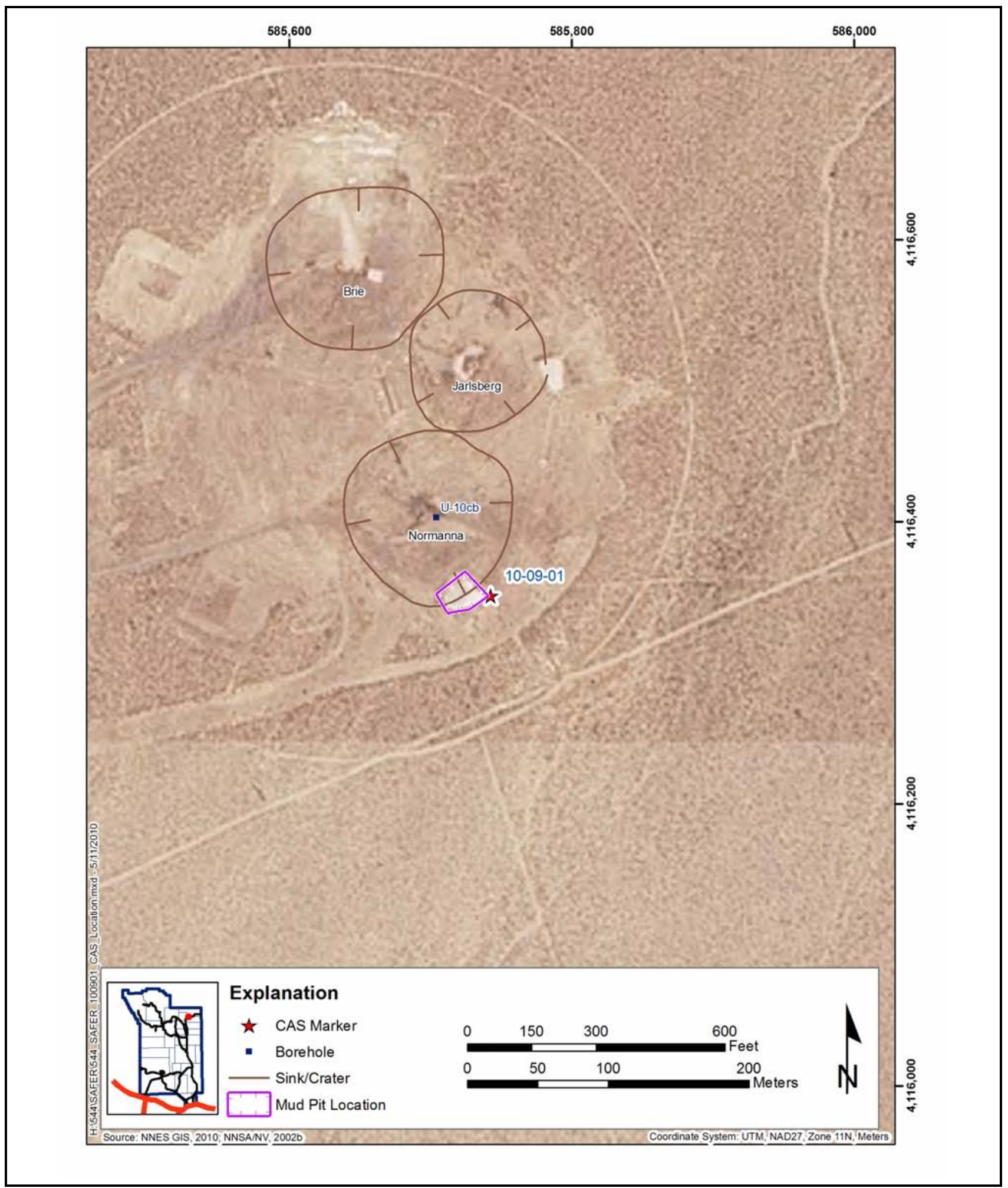

Figure 2-9

CAS 10-09-01, Mud Pit, Location with Respect to Surrounding Roads and Other Physical Features 


\subsubsection{Available Characterization Information}

No sampling activities, radiological surveys, or geophysical surveys have been conducted at this CAS.

\subsubsection{CAS 12-09-03, Mud Pit}

Corrective Action Site 12-09-03 consists of potential environmental releases associated with a mud pit located in the vicinity of the U-12e.14 PS \#1 borehole.

This CAS is located within a crater area and is surrounded by a fence posted with "Danger Potential Crater Area” signs. The mud pit is associated with the post-test drilling efforts. During the May 2010 site visit, the mud pit was not visible from the crater fencing. The road to the borehole continued into the fenced crater area. The size of the mud pit could not be determined, and it is unknown whether there is any debris or staining in the area. No radiological postings were observed in the area or on the crater fencing. Figure 2-10 shows the CAS location with respect to the surrounding roads and other physical features.

\subsubsection{History and Process Knowledge}

The mud pit at this CAS is associated with post-test drilling of borehole U-12e.14 PS \#1. Dido Queen was the associated tunnel weapons effects test that was conducted by LLNL/DoD on June 5, 1973 (DOE/NV, 2000). The CAS is in a potential crater area, but no stability study has been conducted at the site; therefore, access to the CAS will be restricted.

\subsubsection{Available Characterization Information}

No sampling, radiological surveys, or geophysical surveys have been conducted at this CAS.

\subsubsection{CAS 19-09-01, Mud Pits (2)}

Corrective Action Site 19-09-01 consists of potential environmental releases associated with two mud pits located in the vicinity of the U-19ab crater. 


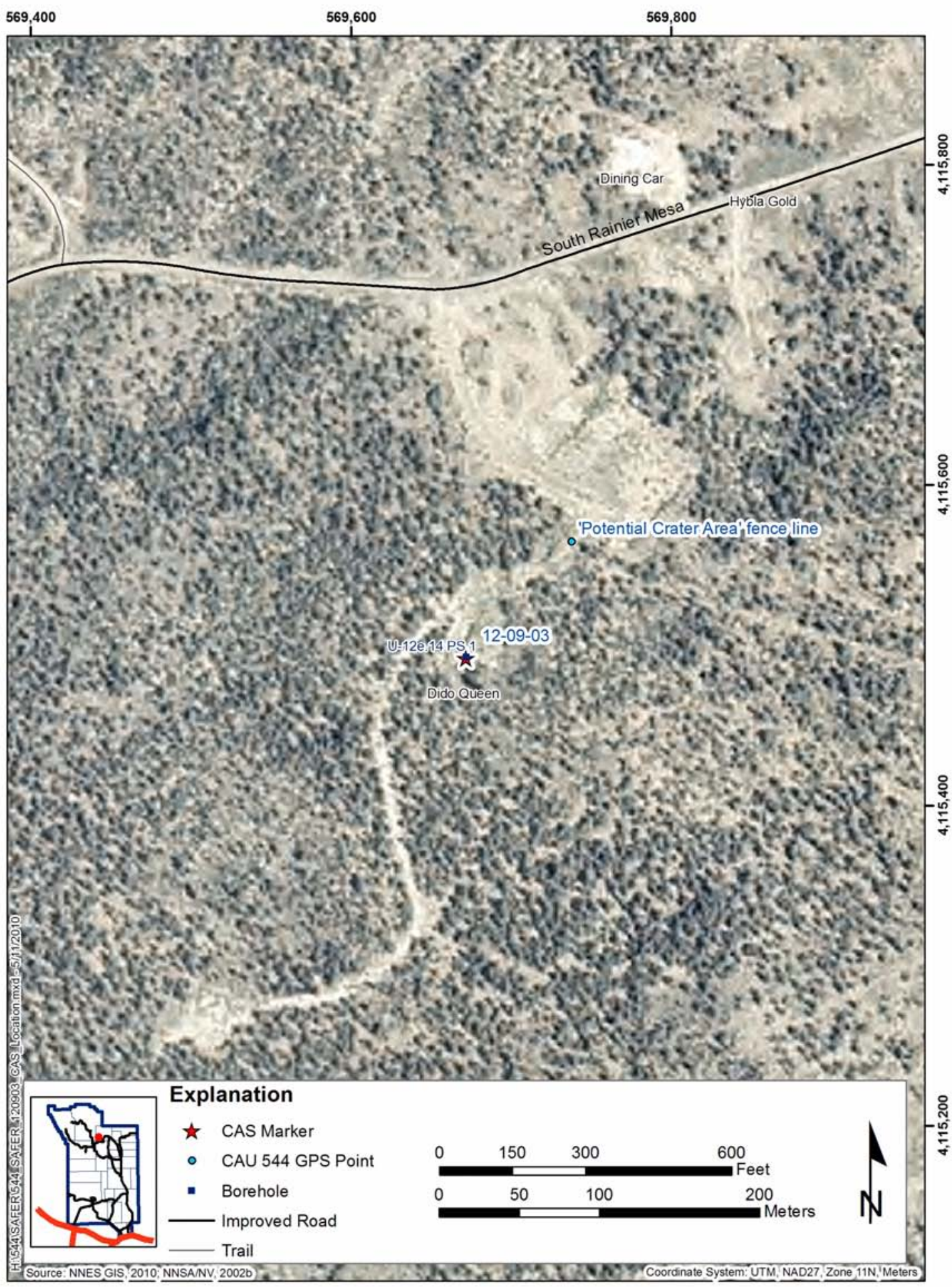

Figure 2-10

CAS 12-09-03, Mud Pit, Location with Respect to Surrounding Roads and Other Physical Features 
This site consists of a two-mud-pit system with one overflow pit. The mud pits are located approximately $150 \mathrm{ft}$ northwest of the U-19ab crater in Area 19. There is light gray drilling mud in the two pits. The mud pits have no radiological postings. Figure 2-11 shows the CAS location with respect to the surrounding roads and other physical features.

\subsubsection{History and Process Knowledge}

Corrective Action Site 19-09-01 is associated with pretest drilling of borehole U-19ab.

Borehole U-19ab was part of the Towanda underground nuclear test conducted by LANL on May 2, 1985 (DOE/NV, 2000). There was no reported detectable release of radioactivity to the atmosphere. A stability study for the U-19ab crater conducted by LANL resulted in the determination that additional subsidence at the site is very unlikely (Aldrich, 2004). There are no radiological postings at the CAS.

\subsubsection{Available Characterization Information}

No sampling, radiological surveys, or geophysical walkover surveys have been conducted at this CAS.

\subsubsection{CAS 19-09-03, Mud Pit}

Corrective Action Site 19-09-03 consists of potential environmental releases associated with a mud pit located in the vicinity of the U-19ar crater.

This CAS is located 100 yards (yd) southwest of the U-19ar ground zero structure. The mud pit measures approximately 165 by $150 \mathrm{ft}$ and is $8 \mathrm{ft}$ deep. The pit lies on a dirt terrace above ground level and is contained by a dirt berm. The mud pit was full of gray mud and drill cuttings as observed in the April 2010 site visit. The mud pit has no radiological postings. Figure 2-12 shows the CAS location with respect to the surrounding roads and other physical features.

\subsubsection{History and Process Knowledge}

Corrective Action Site 19-09-03 is associated with drilling efforts accomplished for the Cybar test. The Cybar test was conducted by LANL on July 17, 1986 (DOE/NV, 2000). The size of this mud pit and the fact that there is no known cellar associated with it would indicate that this site may have been 


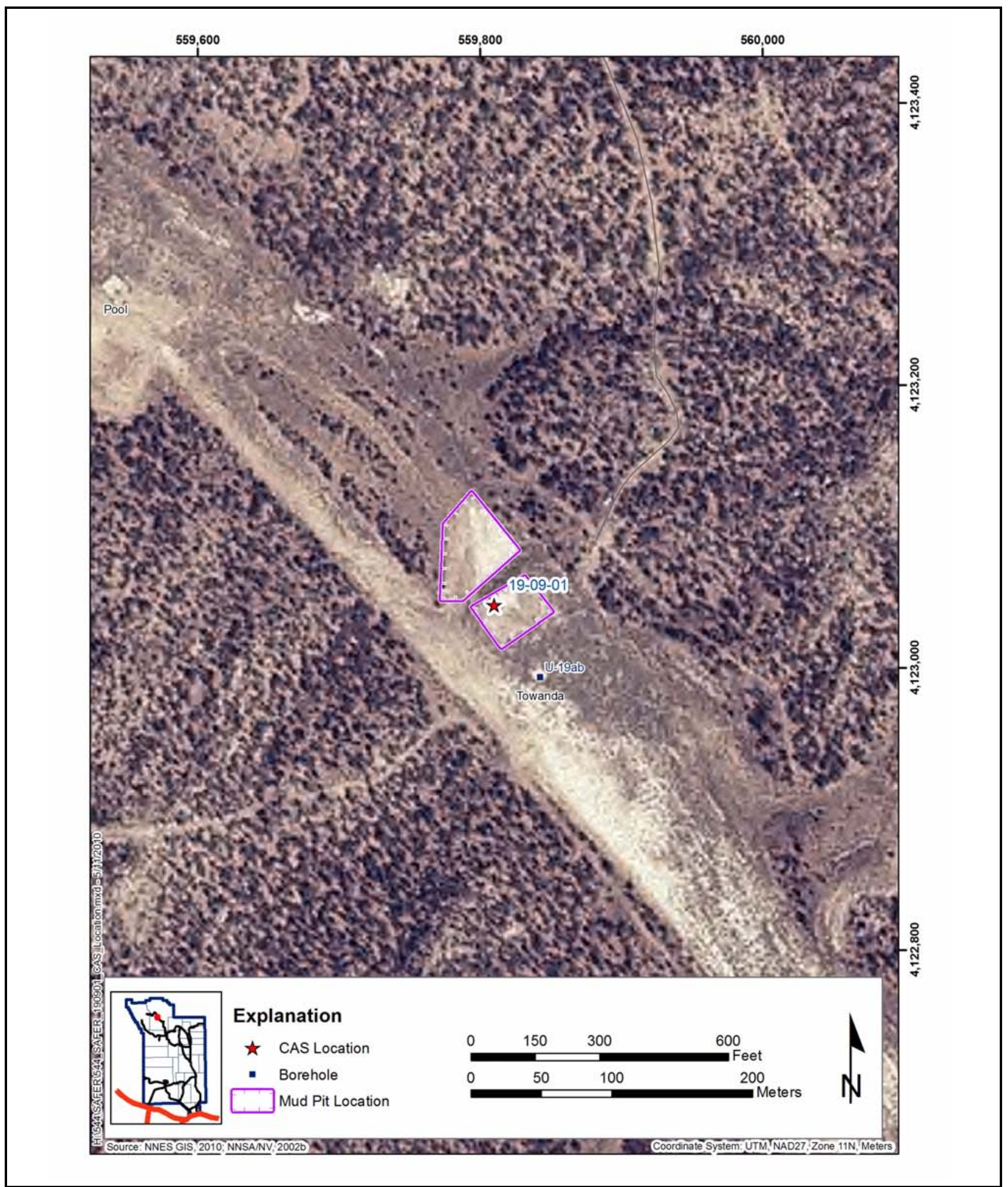

Figure 2-11

CAS 19-09-01, Mud Pits (2), Location with Respect to Surrounding Roads and Other Physical Features 


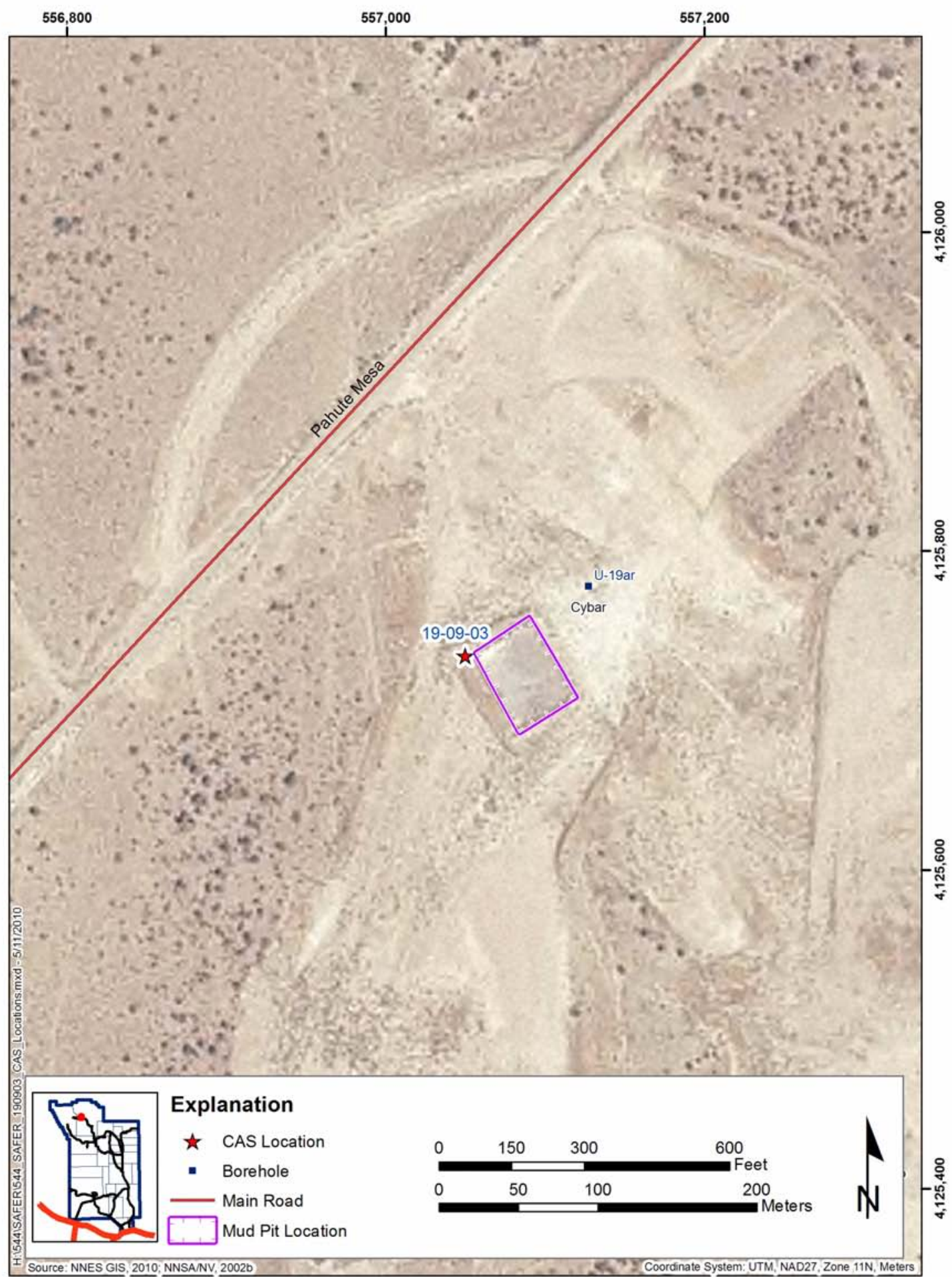

Figure 2-12

CAS 19-09-03, Mud Pit, Location with Respect to Surrounding Roads and Other Physical Features 
affiliated with pretest drilling activities (IT, 2001a). A stability study for the U-19ar crater conducted by LANL resulted in a determination that additional subsidence at the site is very unlikely (Hawkins, 2003). There are no radiological postings at the CAS.

\subsubsection{Available Characterization Information}

No sampling, radiological surveys, or geophysical walkover surveys have been conducted at this CAS.

\subsubsection{CAS 19-09-04, Mud Pit}

Corrective Action Site 19-09-04 consists of potential environmental releases associated with a mud pit located in the vicinity of the U-19ad crater.

The mud pit is located $150 \mathrm{ft}$ west of the U-19ad crater. During the site visit in April 2010, field personnel noted that the mud pit was mostly full of drill cuttings, with some mud. The mud pit dimensions are approximately 135 by 120 by $6 \mathrm{ft}$. The mud pit has no radiological postings. The area is overgrown with shrubs and trees. Figure 2-13 shows the CAS location with respect to the surrounding roads and other physical features.

\subsubsection{History and Process Knowledge}

Corrective Action Site 19-09-04 is associated with drilling efforts accomplished for the Chancellor test. The Chancellor test was conducted by LANL on September 1, 1983 (DOE/NV, 2000). The size of this mud pit and the fact that there is no known cellar associated with it would indicate that this site may have been affiliated with pretest drilling activities. A stability study for the U-19ad crater conducted by LANL resulted in a determination that additional subsidence at the site is very unlikely (Hawkins, 2003). There are no radiological postings at the CAS.

\subsubsection{Available Characterization Information}

No sampling, radiological surveys, or geophysical walkover surveys have been conducted at this CAS. 


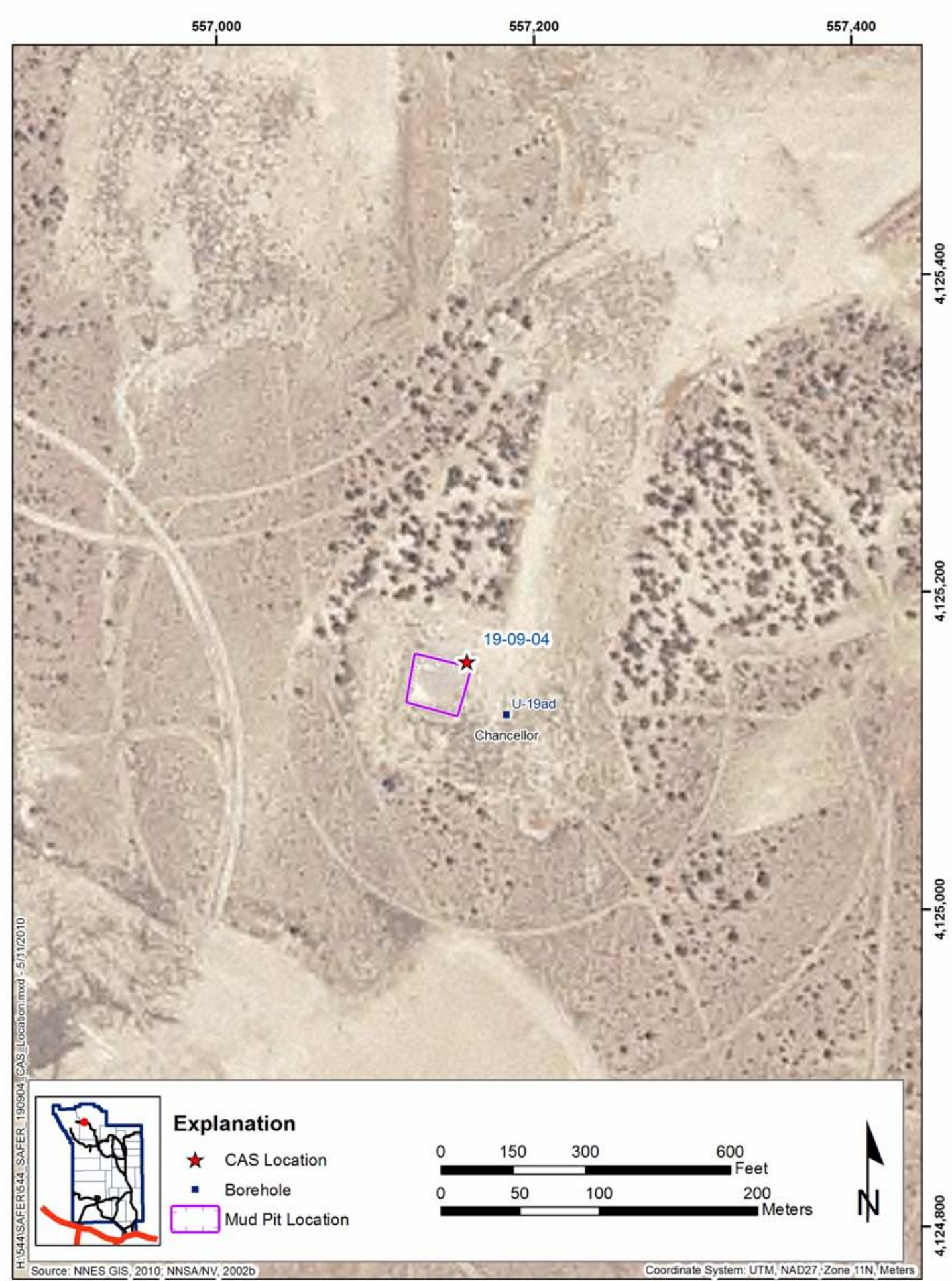

Figure 2-13

CAS 19-09-04, Mud Pit, Location with Respect to Surrounding Roads and Other Physical Features 


\subsubsection{CAS 20-09-01, Mud Pits (2)}

Corrective Action Site 20-09-01 consists of potential environmental releases associated with two mud pits located in the vicinity of the U-20m crater.

The CAS is located in Area 20 near Pahute Mesa Road. The mud pits are located behind a fenced area and are inaccessible. During the March 2010 site visit, one of the mud pits was visible from the fence line. The mud is light gray and dried, and there is some vegetation in the pit. Some dried mud was also discovered outside the fence. The area has no radiological postings. Figure 2-14 shows the CAS location with respect to the surrounding roads and other physical features.

\subsubsection{History and Process Knowledge}

Corrective Action Site 20-09-01 appears to be associated with the post-test drilling efforts accomplished for the Handley test. The U-20m PS \#1D drill hole was completed on September 8, 1970 (RSN, 1991). No stability study has been conducted for the U-20m crater.

\subsubsection{Available Characterization Information}

No sampling, radiological surveys, or geophysical walkover surveys have been conducted at this CAS.

\subsubsection{CAS 20-09-02, Mud Pit}

Corrective Action Site 20-09-02 consists of potential environmental releases associated with a mud pit located in the vicinity of the U-20m crater.

The CAS is located in Area 20 near Pahute Mesa Road. During the March 2010 site visit, the CAS marker was discovered near Rad Safe Marker 20 J37. The location of the CAS marker is shown on Figure 2-14. During the site visit, the mud pit was not visible due to vegetation, but aerial photographs of the area clearly show the mud pit location. Figure 2-14 shows the location of the mud pit. 


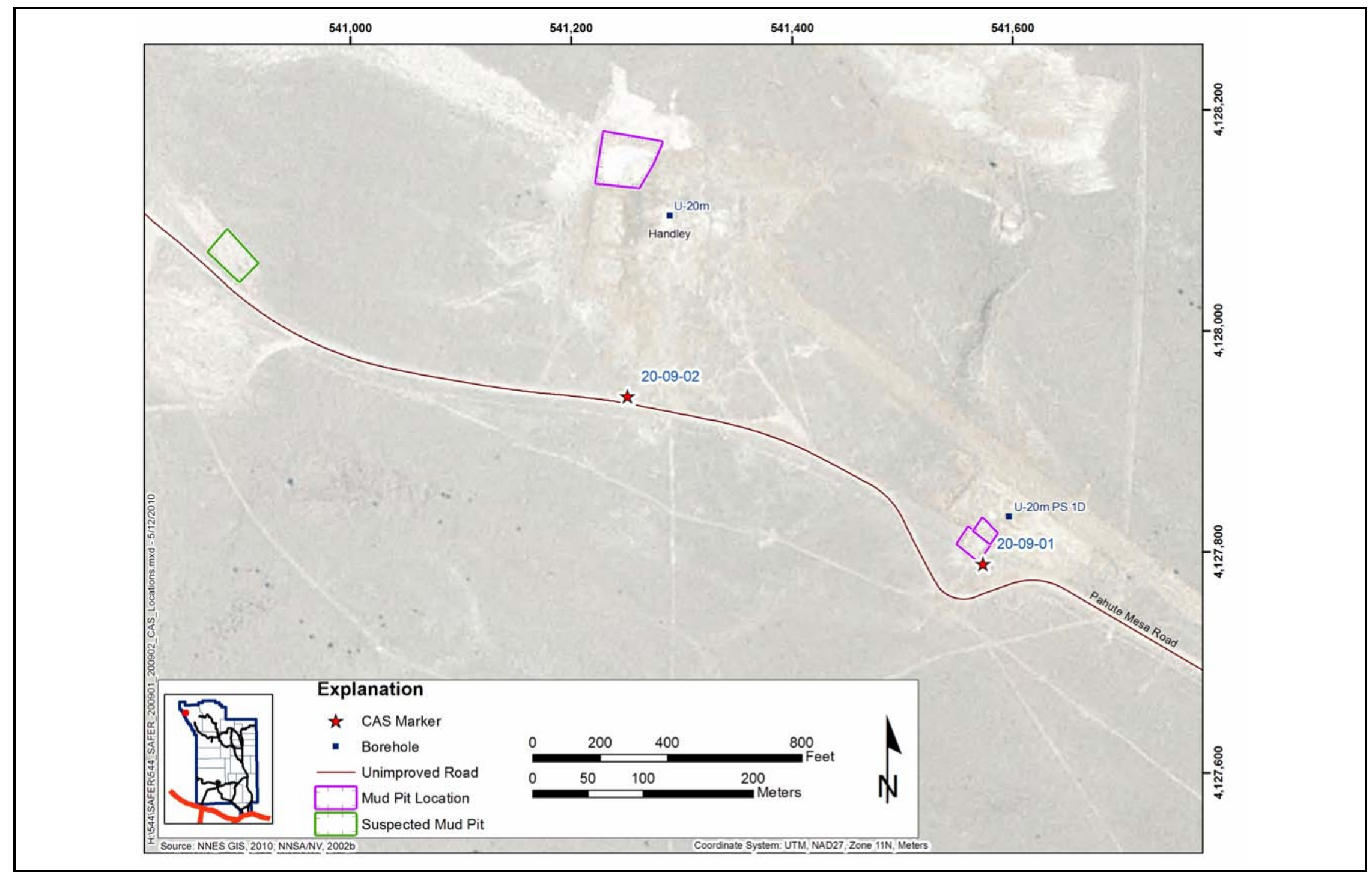

Figure 2-14

CAS 20-09-01, Mud Pits (2), and CAS 20-09-02, Mud Pit, Locations with Respect to Surrounding Roads and Other Physical Features 
During the March 2010 site visit, a suspected mud pit also was discovered. The suspected mud pit is approximately 1,000 ft west of the CAS marker, and is also visible on aerial photographs.

Figure 2-14 shows the location of the suspected mud pit.

\subsubsection{History and Process Knowledge}

Corrective Action Site 20-09-02 appears to be associated with the drilling efforts accomplished for the Handley test and the U-20m emplacement hole. The Handley test was conducted by LLNL on March 26, 1970 (DOE/NV, 2000). There was no reported detectable release of radioactivity to the atmosphere. No stability study has been conducted for the U-20m crater.

\subsubsection{Available Characterization Information}

No sampling, radiological surveys, or geophysical walkover surveys have been conducted at this CAS.

\subsubsection{CAS 20-09-03, Mud Pit}

Corrective Action Site 20-09-03 consists of potential environmental releases associated with a mud pit located in the vicinity of the U-20p crater.

This CAS is located within a crater area and is surrounded by a "Danger Potential Crater Area" fence that measures a 200-yd radius. It is unknown whether there is any debris or staining in the area. This mud pit is believed to be associated with the pretest drilling efforts performed for the Stilton test (IT, 2001a). During the March 2010 site visit, the mud pit was not visible from the crater fencing, so the size of the mud pit could not be determined. Aerial photographs of the area, however, clearly show the location of the mud pit. No radiological postings were identified during the site visit. Figure 2-15 shows the CAS location with respect to the surrounding roads and other physical features.

\subsubsection{History and Process Knowledge}

Corrective Action Site 20-09-03 is associated with the drilling efforts accomplished for the Stilton test and the U-20p emplacement hole. The Stilton test was conducted by LLNL/the U.S. Department of Defense (DoD) on June 3, 1975 (DOE/NV, 2000). There was no reported detectable release of 


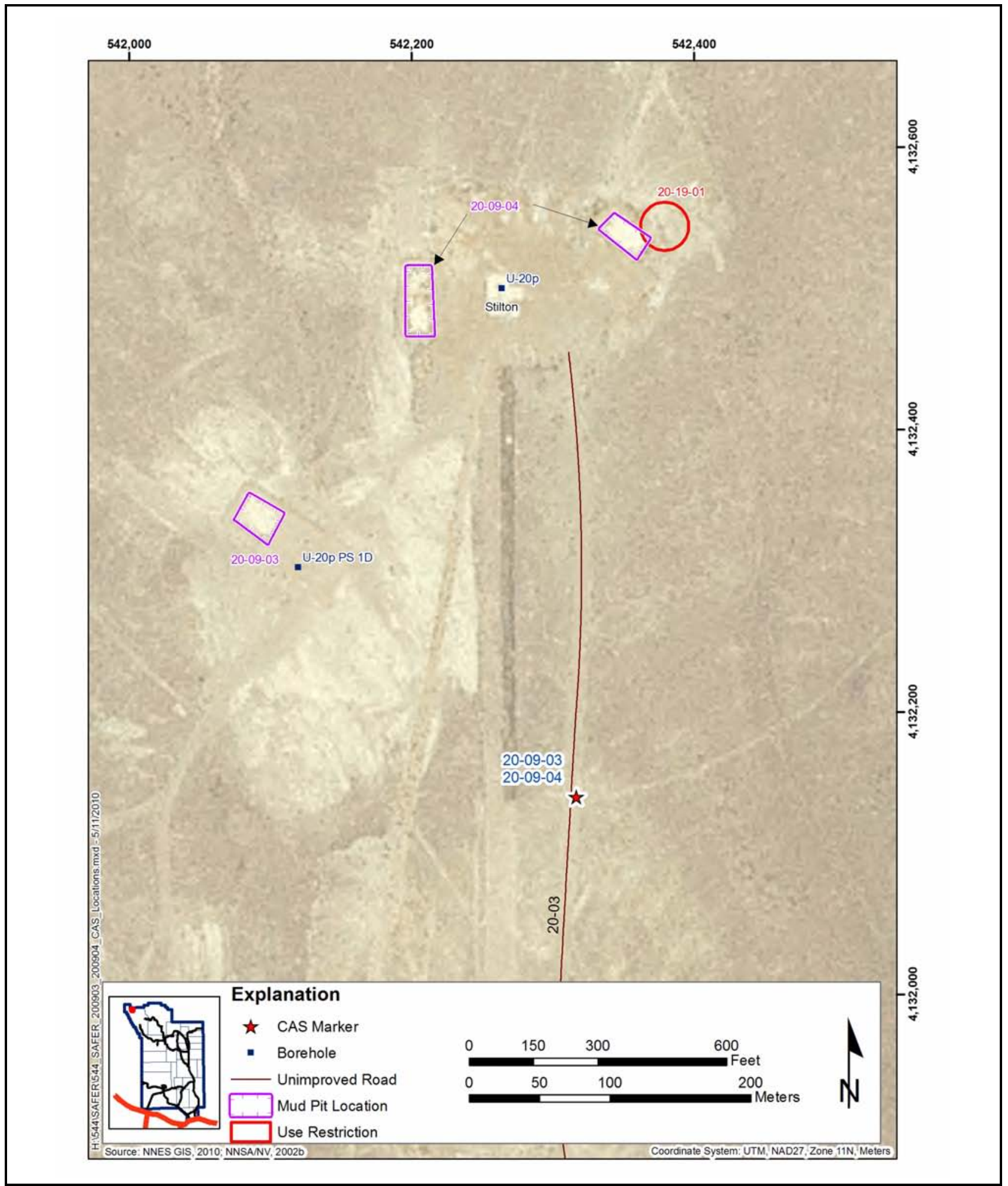

Figure 2-15

CAS 20-09-03, Mud Pit, and CAS 20-09-04, Mud Pits (2) Locations with Respect to Surrounding Roads and Other Physical Features 
radioactivity to the atmosphere. A stability study for the U-20p crater conducted by LLNL resulted in a determination that the crater is stable in its current configuration, but LLNL has less confidence than normal in making this statement (Pawloski, 2003).

\subsubsection{Available Characterization Information}

No sampling, radiological surveys, or geophysical walkover surveys have been conducted at this CAS.

\subsubsection{CAS 20-09-04, Mud Pits (2)}

Corrective Action Site 20-09-04 consists of potential environmental releases associated with two mud pits located in the vicinity of the U-20p crater.

This CAS is located within a crater area and is surrounded by a fence posted with "Danger Potential Crater Area” signs. These mud pits are believed to be associated with pretest drilling efforts conducted in association with the Stilton test (IT, 2001a). During the March 2010 site visit, the mud pits were not visible from the crater fencing, and the size of the mud pits could not be determined. The locations of the mud pits, however, can be easily identified on aerial photographs of the area. It is unknown whether there is any debris or staining in the area. No radiological postings were identified in the area or on the crater fencing. Figure 2-15 shows the CAS location with respect to the surrounding roads and other physical features.

\subsubsection{History and Process Knowledge}

Corrective Action Site 20-09-04 is associated with the drilling efforts accomplished for the Stilton test and the U-20p emplacement hole. A stability study for the U-20p crater conducted by LLNL resulted in a determination that the crater is stable in its current configuration, but LLNL has less confidence than normal in making this statement (Pawloski, 2003).

\subsubsection{Available Characterization Information}

No sampling, radiological surveys, or geophysical walkover surveys have been conducted at this CAS. 


\subsubsection{CAS 20-09-06, Mud Pit}

Corrective Action Site 20-09-06 consists of a suspected environmental release associated with a mud pit located in the vicinity of the U-20z crater.

This CAS consists of a mud pit located approximately $225 \mathrm{ft}$ east of U-20z ground zero. Based on aerial photographs of the area, it is estimated that the mud pit is approximately 150 by $150 \mathrm{ft}$. During the March 2010 site visit, the CAS marker and the mud pit could not be located at the U-20z area; therefore, site conditions could not be confirmed. The ground zero casing could be seen inside the crater fencing, but the mud pit was not observed. There are no radiological postings around the crater. The area is overgrown with shrubs and trees. Figure 2-16 shows the CAS location with respect to the surrounding roads and other physical features.

\subsubsection{History and Process Knowledge}

Corrective Action Site 20-09-06 is associated with the drilling efforts accomplished for the Kasseri test. The Kasseri test was conducted by LLNL on October 28, 1975 (DOE/NV, 2000). This CAS is located within a potential crater area and is considered a part of the pretest drilling efforts conducted for the Kasseri test. A stability study for the U-20z crater was conducted by LLNL (Pawloski, 2003). The crater is stable in its current configuration, but LLNL has less confidence than normal in making this statement. There are no radiological postings at the CAS.

\subsubsection{Available Characterization Information}

No sampling, radiological surveys, or geophysical surveys have been conducted at this CAS.

\subsubsection{CAS 20-09-07, Mud Pit}

Corrective Action Site 20-09-07 consists of potential environmental releases associated with a mud pit located in the vicinity of the U-20aw crater.

The CAS consists of a mud pit located approximately $80 \mathrm{ft}$ southwest of the U-20aw borehole. The mud pit is located inside a potential crater area fence and was inaccessible during the preliminary assessment site visit conducted in January 2001. During the March 2010 site visit, the mud pit was not located, due to overgrown vegetation. The mud pit is evident in aerial photographs. However, 


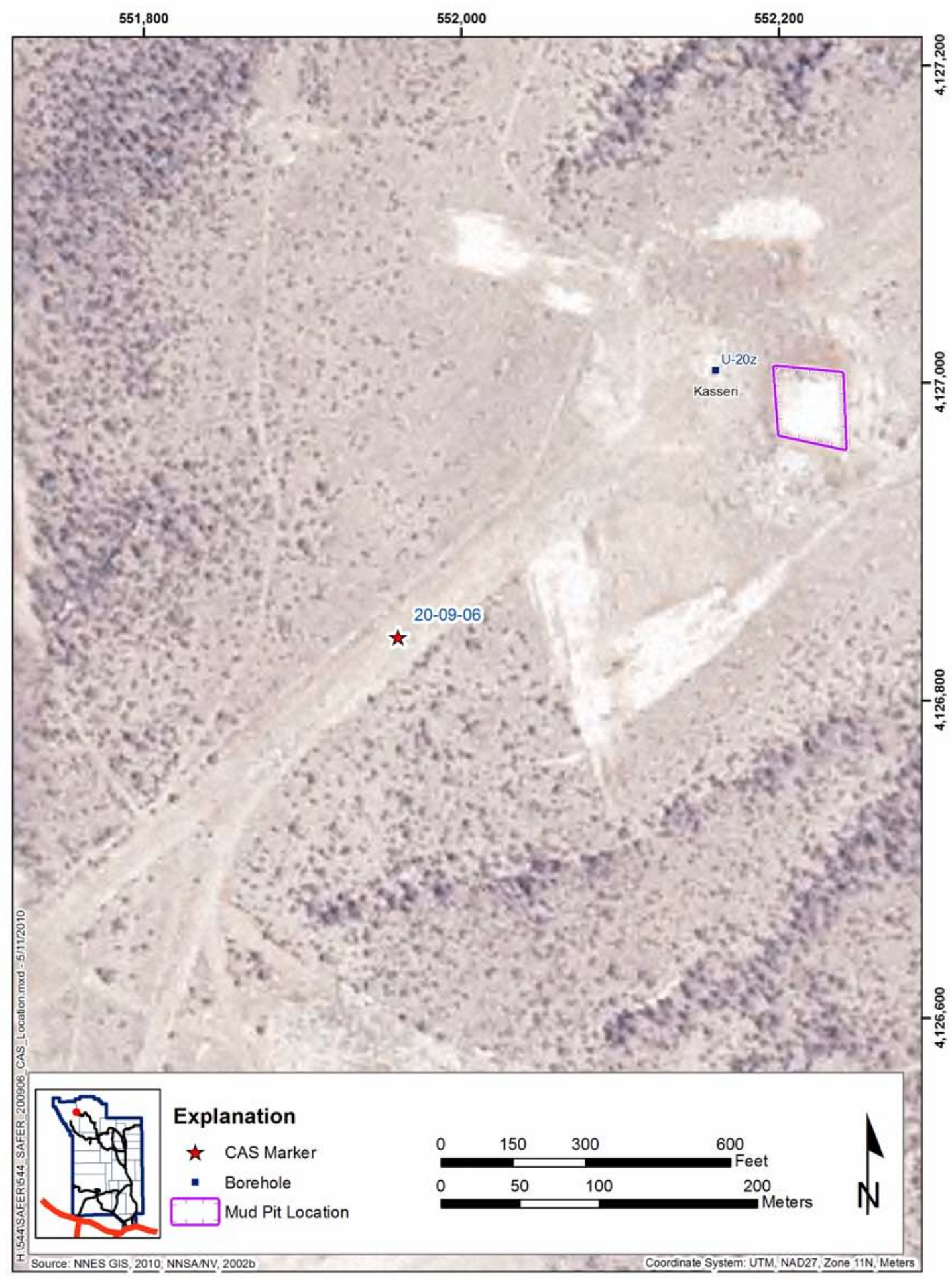

Figure 2-16

CAS 20-09-06, Mud Pit, Location with Respect to Surrounding Roads and Other Physical Features 
dried grout was discovered along the east side of the fence line. The grout appears to have run downhill from a wash-down area associated with CAS 20-09-08. CAS 20-09-08 has been closed with NFA (NNSA/NSO, 2004b). There are no radiological postings around the crater. Figure 2-17 shows the CAS location with respect to the surrounding roads and other physical features.

\subsubsection{History and Process Knowledge}

This CAS is associated with the drilling efforts accomplished for the Contact test. The Contact test was conducted by LLNL on June 22, 1989 (DOE/NV, 2000). This CAS is located within a potential crater area and is considered a part of the pretest drilling efforts conducted for the Contact test. A stability study for the U-20aw crater was conducted by LLNL (Pawloski, 2003). The study suggests that the crater is stable in its current configuration, but LLNL has less confidence than normal in making this statement.

\subsubsection{Available Characterization Information}

No sampling, radiological surveys, or geophysical surveys have been conducted at this CAS.

\subsubsection{CAS 20-09-10, Mud Pit}

Corrective Action Site 20-09-10 consists of potential environmental releases associated with a mud pit located in the vicinity of the U-20bg crater.

This site consists of a large emplacement mud pit that measures approximately 221 by 179 by $25 \mathrm{ft}$. There is no mud but a large amount of drill cuttings is present in the pit. No equipment or debris is visible within the mud pit. Two overflow pipes, each measuring $25 \mathrm{ft}$ in length and $4 \mathrm{in}$. in diameter, are protruding from the top of the mud pit on the north and west sides. These pipes drain into two different man-made overflow areas. The pipe on the west side is buried approximately 8 to $10 \mathrm{in}$. beneath the dirt road separating the mud pit from the overflow area. There are no radiological signs posted in the area. Figure 2-18 shows the CAS location with respect to the surrounding roads and other physical features. 


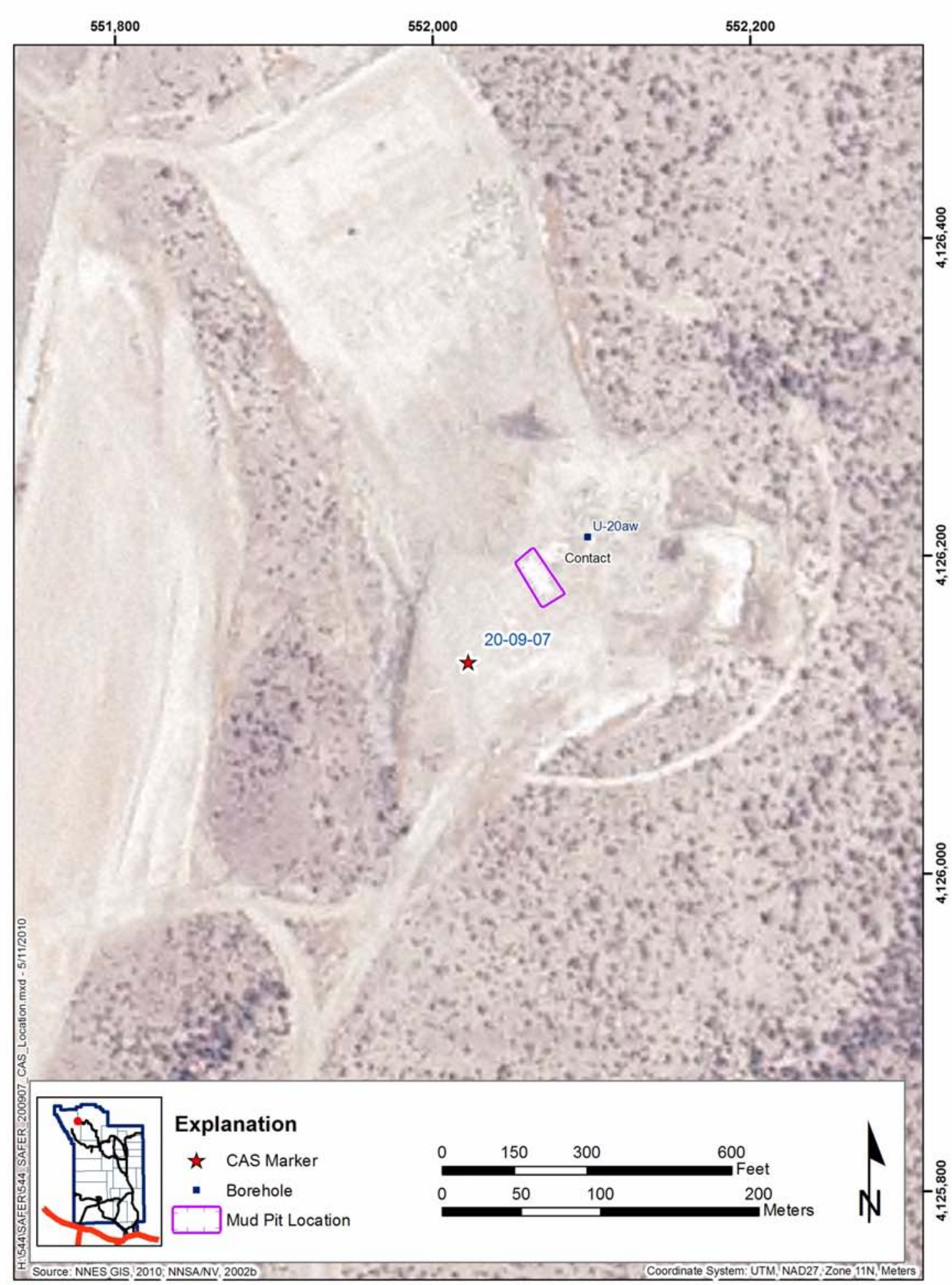

Figure 2-17

CAS 20-09-07, Mud Pit, Location with Respect to Surrounding Roads and Other Physical Features 


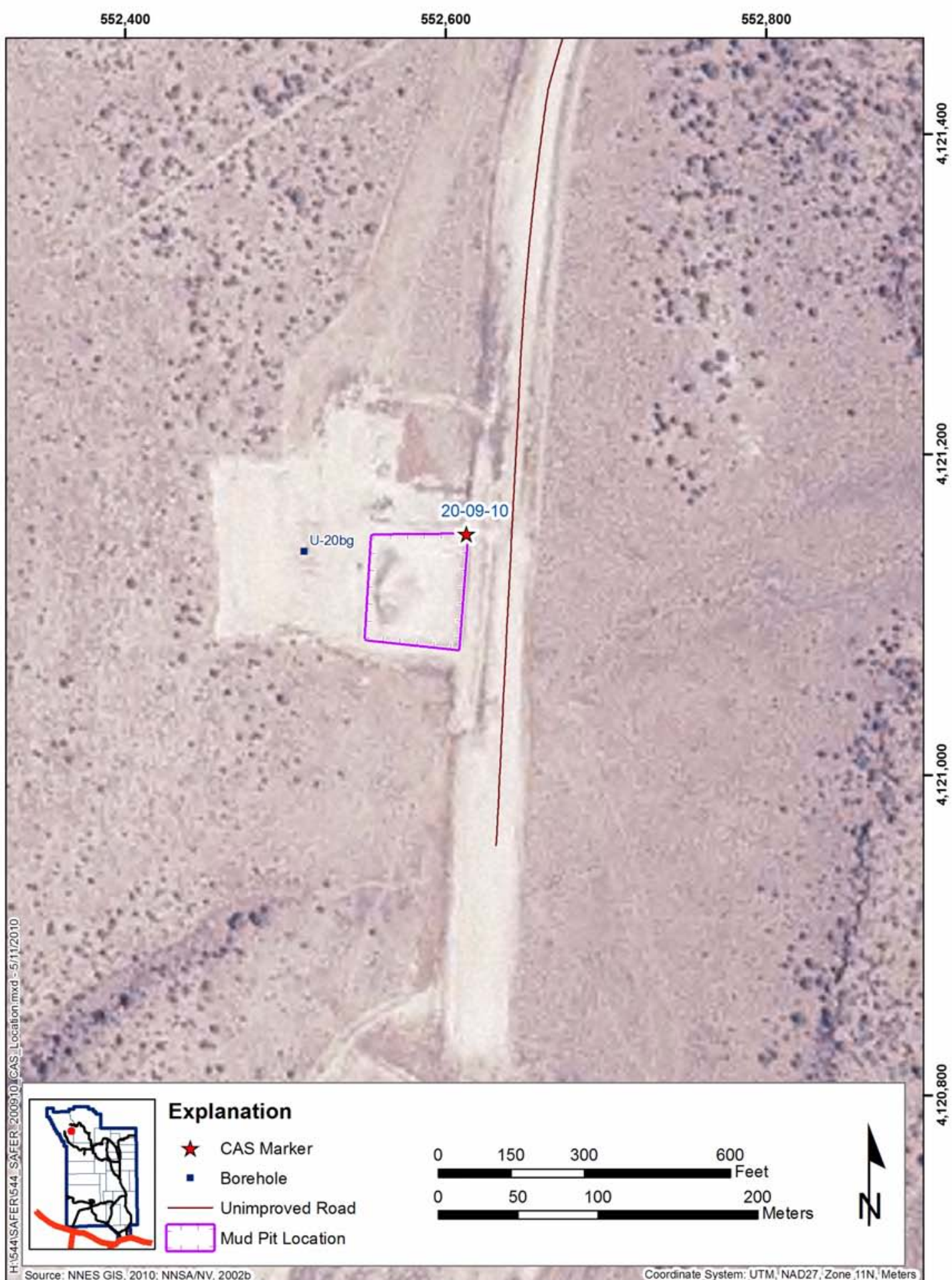

Figure 2-18

CAS 20-09-10, Mud Pit, Location with Respect to Surrounding Roads and Other Physical Features 


\subsubsection{History and Process Knowledge}

Corrective Action Site 20-09-10 is associated with the drilling of the emplacement hole U-20bg. The drilling began on July 12, 1990, and the hole was drilled to 2,200 ft. The borehole is considered active and is used for environmental monitoring (NNES, 2009b). The borehole was not used for underground nuclear testing; therefore, there is no crater associated with the hole.

\subsubsection{Available Characterization Information}

No sampling, radiological surveys, or geophysical surveys have been conducted at this CAS.

\subsection{Summary of Mud Pit CASs Located in Non-radiologically Controlled Areas}

Table 2-2 provides a summary of the mud pit CASs located within non-RCAs. These mud pits are being recommended for NFA and transfer to FFACO Appendix IV because they meet the following criteria from CAUs 530-535 conclusions and recommendations:

- The CAS is either a single mud pit or a system of mud pits.

- The CAS is not located in an RCA.

- There are no biasing factors evident based on visual inspection.

Table 2-2

Summary of Mud Pits Recommended for NFA

(Page 1 of 2)

\begin{tabular}{|c|c|}
\hline CAS Number & Description \\
\hline \hline $02-37-08$ & Mud Pit \\
\hline $07-09-01$ & Mud Pit \\
\hline $10-09-01$ & Mud Pit \\
\hline $12-09-03$ & Mud Pit \\
\hline $19-09-01$ & Mud Pits (2) \\
\hline $19-09-03$ & Mud Pit \\
\hline $19-09-04$ & Mud Pit \\
\hline $20-09-01$ & Mud Pits (2) \\
\hline $20-09-02$ & Mud Pit \\
\hline $20-09-03$ & Mud Pit \\
\hline
\end{tabular}


Table 2-2

Summary of Mud Pits Recommended for NFA (Page 2 of 2)

\begin{tabular}{||c|c|}
\hline CAS Number & Description \\
\hline \hline $20-09-04$ & Mud Pits (2) \\
\hline $20-09-06$ & Mud Pit \\
\hline $20-09-07$ & Mud Pit \\
\hline $20-09-10$ & Mud Pit \\
\hline
\end{tabular}




\subsection{Data Quality Objectives}

\subsection{Summary of DQO Analysis}

This section contains a summary of the DQO process that is presented in Appendix B. The DQO process is a strategic planning approach based on the scientific method that is designed to ensure that the data collected will provide sufficient and reliable information to identify, evaluate, and technically defend the recommendation of viable corrective actions (e.g., NFA, clean closure, or closure in place).

The DQO strategy for CAU 544 was developed at a meeting on April 27, 2010. The DQOs were developed to identify data needs, clearly define the intended use of the environmental data, and to design a data collection program that will satisfy these purposes. During the DQO discussions for this CAU, the informational inputs or data needs to resolve problem statements and decision statements were documented.

The problem statement for CAU 544 is: "Existing information on the nature and extent of contamination is incomplete to evaluate and confirm closure of all the CASs in CAU 544." To address this question, the resolution of two decisions statements is required:

- Decision I: "Is any COC present in environmental media within the CAS?” For the judgmental sampling design, any analytical result for a COPC above the FAL will result in that COPC being designated as a COC. For the probabilistic sampling design, any COPC that has a 95 percent upper confidence limit (UCL) of the average exceeding the FAL will result in that COPC being designated as a COC.

- Decision II: “Is sufficient information available to confirm that closure objectives were met?” Sufficient information is defined to include:

- Identifying the lateral and vertical extent of COC contamination in media, if present

- The information needed to characterize investigation-derived waste (IDW) and remediation waste for disposal

The presence of a COC would require a corrective action. A corrective action may also be necessary if there is a potential for wastes that are present at a site to impose COCs into site environmental media if the wastes were to be released. To evaluate the potential for site wastes to result in the 
introduction of a COC to the surrounding environmental media, the following conservative assumptions were made:

- Any containment of the wastes would fail at some point, and the wastes would be released to the surrounding media.

- The resulting concentration of contaminants in the surrounding media would be equal to the concentration of contaminants in the waste.

- Any liquid waste contaminant concentrations exceeding the RCRA toxicity characteristic concentration would result in COCs in the surrounding media.

Waste solids containing a contaminant exceeding an equivalent FAL concentration would be considered potential source material and would require a corrective action. Waste liquids with contaminant concentrations exceeding an equivalent toxicity characteristic action level would be considered potential source material and would require a corrective action.

Decision I samples will be submitted to analytical laboratories for the analyses listed in Table 3-1. The constituents reported for each analytical method are listed in Table 3-2. Decision II samples will be submitted for the analysis of all unbounded COCs. In addition, samples will be submitted for analyses as needed to support waste management or health and safety decisions.

The list of COPCs is intended to encompass all of the contaminants that could potentially be present at each CAS. These COPCs were identified during the planning process through the review of site history, process knowledge, personal interviews, past investigation efforts (where available), and inferred activities associated with the CASs.

During the review of site history documentation, process knowledge information, personal interviews, past investigation efforts, and inferred activities associated with the CASs, some of the COPCs were identified as targeted contaminants at specific CASs. Targeted contaminants are those COPCs for which evidence in the available site and process information suggests that they may be reasonably suspected to be present at a given CAS. The targeted contaminants are required to meet more stringent completeness criteria than other COPCs, thus providing greater protection against a decision error. Targeted contaminants for each CAU 544 CAS are identified in Table 3-3. 
Table 3-1

Analytical Program ${ }^{\mathrm{a}}$

\begin{tabular}{|c|c|c|c|}
\hline Analyses & Mud Pit & Cellar & Oil/Waste Spill \\
\hline \multicolumn{4}{|c|}{ Organic COPCs } \\
\hline TPH-DRO ${ }^{c}$ & -- & $X$ & $X$ \\
\hline PCBs & -- & $X$ & $X$ \\
\hline $\mathrm{SVOCs}^{\mathrm{b}}$ & -- & $X$ & $X$ \\
\hline $\mathrm{VOCs}^{\mathrm{b}}$ & -- & $X$ & $X$ \\
\hline \multicolumn{4}{|c|}{ Inorganic COPCs } \\
\hline Total RCRA Metals ${ }^{b}$ & -- & $X$ & $X$ \\
\hline \multicolumn{4}{|c|}{ Radionuclide COPCs } \\
\hline Gamma Spectroscopy ${ }^{d}$ & $x$ & $X$ & $x$ \\
\hline Isotopic $U^{d}$ & $X$ & $X$ & -- \\
\hline Isotopic Pu ${ }^{d}$ & $X$ & $x$ & - \\
\hline Sr-90d & $X$ & $x$ & - \\
\hline
\end{tabular}

aThe COPCs are the analytes reported from the analytical methods listed.

${ }^{\text {b} M a y ~ a l s o ~ i n c l u d e ~ T o x i c i t y ~ C h a r a c t e r i s t i c ~ L e a c h i n g ~ P r o c e d u r e ~(T C L P) ~ a n a l y t e s ~ i f ~ s a m p l e ~ i s ~ c o l l e c t e d ~ f o r ~ w a s t e ~}$ management purposes.

${ }^{\mathrm{C}} \mathrm{TPH}-\mathrm{DRO}$ analyses are for waste management purposes only.

${ }^{\mathrm{d}}$ Results of gamma analysis will be used to determine whether further isotopic analysis is warranted.

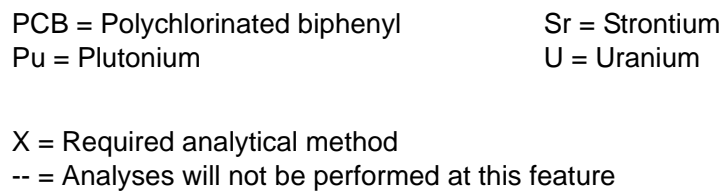

The data quality indicators (DQIs) of precision, accuracy, representativeness, completeness, comparability, and sensitivity needed to satisfy DQO requirements are discussed in Section 7.2.

Laboratory data will be assessed in the CR to confirm or refute the CSM and determine whether the DQO data needs were met. 
Table 3-2

Constituents Reported by Analyses

\begin{tabular}{|c|c|c|c|c|c|c|c|}
\hline \multicolumn{2}{|c|}{ VOCs } & \multicolumn{2}{|c|}{ SVOCs } & TPH & PCBs & Metals & Radionuclides \\
\hline $\begin{array}{l}\text { 1,1,1,2-Tetrachloroethane } \\
\text { 1,1,1-Trichloroethane } \\
\text { 1,1,2,2-Tetrachloroethane } \\
\text { 1,1,2-Trichloroethane } \\
\text { 1,1-Dichloroethane } \\
\text { 1,1-Dichloroethene } \\
\text { 1,2,4-Trichlorobenzene } \\
\text { 1,2,4-Trimethylbenzene } \\
\text { 1,2-Dibromo-3-chloropropane } \\
\text { 1,2-Dichlorobenzene } \\
\text { 1,2-Dichloroethane } \\
\text { 1,2-Dichloropropane } \\
\text { 1,3,5-Trimethylbenzene } \\
\text { 1,3-Dichlorobenzene } \\
\text { 1,4-Dichlorobenzene } \\
\text { 1,4-Dioxane } \\
\text { 2-Butanone } \\
\text { 2-Chlorotoluene } \\
\text { 2-Hexanone } \\
\text { 4-Isopropyltoluene } \\
\text { 4-Methyl-2-pentanone } \\
\text { Acetone } \\
\text { Acetonitrile } \\
\text { Allyl chloride } \\
\text { Benzene } \\
\text { Bromodichloromethane } \\
\text { Bromoform } \\
\text { Bromomethane } \\
\text { Carbon disulfide }\end{array}$ & $\begin{array}{l}\text { Carbon tetrachloride } \\
\text { Chlorobenzene } \\
\text { Chloroethane } \\
\text { Chloroform } \\
\text { Chloromethane } \\
\text { Chloroprene } \\
\text { cis-1,2-Dichloroethene } \\
\text { Dibromochloromethane } \\
\text { Dichlorodifluoromethane } \\
\text { Ethyl methacrylate } \\
\text { Ethylbenzene } \\
\text { Isobutyl alcohol } \\
\text { Isopropylbenzene } \\
\text { Methacrylonitrile } \\
\text { Methyl methacrylate } \\
\text { Methylene chloride } \\
\text { n-Butylbenzene } \\
\text { n-Propylbenzene } \\
\text { sec-Butylbenzene } \\
\text { Styrene } \\
\text { tert-Butylbenzene } \\
\text { Tetrachloroethene } \\
\text { Toluene } \\
\text { Total Xylenes } \\
\text { Trichloroethene } \\
\text { Trichlorofluoromethane } \\
\text { Vinyl acetate } \\
\text { Vinyl chloride }\end{array}$ & $\begin{array}{l}\text { 2,3,4,6-Tetrachlorophenol } \\
\text { 2,4,5-Trichlorophenol } \\
\text { 2,4,6-Trichlorophenol } \\
\text { 2,4-Dimethylphenol } \\
\text { 2,4-Dinitrotoluene } \\
\text { 2-Chlorophenol } \\
\text { 2-Methylnaphthalene } \\
\text { 2-Methylphenol } \\
\text { 2-Nitrophenol } \\
\text { 3-Methylphenol } \text { (m-cresol) }^{\text {4-Methylphenol }} \text { (p-cresol) } \\
\text { 4-Chloroaniline } \\
\text { 4-Nitrophenol } \\
\text { Acenaphthene } \\
\text { Acenaphthylene } \\
\text { Aniline } \\
\text { Anthracene } \\
\text { Benzo(a)anthracene } \\
\text { Benzo(a)pyrene } \\
\text { Benzo(b)fluoranthene } \\
\text { Benzo(g,h,i)perylene } \\
\text { Benzo(k)fluoranthene } \\
\text { Benzoic acid } \\
\text { Benzyl alcohol } \\
\text { Bis(2-ethylhexyl)phthalate } \\
\text { Butyl benzyl phthalate } \\
\text { Carbazole } \\
\text { Chrysene } \\
\text { Di-n-butyl phthalate }\end{array}$ & $\begin{array}{l}\text { Di-n-octyl phthalate } \\
\text { Dibenzo(a,h)anthracene } \\
\text { Dibenzofuran } \\
\text { Diethyl phthalate } \\
\text { Dimethyl phthalate } \\
\text { Fluoranthene } \\
\text { Fluorene } \\
\text { Hexachlorobenzene } \\
\text { Hexachlorobutadiene } \\
\text { Hexachloroethane } \\
\text { Indeno(1,2,3-cd)pyrene } \\
\text { n-Nitroso-di-n-propylamine } \\
\text { Naphthalene } \\
\text { Nitrobenzene } \\
\text { Pentachlorophenol } \\
\text { Phenanthrene } \\
\text { Phenol } \\
\text { Pyrene } \\
\text { Pyridine }\end{array}$ & $\overline{\mathrm{DRO}}$ & $\begin{array}{l}\text { Aroclor } 1016 \\
\text { Aroclor } 1221 \\
\text { Aroclor } 1232 \\
\text { Aroclor } 1242 \\
\text { Aroclor } 1248 \\
\text { Aroclor } 1254 \\
\text { Aroclor } 1260 \\
\text { Aroclor } 1268\end{array}$ & $\begin{array}{l}\text { Arsenic } \\
\text { Barium } \\
\text { Cadmium } \\
\text { Chromium } \\
\text { Lead } \\
\text { Mercury } \\
\text { Selenium } \\
\text { Silver }\end{array}$ & $\begin{array}{l}\text { Gross Alpha/Beta } \\
\text { Alpha-Emitting } \\
\text { Pu-238 } \\
\text { Pu-239/240 } \\
\text { U-234 } \\
\text { U-235 } \\
\text { U-238 } \\
\text { Beta-Emitting } \\
\text { Sr-90 } \\
\text { Tritium } \\
\text { Gamma-Emitting } \\
\text { Ac-228 } \\
\text { Am-241 } \\
\text { Co-60 } \\
\text { Cs-137 } \\
\text { Eu-152 } \\
\text { Eu-154 } \\
\text { Eu-155 } \\
\text { K-40 } \\
\text { Nb-94 } \\
\text { Pb-212 } \\
\text { Pb-214 } \\
\text { Tl-208 } \\
\text { Th-234 } \\
\text { U-235 }\end{array}$ \\
\hline
\end{tabular}

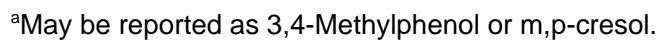

$\begin{array}{ll}\mathrm{Ac}=\text { Actinium } & \mathrm{Nb}=\text { Niobium } \\ \mathrm{Am}=\text { Americium } & \mathrm{Pb}=\text { Lead } \\ \mathrm{Co}=\text { Cobalt } & \mathrm{Th}=\text { Thorium } \\ \mathrm{Cs}=\text { Cesium } & \mathrm{Tl}=\text { Thallium } \\ \text { Eu }=\text { Europium } & \\ \mathrm{K}=\text { Potassium } & \end{array}$


Table 3-3

Targeted Contaminants for CAU 544

\begin{tabular}{|c|c|c||}
\hline Feature & $\begin{array}{c}\text { Chemical } \\
\text { Targeted Contaminants }\end{array}$ & $\begin{array}{c}\text { Radiological } \\
\text { Targeted Contaminants }\end{array}$ \\
\hline \hline Mud Pit $^{\mathrm{a}}$ & None & Gamma emitters, Sr-90, Isotopic U, Isotopic Pu \\
\hline Cellar & VOCs, SVOCs & None \\
\hline Oil/Waste Spill & VOCs, SVOCs & None \\
\hline
\end{tabular}

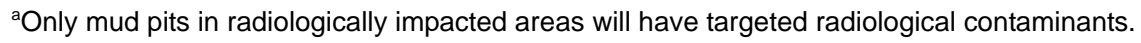

To satisfy the DQI of sensitivity (presented in Section 7.2.6), the analytical methods must be sufficient to detect contamination that is present in the samples at concentrations equal to the corresponding FALs. Analytical methods and minimum detectable concentrations (MDCs) for each CAU 544 COPC are provided in Tables 3-4 and 3-5. The MDC is the lowest concentration of a chemical or radionuclide parameter that can be detected in a sample within an acceptable level of error.

Table 3-4

Analytical Requirements for Radionuclides for CAU 544

(Page 1 of 2)

\begin{tabular}{|c|c|c|c|c|c|}
\hline Analysis $^{a}$ & $\begin{array}{l}\text { Medium or } \\
\text { Matrix }\end{array}$ & $\begin{array}{l}\text { Analytical } \\
\text { Method }\end{array}$ & $\mathrm{MDC}^{\mathrm{b}}$ & $\begin{array}{l}\text { Laboratory } \\
\text { Precision }\end{array}$ & $\begin{array}{l}\text { Laboratory } \\
\text { Accuracy }\end{array}$ \\
\hline \multicolumn{6}{|c|}{ Gamma-Emitting Radionuclides } \\
\hline \multirow[b]{2}{*}{$\begin{array}{c}\text { Gamma } \\
\text { Spectroscopy }\end{array}$} & Aqueous & EPA $901.1^{c}$ & \multirow[b]{2}{*}{$<$ PALS } & RPD & \multirow[b]{2}{*}{$\begin{array}{c}\text { LCS Recovery } \\
(\% \mathrm{R}) \\
80-120^{\dagger}\end{array}$} \\
\hline & Non-aqueous & GA-01-R & & $\begin{array}{c}20 \% \text { (aqueous) }^{\mathrm{d}} \\
\mathrm{ND} \\
-2<\mathrm{ND}<2^{\mathrm{e}}\end{array}$ & \\
\hline \multicolumn{6}{|c|}{ Other Radionuclides } \\
\hline Isotopic U & All & $\mathrm{U}-02-\mathrm{RC}^{\mathrm{g}}$ & \multirow{5}{*}{$<$ PALs } & \multirow{3}{*}{$\begin{array}{c}\text { RPD } \\
\text { 35\% (non-aqueous) } \\
20 \% \text { (aqueous) }^{d}\end{array}$} & \multirow{3}{*}{$\begin{array}{c}\text { Chemical Yield } \\
\text { Recovery }(\% \mathrm{R}) \\
30-105^{\mathrm{h}}\end{array}$} \\
\hline \multirow{2}{*}{ Isotopic Pu } & Aqueous & Pu-10-RC & & & \\
\hline & Non-aqueous & $\mathrm{Pu}-02-\mathrm{RC}^{\mathrm{g}}$ & & & \\
\hline \multirow{2}{*}{ Sr-90 } & Aqueous & EPA $905.0^{c}$ & & \multirow[t]{2}{*}{$\begin{array}{c}N D \\
-2<N D<2^{e}\end{array}$} & \multirow{2}{*}{$\begin{array}{c}\text { LCS Recovery } \\
(\% \mathrm{R}) \\
80-120^{\mathrm{h}}\end{array}$} \\
\hline & Non-aqueous & $\mathrm{Sr}-02-\mathrm{RC}^{\mathrm{g}}$ & & & \\
\hline
\end{tabular}


Table 3-4

Analytical Requirements for Radionuclides for CAU 544

(Page 2 of 2)

\begin{tabular}{|c|c|c|c|c|c|}
\hline Analysis $^{a}$ & $\begin{array}{l}\text { Medium or } \\
\text { Matrix }\end{array}$ & $\begin{array}{c}\text { Analytical } \\
\text { Method }\end{array}$ & $\mathrm{MDC}^{\mathrm{b}}$ & $\begin{array}{l}\text { Laboratory } \\
\text { Precision }\end{array}$ & $\begin{array}{l}\text { Laboratory } \\
\text { Accuracy }\end{array}$ \\
\hline \multirow{2}{*}{ Gross Alpha/Beta } & Aqueous & EPA $900.0^{c}$ & \multirow{4}{*}{$<$ PALS } & \multirow{4}{*}{$\begin{array}{c}\text { RPD } \\
35 \% \text { (non-aqueous) }^{d} \\
20 \% \text { (aqueous) }^{d}\end{array}$} & \multirow{4}{*}{$\begin{array}{c}\text { MS Recovery } \\
(\% R) \\
\text { Lab-specific }^{\mathrm{i}} \\
\text { LCS Recovery } \\
(\% \mathrm{R}) \\
80-120^{\mathrm{h}}\end{array}$} \\
\hline & Non-aqueous & SM $7110 B^{j}$ & & & \\
\hline \multirow{2}{*}{ Tritium } & Aqueous & EPA $906.0^{c}$ & & & \\
\hline & Non-aqueous & $\begin{array}{l}\text { Laboratory } \\
\text { Procedure }^{k}\end{array}$ & & & \\
\hline
\end{tabular}

${ }^{\mathrm{a}} \mathrm{A}$ list of constituents reported for each method is provided in Table 3-2.

${ }^{\mathrm{b}}$ The MDC is the minimum concentration of a constituent that can be measured and reported with $95 \%$ confidence (Standard Methods)'.

'Prescribed Procedures for Measurement of Radioactivity in Drinking Water (EPA, 1980).

'Sampling and Analysis Plan Guidance and Template (EPA, 2000).

${ }^{\mathrm{e}}$ Evaluation of Radiochemical Data Usability (Paar and Porterfield, 1997).

${ }^{\mathrm{f}}$ Test Methods for Evaluating Solid Waste, Physical/Chemical Methods (EPA, 2008).

${ }^{9}$ The Procedures Manual of the Environmental Measurements Laboratory (DOE, 1997).

hProfessional judgment and other industry acceptance criteria are used.

'Accuracy criteria are developed in-house using approved laboratory standard operating procedures in accordance with industry standards and the NNES Statement of Work requirements (NNES, 2009a).

'Standard Methods for the Examination of Water and Wastewater (Clesceri et al., 1998).

kLaboratory standard operating procedures in accordance with industry standards and the NNES Statement of Work requirements (NNES, 2009a).

LCS = Laboratory control sample

MS = Matrix spike

ND = Normalized difference

NNES = Navarro Nevada Environmental Services, LLC
PAL $=$ Preliminary action level

$\mathrm{RPD}=$ Relative percent difference

$\% \mathrm{R}=$ Percent recovery

Table 3-5

Analytical Requirements for Chemical COPCs for CAU 544

(Page 1 of 2)

\begin{tabular}{|c|c|c|c|c|c|}
\hline Analysis $^{a}$ & $\begin{array}{l}\text { Medium or } \\
\text { Matrix }\end{array}$ & $\begin{array}{c}\text { Analytical } \\
\text { Method }\end{array}$ & $\mathrm{MDC}^{\mathrm{b}}$ & $\begin{array}{l}\text { Laboratory } \\
\text { Precision }\end{array}$ & $\begin{array}{c}\text { Laboratory } \\
\text { Accuracy }\end{array}$ \\
\hline \multicolumn{6}{|c|}{ Organics } \\
\hline VOCs & All & $8260^{c}$ & $<$ PALs & Lab-specific $^{d}$ & Lab-specific $^{d}$ \\
\hline TCLP VOCs & Leachate & $1311 / 8260^{c}$ & $\begin{array}{c}<\text { Regulatory } \\
\text { Levels }\end{array}$ & Lab-specific $^{d}$ & Lab-specific $^{d}$ \\
\hline SVOCs & All & $8270^{c}$ & $<$ PALs & Lab-specific $^{d}$ & Lab-specific $^{d}$ \\
\hline TCLP SVOCs & Leachate & $1311 / 8270^{c}$ & $\begin{array}{c}<\text { Regulatory } \\
\text { Levels }\end{array}$ & Lab-specific $^{d}$ & Lab-specific $^{d}$ \\
\hline
\end{tabular}


Table 3-5

\section{Analytical Requirements for Chemical COPCs for CAU 544}

(Page 2 of 2)

\begin{tabular}{|c|c|c|c|c|c|}
\hline Analysis $^{a}$ & $\begin{array}{l}\text { Medium or } \\
\text { Matrix }\end{array}$ & $\begin{array}{c}\text { Analytical } \\
\text { Method }\end{array}$ & $\mathrm{MDC}^{\mathrm{b}}$ & $\begin{array}{l}\text { Laboratory } \\
\text { Precision }\end{array}$ & $\begin{array}{c}\text { Laboratory } \\
\text { Accuracy }\end{array}$ \\
\hline PCBs & All & $8082^{c}$ & \multirow{2}{*}{$<$ PALS } & Lab-specific $^{d}$ & Lab-specific $^{d}$ \\
\hline TPH-DRO & All & 8015 Modified $^{c}$ & & Lab-specific $^{d}$ & Lab-specific $^{d}$ \\
\hline \multicolumn{6}{|c|}{ Inorganics } \\
\hline Metals & All & $6010 / 6020^{c}$ & \multirow{3}{*}{$<$ PALs } & \multirow{4}{*}{ 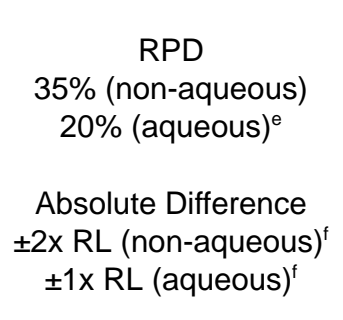 } & \multirow{4}{*}{$\begin{array}{c}\text { MS Recovery } \\
(\% \mathrm{R}) \\
75-125^{\mathrm{c}} \\
\\
\text { LCS Recovery } \\
(\% \mathrm{R}) \\
80-120^{\mathrm{c}}\end{array}$} \\
\hline \multirow{2}{*}{ Mercury } & Aqueous & $7470^{c}$ & & & \\
\hline & Non-aqueous & $7471^{c}$ & & & \\
\hline TCLP Metals & Leachate & $1311 / 6010 / 7470^{c}$ & $\begin{array}{c}<\text { Regulatory } \\
\text { Levels }\end{array}$ & & \\
\hline
\end{tabular}

${ }^{\mathrm{a} A}$ list of constituents reported for each method is provided in Table 3-2.

${ }^{\mathrm{b}}$ The MDC is the minimum concentration of a constituent that can be measured and reported with 99\% confidence (EPA, 2008).

${ }^{\mathrm{c}}$ Test Methods for Evaluating Solid Waste, Physical/Chemical Methods (EPA, 2008).

'Precision and accuracy criteria are developed in-house using approved laboratory standard operating procedures in accordance with industry standards and the NNES Statement of Work requirements (NNES, 2009a).

eSampling and Analysis Plan Guidance and Template (EPA, 2000).

'USEPA Contract Laboratory Program National Functional Guidelines for Inorganic Data Review (EPA, 2004).

$\mathrm{RL}=$ Reporting limit

\subsection{Results of the DQO Analysis}

\subsubsection{Action Level Determination and Basis}

The PALs presented in this section are to be used for site screening purposes. They are not necessarily intended to be used as cleanup action levels or FALs. However, they are useful in screening out contaminants that are not present in sufficient concentrations to warrant further evaluation, therefore streamlining the consideration of remedial alternatives. The RBCA process used to establish FALs is described in the Industrial Sites Project Establishment of Final Action Levels (NNSA/NSO, 2006c). This process conforms with Nevada Administrative Code (NAC) Section 445A.227, which lists the requirements for sites with soil contamination (NAC, 2008a). For the evaluation of corrective actions, NAC Section 445A.22705 (NAC, 2008b) requires the use of American Society for Testing and Materials (ASTM) Method E1739 (ASTM, 1995) to “conduct 
an evaluation of the site, based on the risk it poses to public health and the environment, to determine the necessary remediation standards (i.e., FALs) or to establish that corrective action is not necessary.”

This RBCA process, summarized in Figure 3-1, defines three tiers (or levels) of evaluation involving increasingly sophisticated analyses:

- Tier 1 evaluation - sample results from source areas (highest concentrations) are compared to action levels based on generic (non-site-specific) conditions (i.e., the PALs established in the SAFER). The FALs may then be established as the Tier 1 action levels, or the FALs may be calculated using a Tier 2 evaluation.

- Tier 2 evaluation - conducted by calculating Tier 2 site-specific target levels (SSTLs) using site-specific information as inputs to the same or similar methodology used to calculate Tier 1 action levels. The Tier 2 SSTLs are then compared to individual sample results from reasonable points of exposure (as opposed to the source areas as is done in Tier 1) on a point-by-point basis. Total petroleum hydrocarbon concentrations will not be used for risk-based decisions under Tier 2 or Tier 3. Rather, the individual chemicals of concern will be compared to the SSTLs.

- Tier 3 evaluation - conducted by calculating Tier 3 SSTLs on the basis of more sophisticated risk analyses using methodologies described in ASTM Method E1739 that consider site-, pathway-, and receptor-specific parameters.

Evaluation of DQO decisions will be based on conditions at the site following completion of any corrective actions. Any corrective actions conducted will be reported in the CR.

The FALs (along with the basis for their selection) will be defined in the CR, where they will be compared to laboratory results in the evaluation of site closure.

\subsubsection{Chemical PALS}

Except as noted herein, the chemical PALs are defined as the EPA Regions 3, 6, and 9, Regional Screening Levels (RSL) for Chemical Contaminants at Superfund Sites in industrial soils (EPA, 2009). Background concentrations for RCRA metals will be used instead of RSLs when natural background concentrations exceed the RSL, as is often the case with arsenic on the NTS. Background is considered the mean plus two standard deviations of the mean for sediment samples collected by the Nevada Bureau of Mines and Geology throughout the Nevada Test and Training Range (formerly the 


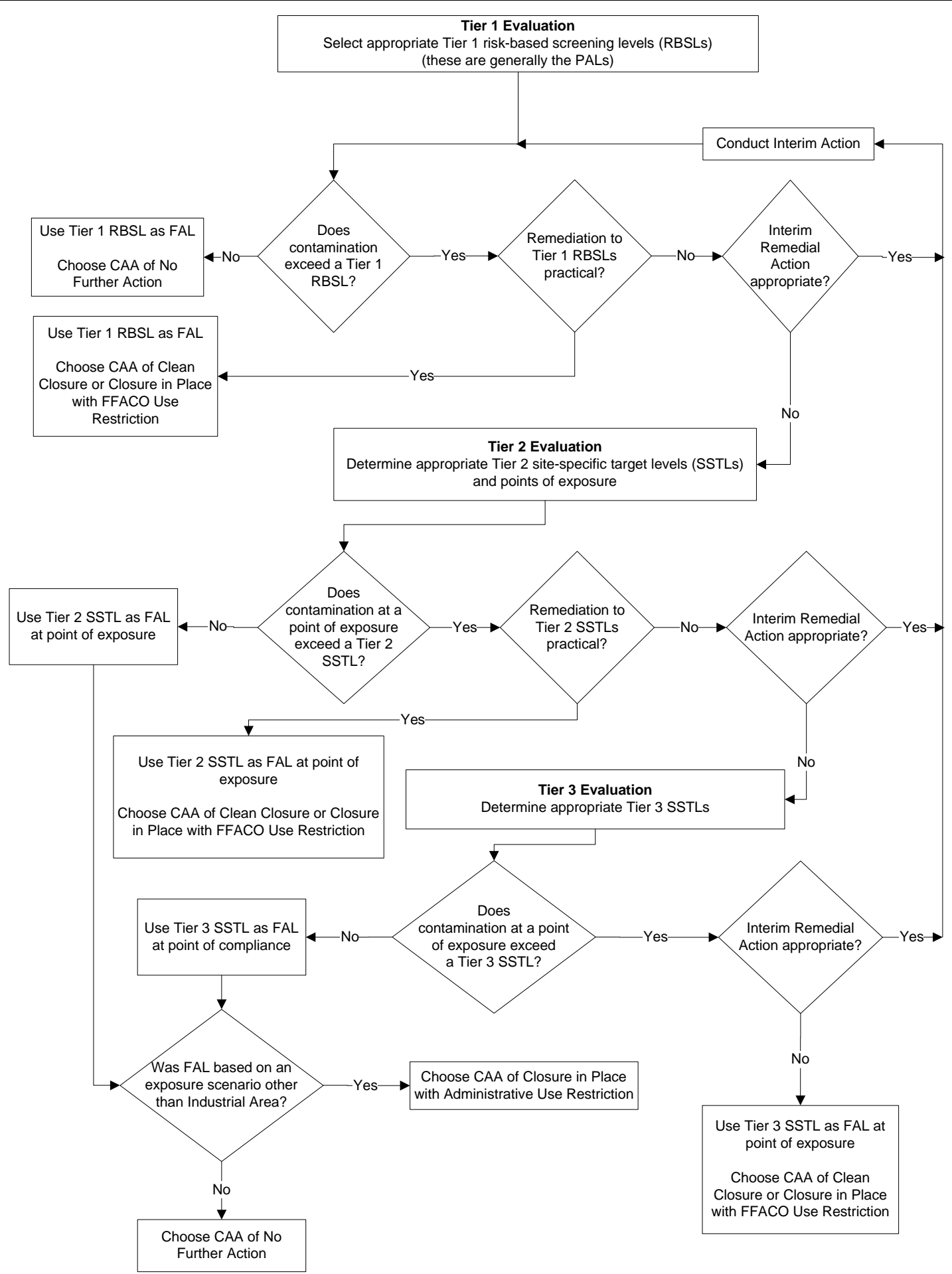

(ASTM, 1995)

Figure 3-1

Risk-Based Corrective Action Decision Process 
Nellis Air Force Range) (NBMG, 1998; Moore, 1999). For detected chemical COPCs without established RSLs, the protocol used by the EPA Regions 3, 6, and 9 in establishing RSLs (or similar) will be used to establish PALs. If used, this process will be documented in the CR.

\subsubsection{Radionuclide PALs}

The PALs for radiological contaminants (other than tritium) are based on the screening limits recommended in the National Council on Radiation Protection and Measurements (NCRP) Report No. 129 for construction, commercial, and industrial land-use scenarios (NCRP, 1999) using a 25-millirem-per-year (mrem/yr) dose constraint (Murphy, 2004) and the generic guidelines for residual concentration of radionuclides in DOE Order 5400.5 (DOE, 1993). These PALs are based on the construction, commercial, and industrial land-use scenario provided in the guidance and are appropriate for the NTS based on future land uses presented in Section B.2.2.6.

\subsubsection{Hypothesis Test}

The baseline condition (i.e., null hypothesis) and alternative condition are:

- Baseline condition: closure objectives have not been met.

- Alternative condition: closure objectives have been met.

Sufficient evidence to reject the null hypothesis is:

- The identification of the lateral and vertical extent of COC contamination in media, if present.

- Sufficient information to properly dispose of IDW and remediation waste.

\subsubsection{Statistical Model}

A judgmental sampling design will be implemented to select sample locations and evaluate DQO decisions for the cellars (CASs 02-37-08 and 02-37-09) and the oil/waste spills (CASs 19-25-01, 19-99-06, 20-25-04, and 20-25-05). A judgmental sampling approach will be implemented for the mud pit CASs if biasing factors are identified in the pit.

A probabilistic sampling scheme will be implemented to select sample locations and evaluate DQO decisions for radiologically impacted mud pits that will potentially be sampled (CASs 02-37-09 and 09-09-46). The CAS 09-09-46 mud pit will not be sampled until an acceptable stability study is conducted on the associated crater (the U-9itsx20 crater) and authorization is given to field personnel 
to enter the area for sampling. If the stability study results in a determination that the crater is unstable and thus shall not be entered, the mud pit will not be sampled and will be closed with a UR.

The statistical test for both sampling designs will compare results to fixed threshold values (i.e., FALs).

\subsubsection{Design Description/Option}

\subsubsection{Judgmental Sampling}

Because individual sample results, rather than an average concentration, will be used to compare to FALs at the CASs undergoing judgmental sampling, statistical methods to generate site characteristics will not be used. Adequate representativeness of the entire target population may not be a requirement to developing a sampling design. If good prior information is available on the target site of interest, then the sampling may be designed to collect samples only from areas known to have the highest concentration levels on the target site. If the observed concentrations from these samples are below the action level, then a decision can be made that the site contains safe levels of the contaminant without the samples being truly representative of the entire area (EPA, 2006).

All sample locations will be selected to satisfy the DQI of representativeness in that samples collected from selected locations will best represent the populations of interest as defined in Section B.5.1. To meet this criterion for judgmentally sampled sites, a biased sampling strategy will be used for Decision I samples to target areas with the highest potential for contamination, if it is present anywhere in the CAS. Sample locations will be determined based on process knowledge, previously acquired data, or the field-screening and biasing factors listed in Section B.4.2.1. If biasing factors are present in soils below locations where Decision I samples were removed, additional Decision I soil samples will be collected at depth intervals selected by the Site Supervisor (SS) based on biasing factors to a depth where the biasing factors are no longer present. The SS has the discretion to modify the judgmental sample locations, but only if the modified locations meet the decision needs and criteria stipulated in this DQO. 


\subsubsection{Probabilistic Sampling}

Statistical methods that generate site characteristics will be used at the mud pit CASs that have been impacted radiologically (CASs 02-37-09 and 09-09-46). The information provided from probabilistic sampling allows for establishing contaminant concentrations that represent the site as a whole.

Random sample locations will be chosen using the Visual Sample Plan (VSP) software (PNNL, 2007). If a sample cannot be collected from a pre-determined location for any reason (e.g., rock, caliche, or along the berm), the SS will establish an alternate location at the nearest location where a sample can be obtained.

\subsubsection{Conceptual Site Model and Drawing}

The CSM describes the most probable scenario for current conditions at each site and defines the assumptions that are the basis for identifying the future land use, contaminant sources, release mechanisms, migration pathways, exposure points, and exposure routes. The CSM was used to develop appropriate sampling strategies and data collection methods. The CSM was developed for CAU 544 using information from the physical setting, potential contaminant sources, release information, historical background information, knowledge from similar sites, and physical and chemical properties of the potentially affected media and COPCs.

Figure 3-2 depicts a tabular representation of the conceptual pathways to receptors from CAU 544 sources. The dominant pathway is exposure of NTS workers or visitors to contaminated residual mud or surface soils through inhalation, ingestion, or dermal contact. The primary release mechanism is the direct release of drilling mud to mud pits, or drill rig fluids and decontamination rinsate to cellars. Surface water is not expected to be impacted by a release as there are no nearby drainages at any CASs. Subsurface media is not expected to be impacted and would only be a pathway if it were excavated. Contaminants are also not expected to reach regional aquifers because leaching of contaminants through soil is limited. 


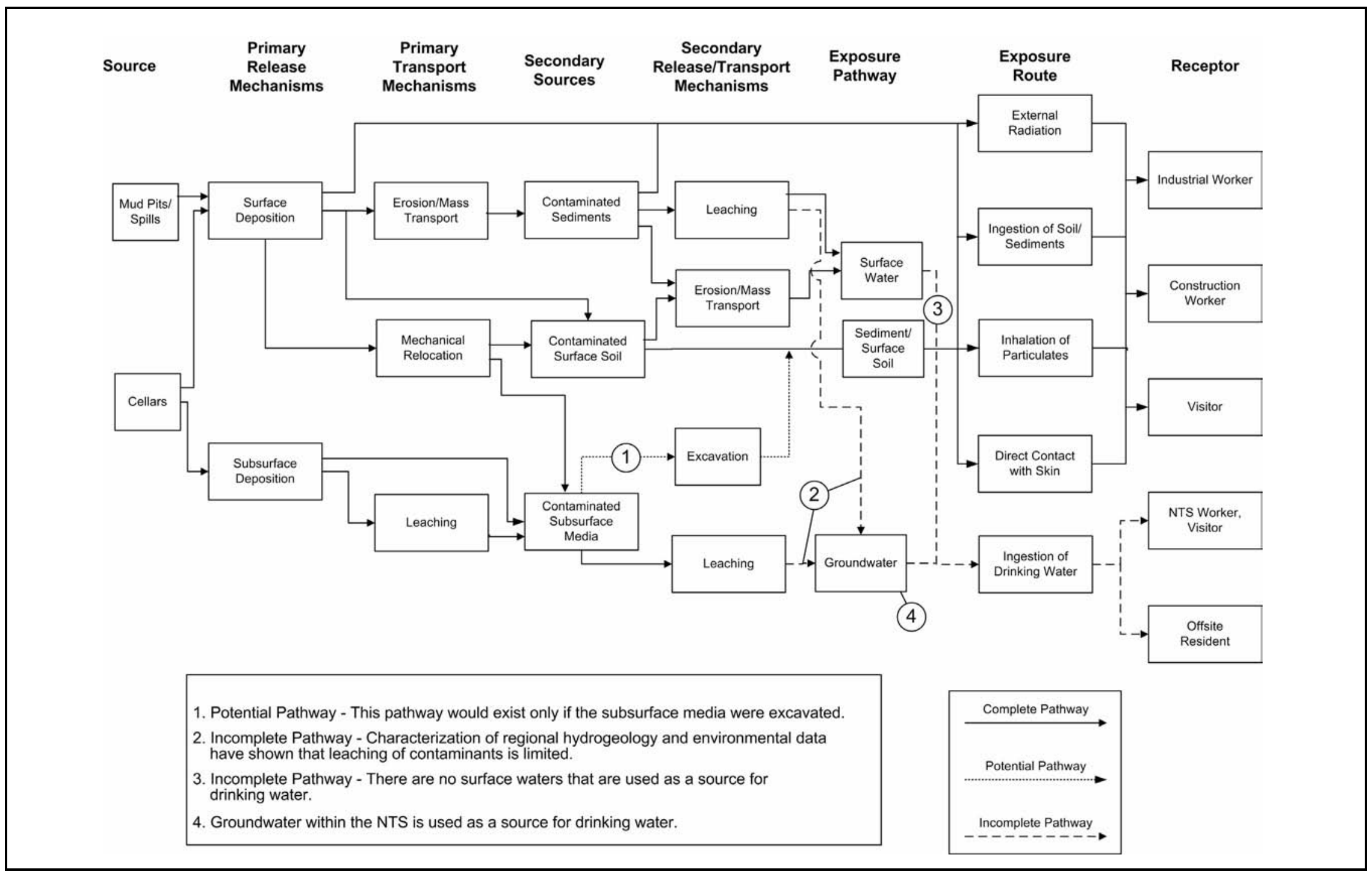

Figure 3-2

Conceptual Site Model Diagram for CAU 544

\section{UNCONTROLLED when Printed}


Figure 3-3 depicts a graphical representation of the CSM. If evidence of contamination that is not consistent with the presented CSM is identified during CAI activities, the situation will be reviewed, the CSM will be revised, the DQOs will be reassessed, and a recommendation will be made as to how best to proceed. In such cases, participants in the DQO process will be notified and given the opportunity to comment on and/or concur with the recommendation. A detailed discussion of the CSM is presented in Appendix B. 


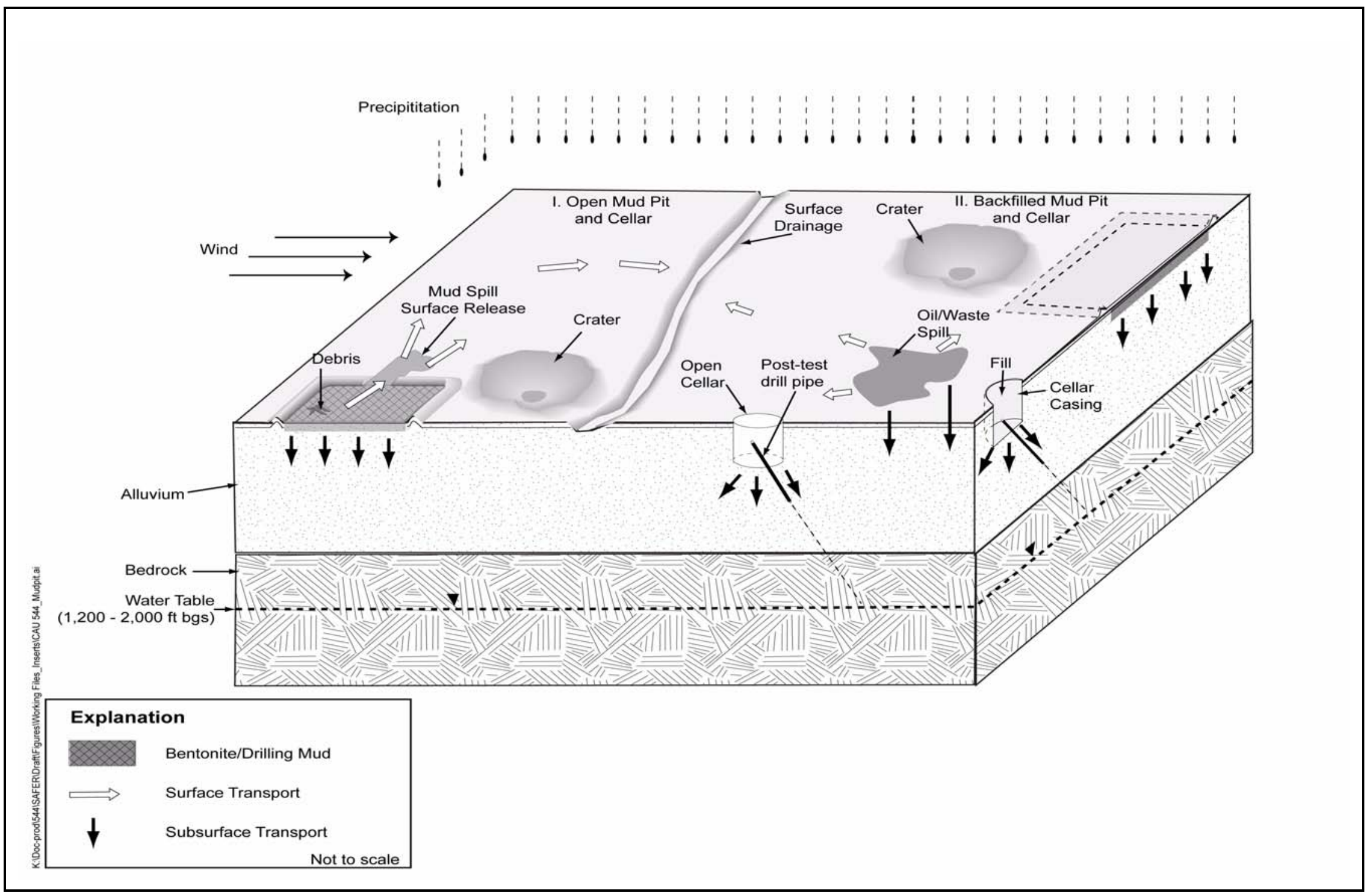

Figure 3-3

CAU 544 Conceptual Site Model 


\subsection{Field Activities and Closure Objectives}

This section of the SAFER Plan provides a description of the field activities and closure objectives for CAU 544. The objectives for the field activities are to determine whether COCs exist.

If remediation is to be accomplished during the SAFER, then the extent of COCs will be determined so that a closure alternative may be implemented. For a CAS that consists of a mud pit and cellar, the closure objective is to close the mud pit and cellar independent of one another utilizing the NFA alternative with a contingency for closure in place with appropriate administrative controls. The rationale for the field activities and sampling approaches presented in this section are based on the CSM. All sampling activities will be conducted in compliance with the Industrial Sites Quality Assurance Project Plan (QAPP) (NNSA/NV, 2002a) and other applicable, approved procedures and instructions.

\subsection{Contaminants of Potential Concern}

The COPCs for CAU 544 are defined as the list of constituents represented by the analyses identified in Table 3-1 for Decision I environmental samples taken at each of the CASs. The constituents reported for each analysis are listed in Table 3-2.

The list of COPCs is intended to encompass all of the contaminants that could potentially be present at each CAS. These COPCs were identified during the planning process through the review of site history, process knowledge, personal interviews, past investigation efforts (where available), and inferred activities associated with the CASs. As a result of this review, it was decided that radiological contaminants are only expected to be present at CAU 544 mud pits located within radiologically posted areas. For the cellar and spill CASs, contaminants detected at other similar NTS sites were also included in the COPC list to reduce the uncertainty about potential contamination at these CASs because complete information regarding activities performed at these CASs is not available.

During the review of site history documentation, process knowledge information, personal interviews, past investigation efforts, and inferred activities associated with the CASs, some of the COPCs were identified as targeted contaminants at specific CASs. Targeted contaminants are those 
COPCs for which available site and process information suggests that they may be reasonably suspected to be present at a given CAS. The targeted contaminants are required to meet more stringent completeness criteria than other COPCs, thus providing greater protection against a decision error. For the cellars and oil/waste spills, VOCs and SVOCs are identified as targeted analytes. There are no targeted chemical or radiological analytes for the mud pits in areas not impacted by radioactivity. Radionuclides are the targeted COPCs for radiologically impacted mud pits. Targeted contaminants for each CAU 544 feature are identified in Table 3-3.

\subsubsection{Radionuclides}

Process knowledge and prior investigations of radiologically impacted mud pits have demonstrated that the only COPCs expected would be radionuclides. Previous investigations have demonstrated that there are no COPCs in mud pits not impacted by radioactivity (NNSA/NSO, 2006b). For mud pits within radiologically posted areas, radionuclides could have been introduced into the drilling mud during the post-test drilling if circulation of the mud was not stopped before the drill string reached the depth potentially affected by the nuclear test. Radionuclides also may have been introduced into the cellars during washing and decontamination of equipment over the cellar or by a malfunction in the circulation system. It is anticipated that no radionuclides will be present in the oil and waste spills because these CASs are in areas unaffected by radioactive fallout.

\subsubsection{Volatile and Semivolatile Organic Compounds}

Although diesel fuel is known to have been added to the drilling fluid, previous mud pit investigations have eliminated all chemical constituents, including TPH-DRO, as being COPCs in the mud pits (NNSA/NSO, 2006b). However, the primary source of potential VOC and SVOC contamination in the cellars could be spills/leaks of drill rig fluids (e.g., oil, hydraulic fluids, greases, diesel fuel) or decontamination of drilling equipment over the cellar cavity. The oil and waste spills have potential for VOC and SVOC contamination due to the nature of the spills.

\subsubsection{Resource Conservation and Recovery Act Metals}

Traces of barium, lead, and chromium were identified in soil samples collected previously from CASs 07-09-01 and 19-99-06 and various oil spills throughout the NTS. Therefore, RCRA metals are included in the list of COPCs for cellars and oil/waste spills. 


\subsubsection{Polychlorinated Biphenyls}

Polychlorinated biphenyls were added to the list of COPCs for the cellars and oil/waste spills because they are a common concern at the NTS.

\subsection{Remediation}

The DQOs developed for CAU 544 identified data gaps that require additional data collection before identifying and implementing the preferred closure alternative for each CAS. A decision point approach, based on the DQOs, for making remediation decisions is summarized in Figure 1-3. The presence of contamination, if any, is assumed to be confined to the spatial boundaries of the sites as defined in the DQO process and CSM. According to DQO guidelines (Appendix B), probabilistic sampling will be conducted at potential radiologically impacted mud pits, and judgmental sampling will be conducted at all oil/waste spills and cellars, as well as mud pits where biasing factors are identified.

If COCs are identified within a CAS based on the initial investigation results, that CAS will be further assessed before implementing closure activities. If COPCs are not present at concentrations exceeding FALs, the CAS will be recommended for NFA. The objective of the initial investigation strategy is to determine whether COCs are present. Laboratory analytical results will be used to confirm the presence or absence of COCs.

If COCs are present, or it is decided that COCs may be present based on the presence of biasing factors, a corrective action of removal for disposal may be implemented and additional verification samples taken from biased locations within the excavation.

The judgmental and probabilistic sampling strategies are presented in Appendix B. Predetermined biased sample locations may be justified by the SS, based on the criteria for satisfying DQO data needs listed in Appendix B. Additional samples may be collected for waste management characterization and disposal purposes. 


\subsubsection{Field Activities}

Field activities at CAU 544 include site preparation, sample location selection, sample collection activities, waste characterization, photodocumentation, and collection of geographic coordinates. Activities at the CASs to be investigated will consist of collecting and analyzing samples at oil/waste spills, and radiologically posted mud pits and cellars to generate the information necessary to satisfy the DQO data needs (Appendix B). The SS has the discretion to modify sample locations or decide whether additional samples are needed, but only if the modified locations meet the decision needs and criteria stipulated in the DQOs (Appendix B). Modifications to the investigative strategy may be required should unexpected field conditions be encountered at any CAS. Significant modifications shall be justified and documented on a Record of Technical Change (ROTC). If an unexpected condition indicates that conditions are significantly different than the corresponding CSM, the activity will be rescoped and the identified decision makers will be notified.

\subsubsection{Site Preparation Activities}

Before collecting soil samples as part of the field investigation, the following site preparation activities must be completed:

- Removal of any debris (e.g., vegetation), if necessary, to access the sampling locations or conduct the visual surveys

- Visual surveys at each mud pit, cellar, and spill to identify any staining, discoloration, or any other biasing factors that are indications of potential contamination

\subsubsection{Cellars}

Both of the cellars to be investigated are backfilled. Therefore, sample collection will involve excavation through the cover material to obtain a sample from the first 6 in. of soil directly below the cover material/soil interface. If the interface between the cover material and impacted soil is not recognizable, then a subsurface sample will be collected at the depth where the cellar bottom is expected to be located based on the dimensions of similar open cellars. It is anticipated that a Geoprobe will be used to collect these cellar samples. 


\subsubsection{Oil and Waste Spills}

Samples collected at the oil and waste spills will be from the surface soil (0 to 6 in.) and below the stained soil/native soil interface. Two biased samples per spill will be collected. One sample will be collected where the heaviest staining of soil occurs, and the second sample will be collected at the edge of the spill.

\subsubsection{Mud Pits}

Based on the results of the RBCSR and the sampling results from CAUs 530-535, single mud pits or mud pit systems that are not within radiologically posted areas and have no visible biasing factors are not contaminated, they will not be sampled during this effort. Mud pits that meet the criteria specified in Section 2.4 will be recommended for NFA based on the results of the RBCSR effort conducted for CAUs 530-535 (NNSA/NSO, 2006b).

If the stability study of the crater associated with CAS 09-09-46 concludes that the crater is safe to enter, then sample locations will be randomly placed in a triangular grid pattern throughout the pit. At the CAS 02-37-09 mud pit, which is located outside the associated crater, sample locations will also be placed systematically in a triangular grid pattern throughout the pit. This ensures the probabilistic sampling approach will yield radiological concentrations that are considered characteristic of the mud pit.

All samples will be surface samples of the residual mud (0 to 6 in. bgs). For those mud pits that have been backfilled, sample collection will involve using a Geoprobe to push through the cover material to obtain a sample that extends from the cover/residual mud interface to 6 in. below the interface. If the interface between the cover material and mud is not recognizable, then a subsurface sample will be collected at the depth where mud is expected to be located based on the dimensions of similar NTS mud pits. Field screening may also be used to select subsurface sample locations in areas where a mud horizon is not recognizable. Additional biased samples may be collected in areas of obvious debris, spills, or soil staining located within or adjacent to the mud pit.

Figure 4-1 shows an example layout of surface sample locations at the radiologically impacted mud pits. Refer to Figure C.1-1 for the actual VSP-generated sample locations at the radiologically posted mud pits. 


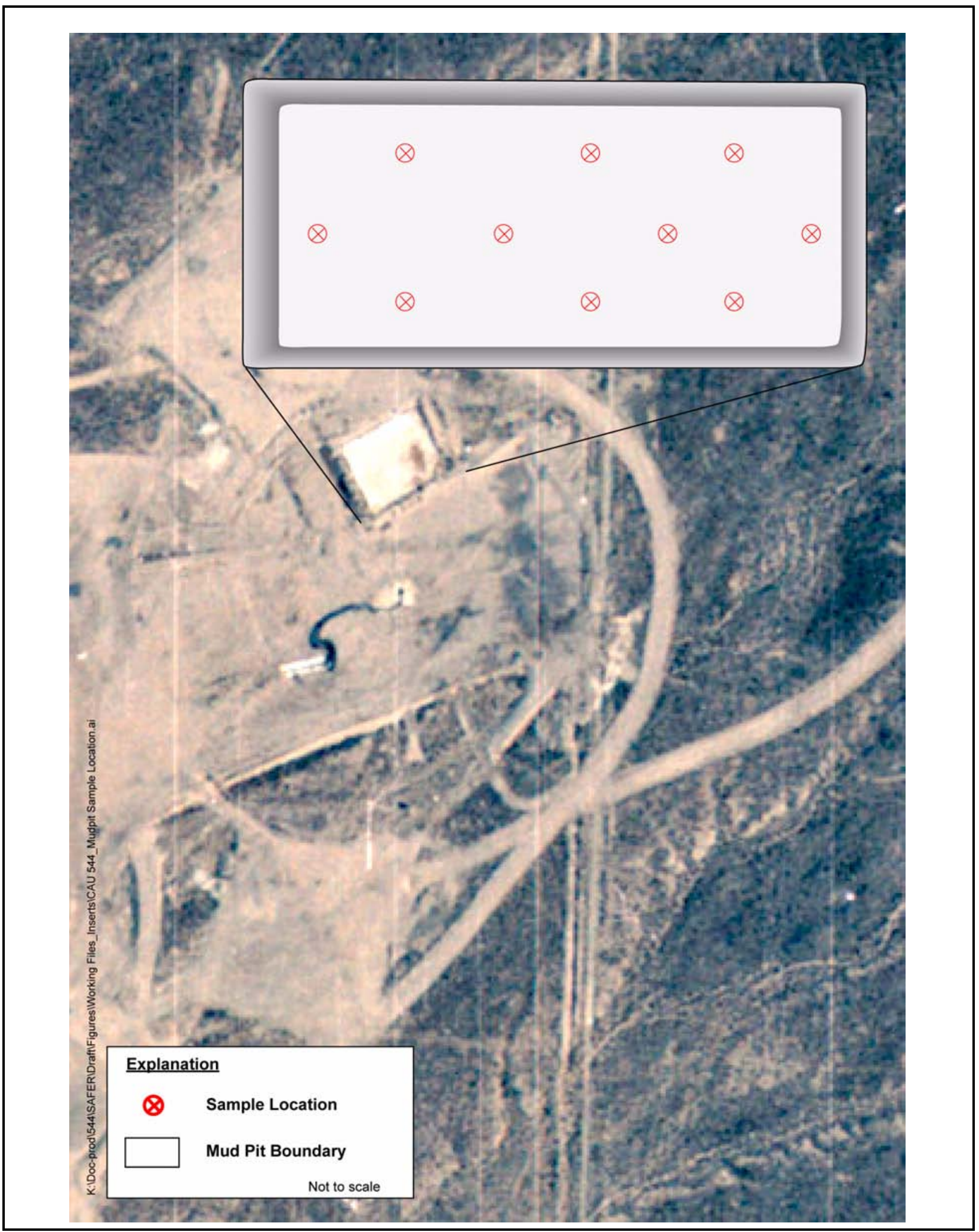

Figure 4-1

Example of Sample Locations at Mud Pits 


\subsection{Verification}

The information necessary to satisfy the closure criteria will be generated for each mud pit, cellar, and spill that requires sampling by collecting and analyzing samples generated during a field investigation. If a COC is present and removal of the COC can be accomplished, verification sampling of remaining environmental media will be required. The verification samples will be collected from the approximate center of the bottom of the excavation below the stained area and at lateral boundaries. The final locations and numbers of verification samples to be collected will be determined in the field based on the presence of any biasing factors as listed in Section B.4.2.1 of Appendix B, the size of the excavation, site conditions, and the professional judgement of the SS. All verification sample locations must meet the DQO decision needs and criteria stipulated in Appendix B. The number and location of verification samples will be justified in the CR.

If a COC is present and removal of the COC cannot be accomplished, information on the extent of COC contamination (mainly spills) will be obtained by collecting step-out (Decision II) samples. Decision II sampling will consist of further defining the extent of contamination where COCs have been confirmed. Step-out (Decision II) sampling locations at each CAS will be selected based on the CSM, biasing factors, field-survey results, existing data, and the outer boundary sample locations where COCs were detected. In general, step-out sample locations at the cellars will be below the Decision I sample locations. Step-out locations at the oil and waste spills will be arranged in a triangular pattern around areas containing a COC at distances based on site conditions, COC concentrations, process knowledge, and other biasing factors. If COCs extend beyond step-out locations, additional Decision II samples will be collected from locations farther from the source. If a spatial boundary is reached, the CSM is shown to be inadequate, or the SS determines that extent sampling needs to be re-evaluated, work will be temporarily suspended, NDEP will be notified, and the investigation strategy will be re-evaluated. Decision II sampling is not required for mud pits because of the assumption that contaminants, if present, are bound within the matrix of the residual drilling mud; therefore, the extent of contamination would be defined as the boundaries of the mud. 
The closure objectives will have been met and the CAS will be proposed for closure if the following conditions are true:

- A COC is not present at a CAS or a COC is present and the extent of each COC has been defined.

- Information is sufficient to characterize remediation waste and IDW for disposal.

- The mud pit meets the closure criteria in the RBCSR.

Because this SAFER Plan only addresses contamination originating from the CAU, it may be necessary to distinguish overlapping contamination originating from other sources. For example, widespread surface radiological contamination originating from atmospheric tests will not be addressed in the CAU 544 investigation. To determine whether contamination is from the CAU or from other sources, soil samples may be collected from background locations at selected CASs.

Table 4-1 summarizes the sampling approach to achieve closure objectives for each of the CASs in CAU 544.

\subsection{Closure}

The following activities, at a minimum, have been identified for closure of these CASs:

- If no COCs are detected, then the corrective action of NFA will be selected.

- If COCs are identified and clean closure cannot be accomplished during the SAFER, then a corrective action of closure in place will be selected. The appropriate URs will then be implemented and documented in the CR.

- If COCs are identified and clean closure can be accomplished during the SAFER, then the corrective action of clean closure will be selected. The material to be remediated will be removed and disposed of as waste, and verification samples will be collected from remaining soil. Verification analytical results will be documented in the CR.

- If a CAS cannot be sampled due to inaccessibility to sampling locations (e.g., stability studies for the potential crater area), then it will be assumed that COCs are present, and the corrective action of closure in place will be selected. The appropriate URs will then be implemented and documented in the CR. 
Table 4-1

Page 73 of 94

Sampling Approach for CAU 544 CASs

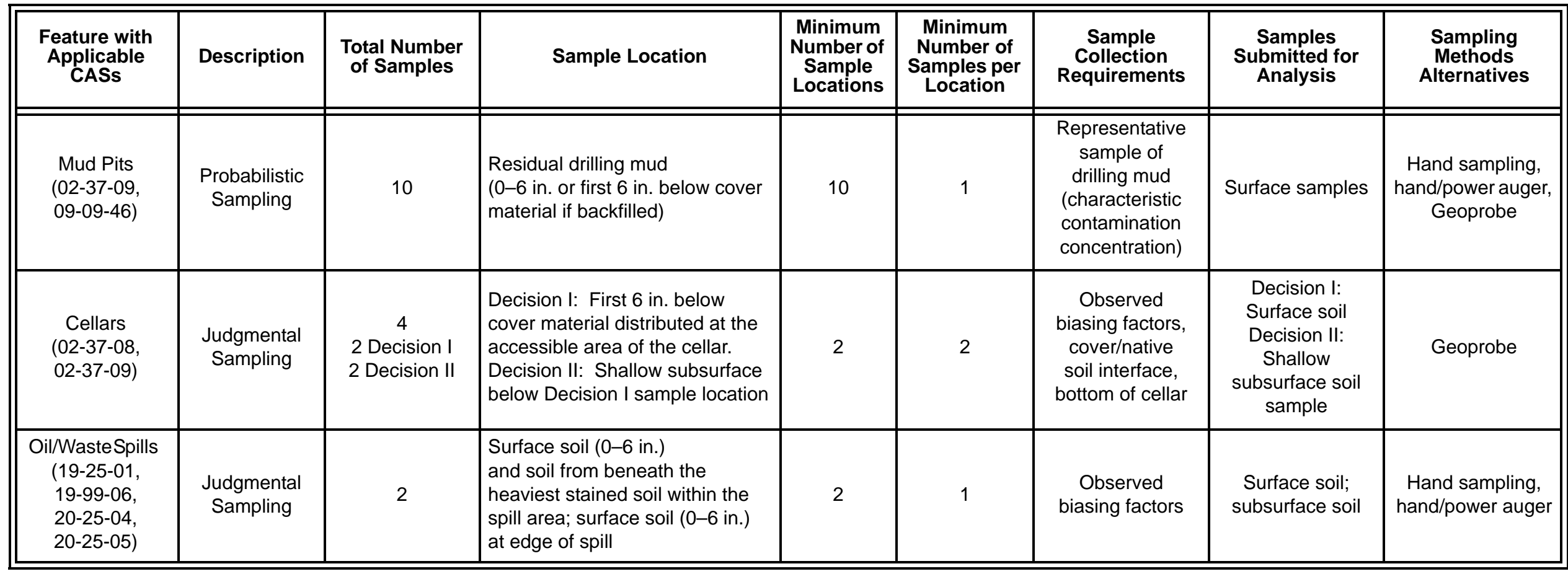


If conditions that violate SAFER assumptions are found, then a hold point will have been reached, and NDEP will be consulted to determine a path forward.

The decision logic behind the activities is provided in Figure 1-3.

Following completion of SAFER investigation and waste management activities, the following actions will be implemented before closure of the site Real Estate/Operations Permit (REOP):

- Removing all equipment, wastes, debris, and materials associated with the investigation.

- Grading site to pre-investigation condition (unless changed condition is necessary under a corrective action).

- Inspecting site and verifying that restoration activities have been completed.

\subsection{Duration}

Table 4-2 provides a tentative duration of activities (in calendar days) for SAFER activities:

Table 4-2

SAFER Field Activities

\begin{tabular}{||c|c|}
\hline Duration (days) & Activity \\
\hline \hline 20 & Site Preparation \\
\hline 3 & Site Mobilization \\
\hline 30 & Fieldwork \\
\hline 30 & Sample Analysis \\
\hline 50 & Data Validation and Assessment \\
\hline 195 & Closure Report \\
\hline 180 & Waste Management and Disposition \\
\hline
\end{tabular}




\subsection{Reports and Records Availability}

Reports generated during ongoing field activities will be provided to NDEP upon request. Historic information and documents referenced in this plan are retained in the NNSA/NSO project files in Las Vegas, Nevada, and can be obtained through written request to the NNSA/NSO Federal Sub-Project Director. This document is available in the DOE public reading rooms located in Las Vegas and Carson City, Nevada, or by contacting the appropriate DOE Federal Sub-Project Director. 


\subsection{Investigation/Remediation Waste Management}

Management, transportation, and disposal of the waste generated during the CAU 544 field investigation will be in accordance with all applicable DOE orders, EPA and U.S. Department of Transportation (DOT) regulations, state and federal waste regulations, and agreements and permits between DOE and NDEP. Wastes will be characterized based on these regulations using process knowledge, field screening, and analytical results from investigation and waste samples. Waste types that may be generated during the field investigation include sanitary, industrial, low-level radioactive, hazardous, hydrocarbon, or mixed wastes.

Disposable sampling equipment, personal protective equipment (PPE), and rinsate are considered potentially contaminated waste only by virtue of contact with potentially contaminated media (e.g., soil) or potentially contaminated debris (e.g., construction materials). Therefore, sampling and analysis of IDW, separate from analyses of site investigation samples, may not be necessary for all IDW. However, if associated investigation samples are found to contain contaminants above regulatory levels, conservative estimates of total waste contaminant concentrations may be made based on the mass of the waste, the amount of contaminated media contained in the waste, and the maximum concentration of contamination found in the media. Direct samples of IDW may also be taken to support waste characterization.

\subsection{Waste Minimization}

Investigation activities are planned to minimize IDW generation. This will be accomplished by incorporating the use of process knowledge, visual examination, and/or radiological survey and swipe results. When possible, disturbed media or debris will be returned to its original location. Contained media (e.g., soil managed as waste) as well as other IDW will be segregated to the greatest extent possible to minimize generation of hazardous, radioactive, or mixed waste. Hazardous material used at the sites will be controlled to limit unnecessary generation of hazardous or mixed waste.

Administrative controls, including decontamination procedures and waste characterization strategies, will minimize waste generated during investigations. 


\subsection{Potential Waste Streams}

Waste generated during the corrective action activities may include the following potential waste streams:

- Disposable sampling equipment (e.g., plastic, paper, sample containers, aluminum foil, spoons, bowls) and PPE

- Decontamination rinsate

- Environmental media (e.g., dried mud, soil)

- Field-screening waste (e.g., spent solvent, disposable sampling equipment, and/or PPE contaminated by field-screening activities)

The onsite management and ultimate disposition of wastes will be based on a determination of the waste type (e.g., sanitary, low-level radioactive, hazardous, hydrocarbon, mixed) or the combination of waste types. A determination of the waste type will be guided by several factors, including, but not limited to, the analytical results of samples either directly or indirectly associated with the waste, historical site knowledge, knowledge of the waste generation process, field observations, field-monitoring/screening results, and/or radiological survey/swipe results.

Table 4-2 of the NTS Radiological Control (RadCon) Manual (NNSA/NSO, 2010) shall be used to determine whether waste generated during the field investigation may be declared nonradioactive. Onsite IDW management requirements by waste type are detailed in the following sections. Waste management activities will follow all current regulations and requirements.

\subsubsection{Sanitary Waste}

Sanitary IDW generated at each CAS will be collected, managed, and disposed of in accordance with the sanitary waste management regulations and the permits for operation of the U10c Industrial Waste Landfill.

Sanitary IDW generated at each CAS will only be collected in plastic bags, sealed, labeled with the CAS number from each site in which it was generated, and dated. The waste will then be placed in a roll-off box located in Mercury, or other approved roll-off box location. The number of bags of sanitary IDW placed in the roll-off box will be counted as they are placed in the roll-off box and noted 
in a log. These logs will provide necessary tracking information for ultimate disposal in the U10c Industrial Waste Landfill.

\subsubsection{Low-Level Radioactive Waste}

Radiological swipe surveys and/or direct-scan surveys may be conducted on reusable sampling equipment and PPE, and disposable sampling equipment waste streams exiting an RCA. This allows for the immediate segregation of radioactive waste from waste that may be unrestricted regarding radiological release. Removable contamination limits, as defined in Table 4-2 of the RadCon Manual (NNSA/NSO, 2010), will be used to determine whether such waste may be declared unrestricted regarding radiological release rather than radioactive waste. Direct sampling of the waste may be conducted to aid in determining whether a particular waste unit (e.g., drum of soil) contains low-level radioactive waste, as necessary. Waste that is determined to be below the values specified in Table 4-2 of the RadCon Manual (NNSA/NSO, 2010), by either direct radiological survey/swipe results or through process knowledge, will be managed not as potential radioactive waste but in accordance with the appropriate section of this document. Wastes in excess of the values in Table 4-2 of the RadCon Manual (NNSA/NSO, 2010) will be managed as potential radioactive waste and in accordance with this section and any other applicable sections of this document.

Low-level radioactive waste, if generated, will be managed in accordance with the contractor-specific waste certification program plan, DOE orders, and the requirements of the current version of the Nevada Test Site Waste Acceptance Criteria (NTSWAC) (NNSA/NSO, 2009). Potential radioactive waste drums containing soil, PPE, disposable sampling equipment, and/or rinsate may be staged at a designated RMA or RCA when full or at the end of an investigation phase. The waste drums will remain at the RMA pending certification and disposal under the NTSWAC requirements (NNSA/NSO, 2009).

\subsubsection{Hazardous Waste}

The CAU will have waste accumulation areas established according to the needs of the project. Satellite accumulation areas and hazardous waste accumulation areas (HWAAs) will be managed consistent with applicable Code of Federal Regulations (CFR) and state administrative codes (CFR, 2009a; NAC, 2008a). The HWAAs will be properly controlled for access and equipped with 
spill kits and appropriate spill containment. Suspected hazardous wastes will be placed in DOT-compliant containers. All containerized hazardous waste will be handled, inspected, and managed in accordance with 40 CFR 265, Subpart I (CFR, 2009b). These provisions include managing the waste in containers compatible with the waste type and segregating incompatible waste types so that in the event of a spill, leak, or release, incompatible wastes shall not contact one another. The HWAAs will be covered under a site-specific emergency response and contingency action plan until such time that the waste is determined to be nonhazardous or all containers of hazardous waste have been removed from the storage area. Hazardous waste will be characterized in accordance with the requirement of 40 CFR 261. No RCRA-“listed” waste has been identified at CAU 544. Any waste determined to be hazardous will be managed and transported to a permitted treatment, storage, and disposal facility in accordance with RCRA (CFR, 2009a) and DOT requirements.

\subsubsection{Hydrocarbon Waste}

Hydrocarbon soil waste containing more than 100 milligrams per kilogram (mg/kg) of TPH will be managed on site in a drum or other appropriate container until fully characterized. Hydrocarbon waste may be disposed of at a designated hydrocarbon landfill (NDEP, 1997), an appropriate hydrocarbon waste management facility (e.g., recycling facility), or other method in accordance with the State of Nevada regulations.

\subsubsection{Mixed Low-Level Waste}

Mixed low-level waste (MLLW), if generated, shall be managed and dispositioned according to the requirements of RCRA (CFR, 2009a), agreements between NNSA/NSO and the State of Nevada, and DOE requirements for radioactive waste. The waste will be marked with the words "Hazardous Waste Pending Analysis and Radioactive Waste Pending Analysis.” Waste characterized as mixed will not be stored for a period of time that exceeds the requirements of RCRA unless subject to agreements between NNSA/NSO and the State of Nevada. The mixed waste shall be transported via an approved hazardous waste/radioactive waste transporter to the NTS transuranic waste storage pad for storage pending treatment or disposal. Mixed waste with hazardous waste constituent concentrations below Land Disposal Restrictions may be disposed of at the NTS Area 5 Radioactive Waste Management Site if the waste meets the requirements of the NTSWAC (NNSA/NSO, 2009), the NTS NDEP permit for a Hazardous Waste Management Facility (NEV HW0021 [NDEP, 2005]), 
and the RCRA Part B Permit Application for Waste Management Activities at the NTS (DOE/NV, 1999). Mixed waste constituent concentrations exceeding Land Disposal Restrictions will require development of a treatment and disposal plan under the requirements of the Mutual Consent Agreement between DOE and the State of Nevada (NDEP, 1995).

\subsubsection{Polychlorinated Biphenyls}

The management of PCBs is governed by the Toxic Substances Control Act (TSCA) and its implementing regulations at 40 CFR 761 (CFR, 2009c). Polychlorinated biphenyl contamination may be found as a sole contaminant or in combination with any of the types of waste discussed in this document. For example, PCBs may be a co-contaminant in soil that contains a RCRA “characteristic” waste (PCB/hazardous waste), or in soil that contains radioactive wastes (PCB/radioactive waste), or even in mixed waste (PCB/radioactive/hazardous waste). The IDW will initially be evaluated using analytical results for media samples from the CAI. If any type of PCB waste is generated, it will be managed in accordance with 40 CFR 761 (CFR, 2009c) as well as State of Nevada requirements (NAC, 2008a), guidance, and agreements with NNSA/NSO.

\subsection{Management of Specific Waste Streams}

\subsubsection{Personal Protective Equipment}

Personal protective equipment and disposable sampling equipment will be visually inspected for stains, discoloration, and gross contamination as the waste is generated, and also evaluated for radiological contamination. Staining and/discoloration will be assumed to be the result of contact with potentially contaminated media such as soil, sludge, or liquid. Gross contamination is the visible contamination of an item (e.g., clumps of soil/sludge on a sampling spoon or free liquid smeared on a glove). While gross contamination can often be removed through decontamination methods, removal of gross contamination from small items, such as gloves or booties, is not typically conducted. Any IDW that meets this description will be segregated and managed as potentially "characteristic" hazardous waste. This segregated population of waste will either (1) be assigned the characterization of the soil/sludge that was sampled, (2) be sampled directly, or (3) undergo further evaluation using the soil/sludge sample results to determine how much soil/sludge would need to be present in the waste to exceed regulatory levels. Waste that is determined to be hazardous will be entered into an 
approved waste management system, where it will be managed and dispositioned in accordance with RCRA requirements or subject to agreements between NNSA/NSO and the State of Nevada. The PPE and equipment that is not visibly stained, discolored, or grossly contaminated and that is within the radiological free-release criteria will be managed as nonhazardous sanitary waste.

\subsubsection{Management of Decontamination Rinsate}

Rinsate at CAU 544 will not be considered hazardous waste unless there is evidence that the rinsate may display a RCRA characteristic. Evidence may include such things as the presence of a visible sheen, $\mathrm{pH}$, or association with equipment/materials used to respond to a release/spill of a hazardous waste/substance. Decontamination rinsate that is potentially hazardous (using associated sample results and/or process knowledge) will be managed as characteristic hazardous waste (CFR, 2009a). The regulatory status of the potentially hazardous rinsate will be determined through the application of associated sample results or through direct sampling. If the associated samples do not indicate the presence of hazardous constituents, then the rinsate will be considered nonhazardous.

The disposal of nonhazardous rinsate will be consistent with guidance established in current NNSA/NSO Fluid Management Plans for the NTS as follows:

- Nonhazardous rinsate with a contamination level less than 5 times Safe Drinking Water Standards (SDWS) is not restricted as to disposal. Nonhazardous rinsate with a contamination level 5 to 10 times SDWS will be either disposed of in an established infiltration basin, or solidified and disposed of as sanitary waste or low-level waste in accordance with the respective sections of this document.

- Nonhazardous rinsate contaminated at greater than 10 times SDWS will be either disposed of in a lined basin, or solidified and disposed of as sanitary waste or low-level waste in accordance with the respective sections of this document.

\subsubsection{Management of Soil and Drilling Mud}

This waste stream consists of soil and drilling mud removed for disposal during sampling, and/or excavation. This waste stream will be characterized based on laboratory analytical results from representative samples. If the soil or mud is determined to contain COCs, the material will be either managed on site or containerized for transportation to an appropriate disposal site. 
Onsite management of the waste soil or mud will be allowed only if it is managed within an area of concern and it is appropriate to defer the management of the waste until the final remediation of the site. If this option is chosen, the waste soil shall be protected from run-on and runoff using appropriate protective measures based on the type of contaminant(s) (e.g., covered with plastic and bermed).

Management of soil or mud waste for disposal consists of placing the waste in containers, labeling the containers, temporarily storing the containers until shipped, and shipping the waste to a disposal site. The containers, labels, management of stored waste, transport to the disposal site, and disposal shall be appropriate for the type of waste (e.g., hazardous, hydrocarbon, mixed).

Note that soils or drilling mud placed back into an excavation in the same approximate location from which it originated is not considered a waste.

\subsubsection{Management of Debris}

This waste stream can vary depending on site conditions. Debris that requires removal for the investigation activities (soil sampling and/or excavation) must be characterized for proper management and disposition. Historical site knowledge, knowledge of the waste generation process, field observations, field-monitoring/screening results, radiological survey/swipe results, and/or the analytical results of samples either directly or indirectly associated with the waste may be used to characterize the debris. Debris will be visually inspected for stains, discoloration, and gross contamination. Debris may be deemed reusable, recyclable, sanitary waste, hazardous waste, PCB waste, or low-level waste. Waste that is not sanitary will be entered into an approved waste management system and managed and dispositioned in accordance with applicable federal and state requirements, and agreements between NNSA/NSO and the State of Nevada. The debris will be managed on site either by berming and covering next to the excavation or by placement in a container(s), or left on the footprint of the CAS and its disposition deferred until implementation of corrective action at the site. 


\subsection{Quality Assurance/Quality Control}

The overall objective of the characterization activities described in this SAFER Plan is to collect accurate and defensible data to support the selection and implementation of a closure alternative for each CAS in CAU 544. Sections 7.1 and 7.2 discuss the collection of required quality control (QC) samples in the field and quality assurance (QA) requirements for laboratory/analytical data to achieve closure. Unless otherwise stated in this SAFER Plan or required by the results of the DQO process (see Appendix B), this CAI will adhere to the Industrial Sites QAPP (NNSA/NV, 2002a).

\subsection{Sample Collection Activities}

Field QC samples will be collected in accordance with established procedures. Field QC samples are collected and analyzed to aid in determining the validity of environmental sample results. The number of required QC samples depends on the types and number of environmental samples collected. The minimum frequencies of collecting and analyzing QC samples for this CAI, as determined in the DQO process, include:

- $\quad$ Trip blanks (1 per sample cooler containing VOC environmental samples)

- Equipment rinsate blanks (1 per sampling event for each type of decontamination procedure)

- $\quad$ Source blanks (1 per uncharacterized lot of source material that contacts sampled media)

- Field duplicates (1 per 20 environmental samples or 1 per CAS per matrix, if less than 20 collected)

- Field blanks (may be 1 per 20 environmental samples, 1 per day, or 1 per CAS depending on site conditions and agreement of DQO participants)

- Laboratory QC samples (1 per 20 environmental samples or 1 per CAS per matrix, if less than 20 collected)

Additional QC samples may be submitted based on site conditions at the discretion of the Task Manager or SS. Field QC samples shall be analyzed using the same analytical procedures implemented for associated environmental samples. Additional details regarding field QC samples are available in the Industrial Sites QAPP (NNSA/NV, 2002a). 


\subsection{Applicable Laboratory/Analytical Data Quality Indicators}

The DQIs are qualitative and quantitative descriptors used in interpreting the degree of acceptability or utility of data. Data quality indicators are used to evaluate the entire measurement system and laboratory measurement processes (i.e., analytical method performance) as well as to evaluate individual analytical results (i.e., parameter performance). The quality and usability of data used to make DQO decisions will be assessed based on the following DQIs:

- Precision

- Accuracy/bias

- Representativeness

- Completeness

- Comparability

- Sensitivity

Table 7-1 provides the established analytical method/measurement system performance criteria for each of the DQIs and the potential impacts to the decision if the criteria are not met. The following subsections discuss each of the DQIs that will be used to assess the quality of laboratory data.

Table 7-1

Laboratory and Analytical Performance Criteria for CAU 544 DQIs (Page 1 of 2)

\begin{tabular}{||c|l|l||}
\hline \multicolumn{1}{|c|}{ DQI } & \multicolumn{1}{|c|}{ Performance Metric } & \multicolumn{1}{|c|}{$\begin{array}{c}\text { Potential Impact on Decision } \\
\text { If Performance Metric Not Met }\end{array}$} \\
\hline \hline Precision & $\begin{array}{l}\text { At least 80\% of the sample results for each } \\
\text { measured contaminant are not qualified for } \\
\text { precision based on the criteria for each analytical } \\
\text { method-specific and laboratory-specific criteria } \\
\text { presented in Section 7.2.1. }\end{array}$ & $\begin{array}{l}\text { The affected analytical results from each } \\
\text { affected CAS will be assessed to determine } \\
\text { whether there is sufficient confidence in } \\
\text { analytical results to use the data in making } \\
\text { DQO decisions. }\end{array}$ \\
\hline Accuracy & $\begin{array}{l}\text { At least 80\% of the sample results for each } \\
\text { measured contaminant are not qualified for } \\
\text { accuracy based on the method-specific and } \\
\text { laboratory-specific criteria presented } \\
\text { in Section 7.2.2. }\end{array}$ & $\begin{array}{l}\text { The affected analytical results from each } \\
\text { affected CAS will be assessed to determine } \\
\text { whether there is sufficient confidence in } \\
\text { analytical results to use the data in making } \\
\text { DQO decisions. }\end{array}$ \\
\hline Representativeness & $\begin{array}{l}\text { Samples contain contaminants at concentrations } \\
\text { present in the environmental media from which they } \\
\text { were collected. }\end{array}$ & $\begin{array}{l}\text { Analytical results will not represent true site } \\
\text { conditions. Inability to make appropriate } \\
\text { DQO decisions. }\end{array}$ \\
\hline $\begin{array}{l}\text { Decision I } \\
\text { Completeness }\end{array}$ & $\begin{array}{l}\text { 80\% of the CAS-specific COPCs have valid results. } \\
\text { 100\% of CAS-specific targeted contaminants have } \\
\text { valid results. }\end{array}$ & $\begin{array}{l}\text { Cannot support/defend decision on } \\
\text { whether COCs are present. }\end{array}$ \\
\hline
\end{tabular}


Table 7-1

Laboratory and Analytical Performance Criteria for CAU 544 DQIs (Page 2 of 2)

\begin{tabular}{|c|l|l|}
\hline DQI & \multicolumn{1}{|c|}{ Performance Metric } & \multicolumn{1}{|c|}{$\begin{array}{c}\text { Potential Impact on Decision } \\
\text { If Performance Metric Not Met }\end{array}$} \\
\hline \hline $\begin{array}{c}\text { Decision II } \\
\text { Completeness }\end{array}$ & $\begin{array}{l}100 \% \text { of COCs used to define extent have } \\
\text { valid results. }\end{array}$ & $\begin{array}{l}\text { Extent of contamination cannot be } \\
\text { accurately determined. }\end{array}$ \\
\hline Comparability & $\begin{array}{l}\text { Sampling, handling, preparation, analysis, reporting, } \\
\text { and data validation are performed using standard } \\
\text { methods and procedures. }\end{array}$ & $\begin{array}{l}\text { Inability to combine data with data obtained } \\
\text { from other sources and/or inability to } \\
\text { compare data to regulatory action levels. }\end{array}$ \\
\hline Sensitivity & $\begin{array}{l}\text { Minimum detectable concentrations are less than or } \\
\text { equal to respective FALs. }\end{array}$ & $\begin{array}{l}\text { Cannot determine whether CoCs are } \\
\text { present or migrating at levels of concern. }\end{array}$ \\
\hline
\end{tabular}

\subsubsection{Precision}

Precision is a measure of the repeatability of the analysis process from sample collection through analysis results. It is used to assess the variability between two equal samples.

Determinations of precision will be made for field duplicate samples and laboratory duplicate samples. Field duplicate samples will be collected simultaneously with samples from the same source under similar conditions in separate containers. The duplicate sample will be treated independently of the original sample in order to assess field impacts and laboratory performance on precision through a comparison of results. Laboratory precision is evaluated as part of the required laboratory internal QC program to assess performance of analytical procedures. The laboratory sample duplicates are an aliquot, or subset, of a field sample generated in the laboratory. They are not a separate sample but a split, or portion, of an existing sample. Typically, laboratory duplicate QC samples may include matrix spike duplicate (MSD) and LCS duplicate samples for organic, inorganic, and radiological analyses.

Precision is a quantitative measure used to assess overall analytical method and field-sampling performance as well as to assess the need to "flag” (qualify) individual parameter results when corresponding QC sample results are not within established control limits.

The criteria used for the assessment of inorganic chemical precision when both results are greater than or equal to 5x RL are 20 and 35 percent for aqueous and soil samples, respectively. When either 
result is less than $5 x \mathrm{RL}$, a control limit of $\pm 1 x \mathrm{RL}$ and $\pm 2 x \mathrm{RL}$ for aqueous and soil samples, respectively, is applied to the absolute difference.

The criteria used for the assessment of organic chemical precision are based on professional judgment using laboratory-derived control limits.

The criteria used for the assessment of radiological precision when both results are greater than or equal to $5 \mathrm{x}$ MDC are 20 and 35 percent for aqueous and soil samples, respectively. When either result is less than $5 x$ MDC, the ND should be between -2 and +2 for aqueous and soil samples.

Any values outside the specified criteria do not necessarily result in the qualification of analytical data. It is only one factor in making an overall judgment about the quality of the reported analytical results. The performance metric for assessing the DQI of precision on DQO decisions (Table 7-1) is that at least 80 percent of sample results for each measured contaminant are not qualified due to duplicates exceeding the criteria. If this performance is not met, an assessment will be conducted in the CR on the impacts to DQO decisions specific to affected contaminants and CASs.

\subsubsection{Accuracy}

Accuracy is a measure of the closeness of an individual measurement to the true value. It is used to assess the performance of laboratory measurement processes.

Accuracy is determined by analyzing a reference material of known parameter concentration or by reanalyzing a sample to which a material of known concentration or amount of parameter has been added (spiked). Accuracy will be evaluated based on results from three types of spiked samples: MS, LCS, and surrogates (organics). The LCS sample is analyzed with the field samples using the same sample preparation, reagents, and analytical methods employed for the samples. One LCS will be prepared with each batch of samples for analysis by a specific measurement.

The criteria used for the assessment of inorganic chemical accuracy are 75 to 125 percent for MS recoveries and 80 to 120 percent for LCS recoveries. For organic chemical accuracy, MS and LCS laboratory-specific percent recovery criteria developed and generated in-house by the laboratory in accordance with approved laboratory procedures are applied. The criteria used for the assessment of radiochemical accuracy are 80 to 120 percent for LCS and MS recoveries. 
Any values outside the specified criteria do not necessarily result in the qualification of analytical data. It is only one factor in making an overall judgment about the quality of the reported analytical results. Factors beyond laboratory control, such as sample matrix effects, can cause the measured values to be outside the established criteria. Therefore, the entire sampling and analytical process may be evaluated when determining the usability of the affected data.

The performance metric for assessing the DQI of accuracy on DQO decisions (Table 7-1) is that at least 80 percent of the sample results for each measured contaminant are not qualified for accuracy. If this performance is not met, an assessment will be conducted in the CR on the impacts to DQO decisions specific to affected contaminants and CASs.

\subsubsection{Representativeness}

Representativeness is the degree to which sample characteristics accurately and precisely represent characteristics of a population or an environmental condition (EPA, 2002). Representativeness is ensured by carefully developing the CAI sampling strategy during the DQO process such that false negative and false positive decision errors are minimized. Meeting the criteria listed below will ensure that sample results will adequately represent actual site characteristics:

- For Decision I judgmental sampling, having a high degree of confidence that the sample locations selected will identify COCs if present anywhere within the CAS.

- For Decision I probabilistic sampling, having a high degree of confidence that the sample locations selected will represent contamination of the CAS.

- Having a high degree of confidence that analyses conducted will be sufficient to detect any COCs present in the samples.

- For Decision II, having a high degree of confidence that the sample locations selected will identify the extent of COCs.

These are qualitative measures that will be used to assess measurement system performance for representativeness. The assessment of this qualitative criterion will be presented in the CR. 


\subsubsection{Completeness}

Page 88 of 94

Completeness is defined as generating sufficient data of the appropriate quality to satisfy the data needs identified in the DQOs. For judgmental sampling, completeness will be evaluated using both a quantitative measure and a qualitative assessment. The quantitative measurement to be used to evaluate completeness is presented in Table 7-1 and is based on the percentage of measurements made that are judged to be valid. For the judgmental sampling approach, the completeness goal for targeted contaminants and the remaining COPCs is 100 and 80 percent, respectively. If this goal is not achieved, the dataset will be assessed for potential impacts on making DQO decisions. For the probabilistic sampling approach, the completeness goal is a calculated minimum sample size required to produce a valid statistical comparison of the sample mean to the FAL. The methodology for determining the minimum sample size required for probabilistic sampling is described in Appendix C.

The qualitative assessment of completeness is an evaluation of the sufficiency of information available to make DQO decisions. This assessment will be based on meeting the data needs identified in the DQOs and will be presented in the CR. Additional samples will be collected if it is determined that the number of samples does not meet completeness criteria.

\subsubsection{Comparability}

Comparability is a qualitative parameter expressing the confidence with which one dataset can be compared to another (EPA, 2002). The criteria for the evaluation of comparability will be that all sampling, handling, preparation, analysis, reporting, and data validation were performed using approved standard methods and procedures. This will ensure that data from this project can be compared to regulatory action levels that were developed based on data generated using the same or comparable methods and procedures. An evaluation of comparability will be presented in the CR.

\subsubsection{Sensitivity}

Sensitivity is the capability of a method or instrument to discriminate between measurement responses representing different levels of the variable of interest (EPA, 2002). The evaluation criterion for this parameter will be that measurement sensitivity (detection limits) will be less than or equal to the corresponding FALs. If this criterion is not achieved, the affected data will be assessed for usability and potential impacts on meeting site characterization objectives. This assessment will be presented in the CR. 


\subsection{References}

ASTM, see American Society for Testing and Materials.

Aldrich, M.J., Los Alamos National Laboratory. 2004. Ground Surface Stability Study for Selected LANL Underground Nuclear Test Locations. Los Alamos, NM.

American Society for Testing and Materials. 1995 (reapproved 2002). Standard Guide for Risk-Based Corrective Action Applied at Petroleum Release Sites, ASTM E1739 - 95(2002). Philadelphia, PA.

Bordelois, B., Science Application International Corporation. 1998a. Memorandum to R. Jackson (IT Corporation) titled “CAU 357, CAS 07-09-01, Sampling Report,” 13 April. Las Vegas, NV.

Bordelois, B., Science Application International Corporation. 1998b. Memorandum to R. Jackson (IT Corporation) titled “CAU 395, CAS 19-99-06, Sampling Report,” 13 April. Las Vegas, NV.

CFR, see Code of Federal Regulations.

Clesceri, L.S., A.E. Greenberg, and A.D. Eaton, eds. 1998. Standard Methods for the Examination of Water and Wastewater, 20th edition. Published by American Public Health Association, American Water Works Association, and Water Environmental Federation.

Code of Federal Regulations. 2009a. Title 40 CFR, Parts 260-282, "Hazardous Waste Management System: General.” Washington, DC: U.S. Government Printing Office.

Code of Federal Regulations. 2009b. Title 40 CFR, Part 265, Subpart I, "Use and Management of Containers.” Washington, DC: U.S. Government Printing Office.

Code of Federal Regulations. 2009c. Title 40 CFR, Part 761, "Polychlorinated Biphenyls (PCBs) Manufacturing, Processing, Distribution in Commerce, and Use Prohibitions.” Washington, DC: U.S. Government Printing Office.

DOE, see U.S. Department of Energy.

DOE/NV, see U.S. Department of Energy, Nevada Operations Office.

EPA, see U.S. Environmental Protection Agency.

FFACO, see Federal Facility Agreement and Consent Order. 
Federal Facility Agreement and Consent Order. 1996 (as amended March 2010). Agreed to by the State of Nevada; U.S. Department of Energy, Environmental Management; U.S. Department of Defense; and U.S. Department of Energy, Legacy Management.

Gustafson, D., National Security Technologies, LLC, 2010. Personal communication (email) to C. Birney (NNES) regarding boreholes on plug-back candidate list. 9 February. Las Vegas, NV.

Hawkins, W., Los Alamos National Laboratory. 2003. Ground Surface Stability Study for Selected LANL Underground Nuclear Test Locations. Los Alamos, NM.

Hawkins, W., Los Alamos National Laboratory. 2005. Ground Surface Stability Study for Selected LANL Underground Nuclear Test Locations. Los Alamos, NM.

IT, see IT Corporation.

IT Corporation. 2001a. Written communication. Subject: "Preliminary Assessment Investigation Summary for CAU 358 Areas 18, 19, and 20 Cellars/Mud Pits, Nevada Test Site.” Las Vegas, NV.

IT Corporation. 2001b. Written communication. Subject: "Preliminary Assessment Investigation Summary for Corrective Action Unit (CAU) 355, Area 2 Cellars/Mud Pits; Corrective Action Site (CAS) 02-37-08, Cellar \& Mud Pit, Nevada Test Site.” Las Vegas, NV.

IT Corporation. 2001c. Written communication. Subject: "Preliminary Assessment Investigation Summary for Corrective Action Unit (CAU) 355, Area 2 Cellars/Mud Pits; Corrective Action Site (CAS) 02-37-09, Cellar \& Mud Pit, Nevada Test Site.” Las Vegas, NV.

IT Corporation. 2002a. Written communication. Subject: "Preliminary Assessment Investigation Summary for Corrective Action Unit (CAU) 396, Area 20 Spill, Nevada Test Site.” Las Vegas, NV.

IT Corporation. 2002b. Written communication. Subject: "Preliminary Assessment: Site Reference Summary for CAU 539 Waste Sites, Nevada Test Site, Volume 1.” Las Vegas, NV.

IT Corporation. 2002c. Written communication. Subject: "Preliminary Assessment: Site Reference Summary for CAU 540 Spill Sites, Nevada Test Site, Volume 1.” Las Vegas, NV.

Moore, J., Science Applications International Corporation. 1999. Memorandum to M. Todd (SAIC) titled "Background Concentrations for NTS and TTR Soil Samples," 3 February. Las Vegas, NV: IT Corporation.

Murphy, T., Bureau of Federal Facilities. 2004. Letter to R. Bangerter (NNSA/NSO) titled "Review of Industrial Sites Project Document Guidance for Calculating Industrial Sites Project Remediation Goals for Radionuclides in Soil Using the Residual Radiation (RESRAD) Computer Code," 19 November. Las Vegas, NV. 
NAC, see Nevada Administrative Code.

NBMG, see Nevada Bureau of Mines and Geology.

NCRP, see National Council on Radiation Protection and Measurements.

NDEP, see Nevada Division of Environmental Protection.

NNES, see Navarro Nevada Environmental Services, LLC.

NNES GIS, see Navarro Nevada Environmental Services Geographic Information Systems.

NNSA/NSO, see U.S. Department of Energy, National Nuclear Security Administration Nevada Site Office.

NNSA/NV, see U.S. Department of Energy, National Nuclear Security Administration Nevada Operations Office.

National Council on Radiation Protection and Measurements. 1999. Recommended Screening Limits for Contaminated Surface Soil and Review of Factors Relevant to Site-Specific Studies, NCRP Report No. 129. Bethesda, MD.

Navarro Nevada Environmental Services, LLC. 2009a. Statement of Work for Analytical Laboratories, Section C. Las Vegas, NV.

Navarro Nevada Environmental Services, LLC. 2009b. "Underground Test Area Borehole Index: U-20bg - Borehole Index Coordinate Data Sheet - 3641.” Las Vegas, NV.

Navarro Nevada Environmental Services Geographic Information Systems. 2010. ESRI ArcGIS Software.

Nevada Administrative Code. 2008a. NAC 445A.227, "Contamination of Soil: Order by Director for Corrective Action; Factors To Be Considered in Determining Whether Corrective Action Required.” Carson City, NV. As accessed at http://www.leg.state.nv.us/nac on 3 March, 2010.

Nevada Administrative Code. 2008b. NAC 445A.22705, "Contamination of Soil: Evaluation of Site by Owner or Operator; Review of Evaluation by Division.” Carson City, NV. As accessed at http://www.leg.state.nv.us/nac on 3 March, 2010.

Nevada Bureau of Mines and Geology. 1998. Mineral and Energy Resource Assessment of the Nellis Air Force Range, Open-File Report 98-1. Reno, NV.

Nevada Division of Environmental Protection. 1995. Mutual Consent Agreement between the State of Nevada and the U.S. Department of Energy for the Storage of Low-Level Land Disposal Restricted Mixed Waste. Carson City, NV. 
Nevada Division of Environmental Protection. 1997 (as amended in August 2006). Class III Solid Waste Disposal Site for Hydrocarbon Burdened Soils, Area 6 of the NTS, Permit SW 13-097-02, Rev. 7. Carson City, NV.

Nevada Division of Environmental Protection. 2005. Nevada Division of Environmental Protection Permit for a Hazardous Waste Management Facility, Permit Number NEV HW0021. Las Vegas, NV.

PNNL, see Pacific Northwest National Laboratory.

Paar, J.G., and D.R. Porterfield. 1997. Evaluation of Radiochemical Data Usability, ES/ER/MS-5. April. Oak Ridge, TN: U.S. Department of Energy.

Pacific Northwest National Laboratory. 2007. Visual Sample Plan, Version 5.0 User's Guide, PNNL-16939. Richland, WA.

Pawloski, G. A., Lawrence Livermore National Laboratory. 2003. Memorandum to B. Bangeter (NNSA/NSO) regarding status of surface crater collapse for selected LLNL tests on Pahute Mesa and Yucca Flat, 27 January. Livermore, CA.

RSN, see Raytheon Services Nevada.

Raytheon Services Nevada. 1991. Nevada Test Site Drilling and Mining Summary Through December 1990. Prepared for U.S. Department of Energy, Nevada Operations Office.

SNJV, see Stoller-Navarro Joint Venture.

Stoller-Navarro Joint Venture. 2007. Preliminary Assessment: Site Reference Summary for CAU 544 Cellars, Mud Pits, and Oil Spills, Nevada Test Site. Las Vegas, NV.

USGS and DOE, see U.S. Geological Survey and U.S. Department of Energy.

U.S. Department of Energy. 1993. Radiation Protection of the Public and the Environment, DOE Order 5400.5, Change 2. Washington, DC.

U.S. Department of Energy. 1997. The Procedures Manual of the Environmental Measurements Laboratory, HASL-300, 28th edition, Vol. I. February. New York, NY.

U.S. Department of Energy, National Nuclear Security Administration Nevada Operations Office. 2002a. Industrial Sites Quality Assurance Project Plan, Nevada Test Site, Nevada, Rev. 3, DOE/NV--372. Las Vegas, NV.

U.S. Department of Energy, National Nuclear Security Administration Nevada Operations Office. 2002b. Nevada Test Site Orthophoto Site Atlas, DOE/NV/11718--604. Aerial photos acquired Summer 1998. Prepared by Bechtel Nevada. Las Vegas, NV. 
U.S. Department of Energy, National Nuclear Security Administration Nevada Site Office. 2003a. Closure Report for Corrective Action Unit 355: Area 2 Cellars/Mud Pits, Nevada Test Site, Nevada, DOE/NV--934-Rev. 0. November. Las Vegas, NV.

U.S. Department of Energy, National Nuclear Security Administration Nevada Site Office. 2003b. Closure Report for Corrective Action Unit 358: Area 18, 19, 20 Cellars/Mud Pits, Nevada Test Site, Nevada. November. Las Vegas, NV.

U.S. Department of Energy, National Nuclear Security Administration Nevada Site Office. 2004a. Mud Pit Risk-Based Closure Strategy Report, Nevada Test Site, Nevada, DOE/NV--991. Las Vegas, NV.

U.S. Department of Energy, National Nuclear Security Administration Nevada Site Office. 2004b. Closure Report for Corrective Action Unit 358: Areas 18, 19, 20 Cellars/Mud Pits, Nevada Test Site, Nevada, DOE/NV--944. Las Vegas, NV.

U.S. Department of Energy, National Nuclear Security Administration Nevada Site Office. 2005. Streamlined Approach for Environmental Restoration (SAFER) Plan for Corrective Action Units 530, 531, 532, 533, 534, and 535: NTS Mud Pits Nevada Test Site, DOE/NV--1057. Las Vegas, NV.

U.S. Department of Energy, National Nuclear Security Administration Nevada Site Office. 2006a. Streamlined Approach for Environmental Restoration (SAFER) Plan for Corrective Action Unit 177: Mud Pits and Cellars, Nevada Test Site, DOE/NV--1126. Las Vegas, NV.

U.S. Department of Energy, National Nuclear Security Administration Nevada Site Office. 2006b. Closure Report for Corrective Action Units 530, 531, 532, 533, 534, and 535: NTS Mud Pits, Nevada Test Site, Nevada, DOE/NV--1131-Rev. 0. Las Vegas, NV.

U.S. Department of Energy, National Nuclear Security Administration Nevada Site Office. 2006c. Industrial Sites Project Establishment of Final Action Levels, Rev. 0, DOE/NV--1107. Las Vegas, NV.

U.S. Department of Energy, National Nuclear Security Administration Nevada Site Office. 2009. Nevada Test Site Waste Acceptance Criteria, DOE/NV-325-Rev. 7-01. Las Vegas, NV.

U.S. Department of Energy, National Nuclear Security Administration Nevada Site Office. 2010. Nevada Test Site Radiological Control Manual, DOE/NV/25946--801, Rev. 1. Prepared by Radiological Control Managers’ Council. Las Vegas, NV.

U.S. Department of Energy, Nevada Operations Office. 1998. Radiologically Controlled Areas Report, Appendix B, Site Reports and Survey Data, September. Las Vegas, NV.

U.S. Department of Energy, Nevada Operations Office. 1999. RCRA Part B Permit (NEV HW0021) Application for Waste Management Activities at the Nevada Test Site. Las Vegas, NV. 
U.S. Department of Energy, Nevada Operations Office. 2000. United States Nuclear Tests July 1945 Through September 1992, DOE/NV--209-REV 15. Las Vegas, NV.

U.S. Environmental Protection Agency. 1980. Prescribed Procedures for Measurement of Radioactivity in Drinking Water, EPA 600/4-80-032. Cincinnati, OH: Environmental Monitoring and Support Laboratory Office of Research and Development.

U.S. Environmental Protection Agency. 2000. Sampling and Analysis Plan Guidance and Template, R9QA/002.1. As accessed at http://www.epa.gov/region09/qa/projplans.html on 3 March 2010.

U.S. Environmental Protection Agency. 2002. Guidance for Quality Assurance Project Plans, EPA QA/G5, EPA/240/R-02/009. Washington, DC.

U.S. Environmental Protection Agency. 2004. USEPA Contract Laboratory Program National Functional Guidelines for Inorganic Data Review, OSWER 9240.1-45/EPA 540-R-04-004. October. Washington, DC: Office of Superfund Remediation and Technology Innovation.

U.S. Environmental Protection Agency. 2006. Guidance on Systematic Planning Using the Data Quality Objective Process, EPA/240/B-06/001. Washington, D.C.

U.S. Environmental Protection Agency. 2008. SW-846 On-Line, Test Methods for Evaluating Solid Waste, Physical/Chemical Methods. As accessed at http://www.epa.gov/epaoswer/hazwaste/test/main.htm on 3 March 2010.

U.S. Environmental Protection Agency. 2009. Regions 3, 6, and 9, Regional Screening Levels (RSL) for Chemical Contaminants at Superfund Sites. As accessed at http://www.epa.gov/region09/superfund/prg/index.html on 3 March 2010.

U.S. Geological Survey and U.S. Department of Energy. 2009. "USGS/DOE Cooperative Studies in Nevada; Water-Level Wells, Nevada Test Site.” As accessed at http://nevada.usgs.gov/doe_nv/ntsmap.htm on 3 March 2010. 


\section{Appendix A}

\section{Project Organization}




\section{A.1.0 Project Organization}

The NNSA/NSO Federal Sub-Project Director is Mr. Kevin Cabble. He can be contacted at (702) 295-5000. The NNSA/NSO Task Manager is Ms. Tiffany Lantow. She can be contacted at (702) 295-7645.

The identification of the project Health and Safety Officer and the Quality Assurance Officer can be found in the appropriate plan. However, personnel are subject to change, and it is suggested that the NNSA/NSO Federal Sub-Project Director be contacted for further information. 


\section{Appendix B}

\section{Data Quality Objective Process}




\section{B.1.0 Introduction}

The DQO process described in this appendix is a seven-step strategic systematic planning method used to plan data collection activities and define performance criteria for the CAU 544, Cellars, Mud Pits, and Oil Spills, field investigation. The DQOs are designed to ensure that the data collected will provide sufficient and reliable information to determine the appropriate corrective actions, to verify the adequacy of existing information, to provide sufficient data to implement the corrective actions, and to verify that closure was achieved.

The CAU 544 field investigation will be based on the DQOs presented in this appendix as developed by representatives of NDEP and NNSA/NSO. The seven steps of the DQO process presented in Sections B.2.0 through B.8.0 were developed in accordance with EPA Guidance on Systematic Planning Using the Data Quality Objectives Process (EPA, 2006b) and the CAS-specific information presented in Section B.2.0.

The DQO process presents a combination of probabilistic and judgmental sampling approaches. In general, the procedures used in the DQO process provide:

- A method to establish performance or acceptance criteria, which serve as the basis for designing a plan for collecting data of sufficient quality and quantity to support the goals of a study.

- Criteria that will be used to establish the final data collection design such as:

- The nature of the problem that has initiated the study and a conceptual model of the environmental hazard to be investigated.

- The decisions or estimates that need to be made and the order of priority for resolving them.

- $\quad$ The type of data needed.

- An analytic approach or decision rule that defines the logic for how the data will be used to draw conclusions from the study findings.

- Acceptable quantitative criteria on the quality and quantity of the data to be collected, relative to the ultimate use of the data. 
- A data collection design that will generate data meeting the quantitative and qualitative criteria specified. A data collection design specifies the type, number, location, and physical quantity of samples and data, as well as the QA and QC activities that will ensure that sampling design and measurement errors are managed sufficiently to meet the performance or acceptance criteria specified in the DQOs.

- Acceptable process knowledge and historical information to support the closure of the mud pits that have not been radiologically impacted and meet the criteria specified in the mud pit RBCSR (NNSA/NSO, 2004). 


\section{B.2.0 Step 1 - State the Problem}

Step 1 of the DQO process defines the problem that requires study, identifies the planning team, and develops a conceptual model of the environmental hazard to be investigated.

The problem statement for the CAU 544 CASs is: "Existing information on the nature and extent of contamination is incomplete to evaluate and confirm closure of all the CASs in CAU 544.”

\section{B.2.1 Planning Team Members}

The DQO planning team consists of representatives from NDEP and NNSA/NSO. The planning team met on April 27, 2010, for the DQO meeting.

\section{B.2.2 Conceptual Site Model}

The CSM is used to organize and communicate information about site characteristics. It reflects the best interpretation of available information at a point in time. The CSM is a primary vehicle for communicating assumptions about release mechanisms, potential migration pathways, or specific constraints. It provides a summary of how and where contaminants are expected to move and what impacts such movement may have. It is the basis for assessing how contaminants could reach receptors both in the present and future. The CSM describes the most probable scenario for current conditions at each site and defines the assumptions that are the basis for identifying appropriate sampling strategy and data collection methods. An accurate CSM is important as it serves as the basis for all subsequent inputs and decisions throughout the DQO process.

The CSM was developed for CAU 544 using information from the physical setting, potential contaminant sources, release information, historical background information, knowledge from similar sites, and physical and chemical properties of the potentially affected media and COPCs.

The CSM consists of:

- Potential contaminant releases, including media subsequently affected. 
- Release mechanisms (the conditions associated with the release).

- Potential contaminant source characteristics, including contaminants suspected to be present and contaminant-specific properties.

- Site characteristics, including physical, topographical, and meteorological information.

- Migration pathways and transport mechanisms that describe the potential for migration and where the contamination may be transported.

- The locations of points of exposure where individuals or populations may come in contact with a COC associated with a CAS.

- Routes of exposure where contaminants may enter the receptor.

If additional elements are identified during the CAI that are outside the scope of the CSM, the situation will be reviewed and a recommendation will be made as to how to proceed. In such cases, NDEP and NNSA/NSO will be notified and given the opportunity to comment on, and concur with, the recommendation.

The applicability of the CSM to mud pits and cellars, and oil/waste spills is summarized in Table B.2-1 and discussed below. Table B.2-1 provides information on CSM elements that will be used throughout the remaining steps of the DQO process. Figure B.2-1 represents site conditions applicable to the CSM.

\section{B.2.2.1 Contaminant Release}

Releases of contamination to the environment at the oil/waste spills are to the soils directly below or adjacent to the spill location. Any contaminants migrating from spills, regardless of physical or chemical characteristics, are expected to exist at interfaces, and in the soil adjacent to disposal features in lateral and vertical directions.

The radiologically impacted mud pits and cellars in the CASs of CAU 544 are suspected to contain contaminated media generated by activities associated with nuclear testing. The current radiological postings serve as the indication for identifying the radiologically impacted CASs or CAS components. 
Table B.2-1

Conceptual Site Model Description of Elements for Each CAS Feature in CAU 544 (Page 1 of 3 )

\begin{tabular}{|c|c|}
\hline CAU Description & Cellars, Mud Pits, and Oil Spills \\
\hline Site Status & Sites are inactive and/or abandoned \\
\hline Exposure Scenario & Occasional Use \\
\hline $\begin{array}{l}\text { Sources of Potential } \\
\text { Soil Contamination }\end{array}$ & $\begin{array}{l}\text { Mud Pit: Primary source for radiological contamination is a release of drilling mud } \\
\text { associated with post-test drilling activities subsequent to underground nuclear testing. } \\
\text { Other contributors to contamination may include a release of radiological effluents from } \\
\text { an underground test or fallout from an atmospheric test. Organic or inorganic } \\
\text { contamination is not expected at mud pits. Radioactive contamination may be expected at } \\
\text { radiologically posted mud pits. All non-posted mud pits are not expected to contain } \\
\text { radiological contamination. } \\
\text { Cellar: Primary source for chemical contamination is a direct release of drill rig fluids } \\
\text { (hydraulic fluid, oils, greases, diesel fuel). Other contributors may include the } \\
\text { decontamination of drilling equipment over the cellar cavity or discarding of potentially } \\
\text { hazardous drilling materials. The primary source for radiological contamination is an } \\
\text { accidental release of contaminated drilling mud via spills, or leaks from drilling hoses or } \\
\text { tubing. Other contributors may include a release of radiological effluents from an } \\
\text { underground test or fallout from an atmospheric test. } \\
\text { Oil/Waste Spill: Primary source for chemical contamination is a direct release of oil/waste } \\
\text { to environmental media. }\end{array}$ \\
\hline $\begin{array}{l}\text { Location of } \\
\text { Contamination/ } \\
\text { Release Point }\end{array}$ & $\begin{array}{l}\text { Mud Pit: Residual drilling mud contained within the boundaries of the radiologically posted } \\
\text { mud pit walls/berms. If a backfilled mud pit, the mud would be located directly beneath the } \\
\text { cover material (typically } 4-5 \mathrm{ft} \text { bgs). } \\
\text { Cellar: Surface and shallow subsurface soils at the base of the cellar } \\
\text { (typically } 10-12 \mathrm{ft} \text { bgs) contained within the boundaries of the corrugated metal casing } \\
\text { (typically } 10 \mathrm{ft} \text { in diameter). } \\
\text { Oil/Waste Spill: Surface and shallow subsurface soils. }\end{array}$ \\
\hline Amount Released & Unknown \\
\hline Affected Media & $\begin{array}{l}\text { Mud Pit: Residual mud contained in the boundaries of the radiologically posted mud pits. } \\
\text { Underlying soils are not expected to have been affected due to properties of drilling mud. } \\
\text { Cellar: Surface and shallow subsurface soil at the base of the cellar. } \\
\text { Oil/Waste Spill: Surface and shallow subsurface soil underlying the spill. }\end{array}$ \\
\hline $\begin{array}{c}\text { Potential } \\
\text { Contaminants }\end{array}$ & $\begin{array}{l}\text { Mud Pit: Limited to radionuclides (gamma emitters, isotopic U, isotopic Pu, and Sr-90) } \\
\text { only at radiologically posted mud pits. } \\
\text { Cellar: Contaminants include VOCs, SVOCs, PCBs, metals, and radionuclides } \\
\text { (gamma emitters, isotopic U, isotopic Pu, and Sr-90). } \\
\text { Oil/Waste Spill: Contaminants include VOCs, SVOCs, PCBs, and metals. }\end{array}$ \\
\hline
\end{tabular}


Table B.2-1

Conceptual Site Model Description of Elements for Each CAS Feature in CAU 544 (Page 2 of 3)

\begin{tabular}{|c|c|}
\hline CAU Description & Cellars, Mud Pits, and Oil Spills \\
\hline $\begin{array}{c}\text { Transport } \\
\text { Mechanisms }\end{array}$ & $\begin{array}{l}\text { - Infiltration and percolation of precipitation through affected media serves as the major } \\
\text { driving force for contamination to migrate vertically. Due to the low precipitation and } \\
\text { high evaporation rates of the arid environment, percolation of infiltrated precipitation is } \\
\text { limited and is not considered a significant mechanism regarding the transport of } \\
\text { contaminants to groundwater. } \\
\text { - Lateral transportation of some contaminants may occur as a result of surface water } \\
\text { runoff or overflow of surface water accumulated in the mud pits and cellars. } \\
\text { - Evaporation of volatile components may release contaminants to the air. } \\
\text { - Wind blowing over open mud pits, cellars, and spills may resuspend contaminated } \\
\text { surface soil particles. }\end{array}$ \\
\hline Migration Pathways & $\begin{array}{l}\text { - Vertical migration of contaminants through the affected media is considered } \\
\text { insignificant due to the arid climate of the NTS. Cover material for backfilled mud pits } \\
\text { and cellars could also significantly prevent percolation of precipitation as a driving } \\
\text { force. Also, vertical migration of contaminants through drilling mud into the underlying } \\
\text { soil is not expected due to the physical properties of the drilling mud. } \\
\text { - Without a breach in the berms of a mud pit, or a large rainfall event that would cause } \\
\text { overtopping of the mud pit or cellar, potential lateral migration or overland flow is } \\
\text { considered to be limited. } \\
\text { - Evaporation as a migration pathway would only be applicable to open cellars and } \\
\text { oil/waste spills; however, this pathway is considered insignificant because the volatile } \\
\text { components of TPH are expected to have weathered away. Contaminants of potential } \\
\text { concern for mud pits do not include vapor phases. Previous sampling has eliminated } \\
\text { VOCs and SVOCs as COPCs for mud pits. } \\
\text { - Wind transport of resuspended particles is considered an insignificant pathway } \\
\text { because the affected media in mud pits and cellars is protected by berms and } \\
10-12 \mathrm{ft} \text { bgs metal casing, respectively. A release of contaminants to the air is not } \\
\text { considered a complete migration pathway for mud pits and cellars that have been } \\
\text { backfilled because the affected media is covered. Wind transport of resuspended } \\
\text { particles could be a potential pathway for the oil/waste spills. }\end{array}$ \\
\hline $\begin{array}{l}\text { Lateral and Vertical } \\
\text { Extent of } \\
\text { Contamination }\end{array}$ & $\begin{array}{l}\text { Mud Pit: The lateral extent of contamination in mud pits is expected to be limited to the } \\
\text { walls/berms of the mud pit unless there is a noticeable breach that would allow for } \\
\text { overland transport. The vertical extent of potential contamination at a mud pit is expected } \\
\text { to be bound within the residual mud and would not be expected to migrate vertically } \\
\text { downward into the underlying soil. } \\
\text { Cellar: The lateral extent of contamination in cellars is expected to be limited by the metal } \\
\text { casing that surrounds the cellar cavity. The lateral extent of contamination of the oil/waste } \\
\text { spills is expected to be contiguous to the release points. The vertical extent of potential } \\
\text { contamination in the affected media of a cellar is not expected to infiltrate more than a few } \\
\text { inches below the base of cellar, if at all. } \\
\text { Oil/Waste Spill: The vertical extent of potential contamination in the affected media at the } \\
\text { oil/waste spills is dependent upon the soil type immediately below the spill. Lateral and } \\
\text { vertical extent of COC contamination is assumed to be within the spatial boundaries. } \\
\text { Groundwater contamination is not expected because depth to groundwater varies } \\
\text { between } 725 \text { to } 3,100 \mathrm{ft} \text { bgs and averages approximately } 800 \mathrm{ft} \text { bgs } \\
\text { (USGS and DOE, 2009). }\end{array}$ \\
\hline
\end{tabular}


Table B.2-1

Conceptual Site Model Description of Elements for Each CAS Feature in CAU 544 (Page 3 of 3 )

\begin{tabular}{|c|l||}
\hline CAU Description & \multicolumn{1}{|c|}{ Cellars, Mud Pits, and Oil Spills } \\
\hline \hline Exposure Pathways & $\begin{array}{l}\text { The potential for contamination exposure is limited to industrial and construction } \\
\text { workers, and military personnel conducting training. These human receptors may be } \\
\text { exposed to COPCs through oral ingestion, inhalation, or dermal contact (absorption) of } \\
\text { soil and/or debris due to inadvertent disturbance of these materials, or irradiation by } \\
\text { radioactive materials. }\end{array}$ \\
\hline
\end{tabular}

There have been no inorganic or organic COPCs identified for NTS mud pits based on the conclusions of the RBCSR (NNSA/NSO, 2004) and the available documentation from the investigation of CAUs 530-535, Mud Pits (NNSA/NSO, 2006a). Results of the RBCSR have eliminated VOCs, SVOCs, PCBs, and metals as COPCs from NTS mud pits based on the conclusion that there is no analytical or process knowledge to suggest these constituents are present at significant concentrations in residual mud. Although TPH was detected in about 22 percent of the mud pits studied, the risk assessment concluded that TPH would not pose an unacceptable risk to human health or the environment. The CAUs 530-535 investigation verified that concentrations of TPH-DRO typically found in mud pits do not pose an unacceptable risk to human health or the environment, and therefore, it is eliminated as a COPC for CAU 544 mud pits.

For mud pits that are located in areas or craters that have not been impacted by radiological releases, no COPCs are identified. The RBCSR (NNSA/NSO, 2004) stated that based on process knowledge and previous sampling, these mud pits contained no COCs. The SAFER effort for CAUs 530-535 (NNSA/NSO, 2005) confirmed that there are no COCs present in the mud pits not impacted by radiological releases. It further recommended that if additional mud pits are identified that meet the established criteria, they should be closed and moved to FFACO Appendix IV without further investigation. The criteria are detailed in these reports, but in summary, include the following:

- The CAS is a single mud pit or a system of mud pits.

- The mud pit CAS is located in an area that is not radiologically posted (e.g., contaminated area, RMA, URMA).

- There are no biasing factors such as hydrocarbon staining or hazardous debris (e.g., lead bricks). 


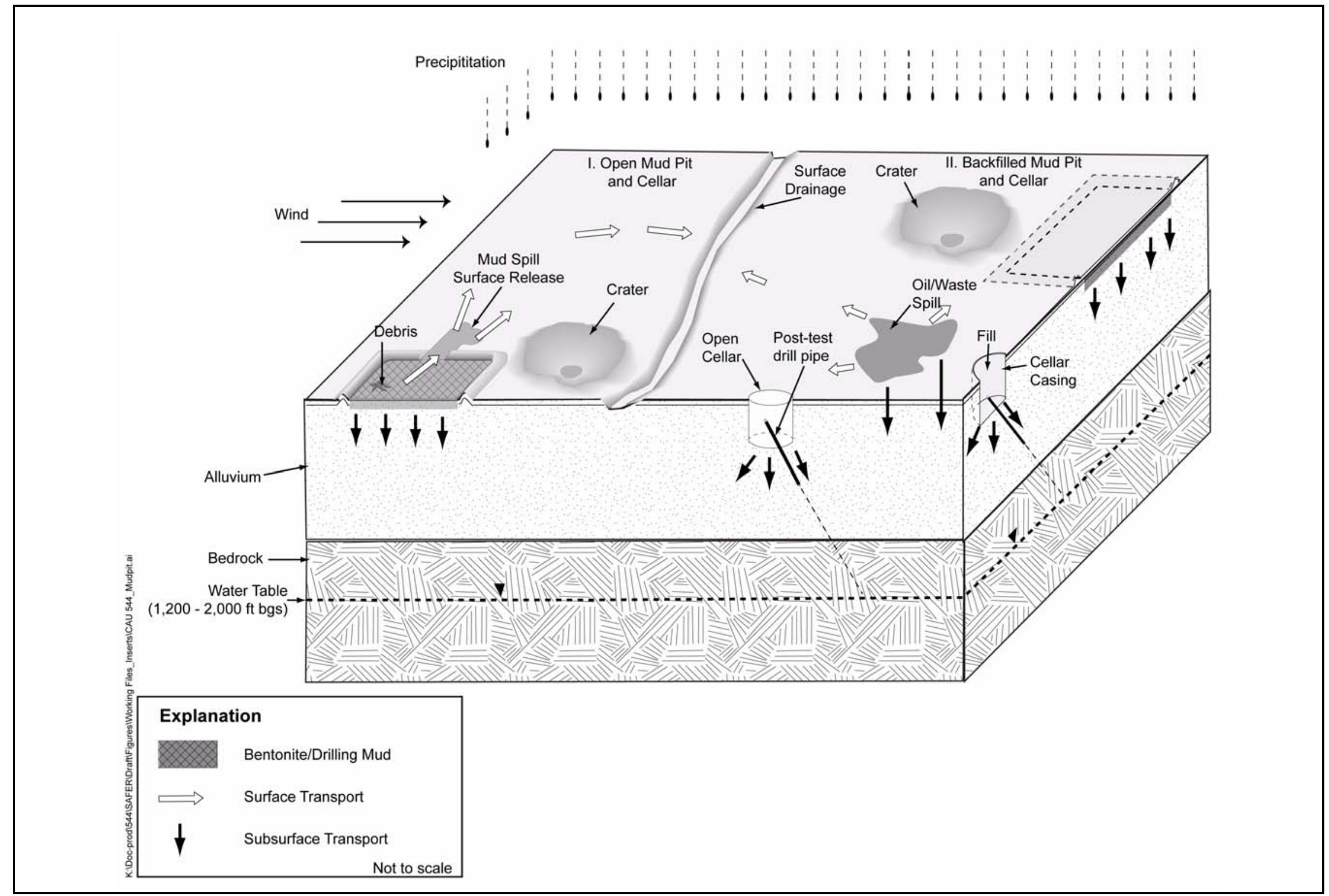

Figure B.2-1

Conceptual Site Model for CAU 544 CASs 
Based on the CAUs 530-535 approach, which has been reviewed and accepted by NDEP, all mud pits within CAU 544 that are single or systems of mud pits not located in radiologically posted area and have no visible biasing factors will be closed under the NFA alternative and promoted from Appendix III to Appendix IV of the FFACO without further sampling.

The only mud pits that would potentially be sampled would be any mud pit CAS within a radiologically posted area that can be accessed safely. This means that if a mud pit is in a crater and there has not been any study done on the crater to demonstrate its stability, an acceptable stability study must be completed and access to the crater authorized before any sampling activity may begin. If the stability study cannot be accomplished or results in a determination that the crater is unstable and thus shall not be entered, the mud pit will be closed with a use restriction and no sampling will be conducted.

Because complete information regarding activities performed at the CAU 544 cellars is not available, chemical constituents will be included as COPCs in addition to radionuclides to fully characterize cellars and reduce uncertainty.

The process associated with potential contamination at a mud pit is different from the process that may have contributed to contamination at a cellar or an oil/waste spill. Therefore, the following sections will address the release of contaminants associated with each feature separately.

\section{B.2.2.1 Mud Pits}

The primary source of potential radiological contamination is the release of drilling mud that may have been in contact with radioactive rock and circulated from the borehole to the mud pit during post-test drilling. The locations for a release of drilling mud are at the base of the excavated mud pit or at drilling mud spills adjacent to the pits. The media affected by a release is typically the surface and shallow subsurface soil; however, due to the binding properties of bentonite, contamination is expected to be bound within the mud with no migration to the native soil adjacent to the floor and walls of the mud pits. Contamination, if any, is expected to be evenly dispersed and present at relatively uniform concentrations because the mud was homogenized as it was circulated. This suggests that surface samples of the residual mud would be representative of the mud throughout the 
depth of the mud pit. Contamination unrelated to the mud pit process may be localized beneath potentially hazardous discarded drilling materials, if present.

\section{B.2.2.1.2 Cellars}

A release of radiological or chemical contaminants to media within a cellar is not expected based on cellar processes; however, contamination, if any, can be attributed to accidental spills and leaks, or materials discarded during drilling activities.

The primary source of a release of radionuclides is suspected to be radiologically contaminated drilling mud that either spilled or leaked into the cellar cavity as a result of careless activities or a failure of the circulation system. Typically, a release of drilling mud to the cellar would not occur because the drilling mud was recirculated from the borehole to the mud pit through a closed system. Although unlikely, another potential contributor to radiological contamination is a release of radiological effluents from underground tests through a vent or fissure, or fallout from an atmospheric test. The primary source of a chemical contaminant release is suspected to be drill rig fluids, such as hydraulic fluid, oils, greases, and potentially diesel fuel, that were directly introduced to the cellar cavity through either spills or leaks, decontamination of drilling equipment over the cellar cavity, or discarded drilling materials. The organic components of these materials would show up in the analyses as VOCs, SVOCs, PCBs, and TPH. If TPH is detected, the source may be either from drilling fluid known to contain diesel fuel as an additive (DOE/NV, 2001; NNSA/NSO, 2004), or from fluids associated with the drill rig as described above.

A release of either radiological or chemical contamination is expected to be located at the base of the cellar (typically 10 to $12 \mathrm{ft}$ bgs) and contained within the boundaries of the corrugated metal casing (typically $10 \mathrm{ft}$ in diameter). The affected media is expected to be the surface and shallow subsurface soil at the cellar bottom. Soil outside the cellar casing is not expected to have been impacted because the casing acts as a barrier to contaminant migration. In the event of a release immediately adjacent to the cellar, the concrete foundation that surrounds the cellar casing would provide a barrier to contaminants migrating into the underlying soil. Contamination, if present, is expected to be 
contiguous to the respective release locations described for cellars and is expected to decrease with horizontal and vertical distance from the source.

\section{B.2.2.2 Potential Contaminants}

Based on the results of the RBCSR and the sampling results from CAUs 530-535, single mud pits or two-mud-pit systems that are not within radiologically posted areas and that have no visible biasing factors are not considered contaminated, and therefore, will not be sampled during this effort. The mud pit sampling will be limited to the mud pits that are within radiologically posted areas (CASs 02-37-09 and 09-09-46). The COPCs were identified during the planning process through the review of site history, process knowledge, personal interviews, past investigation efforts (where available), and inferred activities associated with the CASs. Because complete information regarding activities performed at the CAU 544 cellars is not available, contaminants detected at similar NTS sites were included in the list of contaminants to reduce uncertainty. The list of COPCs is intended to encompass all of the contaminants that could potentially be present at each cellar CAS. The COPCs applicable to both Decision I and Decision II environmental samples from each of the CASs of CAU 544 are defined as the constituents reported from the analytical methods stipulated in Table B.2-2.

During the review of site history documentation, process knowledge information, personal interviews, past investigation efforts (where available), and inferred activities associated with the CASs, some of the COPCs were identified as targeted contaminants at specific CASs. Targeted contaminants are those COPCs for which evidence in the available site and process information suggests that they may be reasonably suspected to be present at a given CAS. The targeted contaminants are required to meet more stringent completeness criteria than other COPCs, thus providing greater protection against a decision error (see Section B.7.1). Targeted contaminants for each CAU 544 feature are identified in Table B.2-3. 
Table B.2-2

Analytical Program ${ }^{\mathrm{a}}$

\begin{tabular}{|c|c|c|c|}
\hline Analyses $^{b}$ & Mud Pit & Cellar & Oil/Waste Spill \\
\hline \multicolumn{4}{|c|}{ Organic COPCs } \\
\hline TPH-DRO ${ }^{\mathrm{C}}$ & -- & $x$ & $x$ \\
\hline PCBs & -- & $x$ & $x$ \\
\hline SVOCs $^{b}$ & -- & $x$ & $x$ \\
\hline VOCs $^{b}$ & -- & $x$ & $x$ \\
\hline \multicolumn{4}{|c|}{ Inorganic COPCs } \\
\hline Total RCRA Metals ${ }^{b}$ & -- & $x$ & $x$ \\
\hline \multicolumn{4}{|c|}{ Radionuclide COPCs } \\
\hline Gamma Spectroscopy $^{d}$ & $x$ & $x$ & $x$ \\
\hline Isotopic $U^{d}$ & $x$ & $x$ & -- \\
\hline Isotopic $\mathrm{Pu}^{\mathrm{d}}$ & $x$ & $x$ & -- \\
\hline $\operatorname{Sr}-90^{d}$ & $x$ & $x$ & -- \\
\hline
\end{tabular}

${ }^{\text {aT }}$ The COPCs are the analytes reported from the analytical methods listed.

${ }^{b}$ May also include TCLP analytes if sample is collected for waste management purposes.

${ }^{\mathrm{C}} \mathrm{TPH}-\mathrm{DRO}$ analyses are for waste management purposes only.

${ }^{\mathrm{d}}$ Results of gamma analysis will be used to determine whether further isotopic analysis is warranted.

$X=$ Required analytical method

$--=$ Analyses will not be performed at this feature

Table B.2-3

Targeted Contaminants for CAU 544

\begin{tabular}{|c|c|c|}
\hline Feature & $\begin{array}{c}\text { Chemical } \\
\text { Targeted Contaminants }\end{array}$ & $\begin{array}{c}\text { Radiological } \\
\text { Targeted Contaminants }\end{array}$ \\
\hline \hline Mud Pit ${ }^{\mathrm{a}}$ & None & Gamma emitters, Sr-90, Isotopic U, Isotopic Pu \\
\hline Cellar & VOCs, SVOCs & None \\
\hline Oil/Waste Spill & VOCs, SVOCs & None \\
\hline
\end{tabular}

${ }^{a}$ Only mud pits in radiologically impacted areas will have targeted radiological contaminants. 


\section{B.2.2.3 Contaminant Characteristics}

Contaminant characteristics include, but are not limited to, solubility, density, and adsorption potential. In general, contaminants with large particle size, low solubility, high affinity for media, and/or high density can be expected to be found relatively close to release points. Contaminants with small particle size, high solubility, low affinity for media, and/or low density are found further from release points or in low areas where evaporation of ponding will concentrate dissolved contaminants.

\section{B.2.2.4 Site Characteristics}

Site characteristics are defined by the interaction of physical, topographical, and meteorological attributes and properties.

Physical properties include permeability, porosity, hydraulic conductivity, degree of saturation, sorting, chemical composition, and organic content. The mud pit CASs will have low permeability, porosity, hydraulic conductivity, and organic content due to the presence of bentonite in the drilling fluid. Additional information regarding the physical properties is not necessary for this investigation because contaminant fate and transport modeling has been completed previously (Appendix A, NNSA/NSO, 2004).

Topographical and meteorological properties and attributes include slope stability, precipitation frequency and amounts, runoff pathways, drainage channels and ephemeral streams, and evapotranspiration potential. This information is used to quantify the amount of infiltration expected at the mud pits. While the amount of infiltration generated at any specific mud pit is unknown, it is expected to be minimal because of the physical properties of bentonite as well as the low precipitation and high evapotranspiration rates common at the NTS.

The annual potential evapotranspiration at the Area 3 Radiological Waste Management Site has been estimated at 62.6 in. (Shott et al., 1997), but the annual precipitation for southern Nevada is between 3.5 and 6 in. (Winograd and Thordarson, 1975).

Groundwater contamination is not considered a likely scenario at any CAS based on the depth to groundwater in Areas 2, 7, 9, 10, 12, 19, and 20. Data from nearest wells indicate that groundwater 
levels may range from 725 to 1,725 ft bgs for the CASs in Areas 2, 9, and 10; average approximately 1,915 ft bgs for the Area 7 CAS; range from 1,520 to 3,100 ft bgs for the Area 12 CAS; average approximately 2,240 ft bgs for the Area 19 CASs; and range from 860 to 2,100 ft bgs for the Area 20 CASs (USGS and DOE, 2009). Surface migration is not expected to be significant because the engineered structure of a mud pit and cellar would limit surface migration to within the physical barriers (i.e, mud pit berms and cellar casing).

\section{B.2.2.5 Migration Pathways and Transport Mechanisms}

An important element of the CSM is the expected fate and transport of contaminants (i.e., how contaminants migrate through media and where they can be expected in the environment). Fate and transport of contaminants are presented in the CSM as the migration pathways and transport mechanism that could potentially move the contaminants vertically and laterally throughout the various media. The pathways include air, surface water, and groundwater, and are the routes through which possible contamination could migrate from the site(s) to locations where a receptor might receive an exposure. Fate and transport are influenced by physical and chemical characteristics of the contaminants and media described in Sections B.2.2.3 and B.2.2.4. For the mud pits and cellars, given the characteristics of both the contaminants and the bentonite drilling mud, contaminant migration is expected to be limited.

Infiltration and percolation of precipitation serves as a driving force for the downward vertical migration of contaminants through the mud or underlying soil in the mud pits and cellars, and oil/waste spills. Based on the high evaporation and low precipitation typical of the Mojave Desert, percolation of infiltrated precipitation at the NTS does not provide a significant mechanism for vertical migration of contaminants to groundwater (DOE/NV, 1992; NNSA/NSO, 2004). Cover material, depending on its thickness, for backfilled mud pits and cellars could significantly diminish infiltration and percolation of precipitation as a driving force for vertical migration of contaminants in the affected media. Also, if present, the concrete floor of a cellar would limit infiltration.

Lateral migration of contaminants through impacted media is expected to be limited to within the physical boundaries of the mud pits and cellars, identified as the walls/berms and metal casing, 
respectively. Lateral migration may occur as a result of overland flow or erosion and is dependent on the integrity of the mud pit berms and the depth to the base of the excavated cellar. Without a breach in the berm or a large rainfall event that would cause overtopping of the berm, lateral migration through media contained in or surrounding mud pits is expected to be insignificant. Similarly, without a large rainfall event that would cause the cellar cavity to be filled with water and overflow, lateral migration through media contained in or surrounding cellars is not expected. Lateral migration of contaminants through the soil from beneath the cellar casing (i.e., 10 to $12 \mathrm{ft} \mathrm{bgs)} \mathrm{is} \mathrm{possible;}$ however, vertical migration would dominate due to infiltration of precipitation through the soil. Also, there applicable, the process of backfilling mud pits and cellars following the completion of drilling activities, or plug-back activities, would further limit the potential of lateral migration due to lack of a driving force. Lateral migration of contaminants at the oil/waste spills is dependent upon the soil type underlying the spill, and the contamination is expected to be found relatively close to the release point.

Releases to the air may result from resuspension of contaminated surface soil particles with wind movement, or evaporation of the volatile components of TPH in regard to the cellars and oil spills. Wind could potentially suspend surface soil particles and carry them beyond the boundaries of the mud pits, cellars, and spills. However, the mud pits were typically constructed by excavating native soils and creating a protective berm that surrounds the mud pits and reduces the potential for wind to disturb the mud pit surface. Similarly, the soil at the base of open cellars is protected by the metal casing located approximately 10 to $12 \mathrm{ft}$ bgs, thereby reducing the potential for wind disturbance. In regard to the open cellars and spills, given the fact that they have been weathered for many years, it is highly unlikely that evaporation of TPH components is a significant migration pathway. A release of contaminants to the air is not considered an active transport mechanism for mud pits and cellars that have been backfilled because the overlying fill would prevent the resuspension of impacted media. Overall, airborne migration of contaminants is considered a minor transport mechanism for CAU 544. 


\section{B.2.2.6 Exposure Scenarios}

Human receptors may be exposed to COPCs through oral ingestion, inhalation, or dermal contact (absorption) of drilling mud, soil, or debris due to inadvertent disturbance of these materials, or irradiation by radioactive materials. The land-use and exposure scenarios for the CAU 544 CASs are listed in Table B.2-4. These are based on NTS current and future land use (DOE/NV, 1998). All the CAU 544 CASs are at remote locations without any site improvements and where no regular work is performed. There is still the possibility, however, that site workers could occupy these locations on an occasional and temporary basis such as a military exercise. Therefore, these sites are classified as occasional work areas.

Table B.2-4

\section{Land Use and Exposure Scenarios}

\begin{tabular}{|c|c|c|}
\hline CAS & Record of Decision Land Use Zone & Exposure Scenario \\
\hline $\begin{array}{l}02-37-08 \\
02-37-09 \\
12-09-03\end{array}$ & $\begin{array}{l}\text { Nuclear and High Explosives Test } \\
\text { This area is designated within the Nuclear Test Zone } \\
\text { for additional underground nuclear weapons tests and } \\
\text { outdoor high-explosive tests. This zone includes } \\
\text { compatible defense and nondefense research, } \\
\text { development, and testing activities. }\end{array}$ & $\begin{array}{l}\text { Occasional Use Area } \\
\text { Worker will be exposed to the site occasionally } \\
\text { (up to } 80 \text { hours per year for } 5 \text { years). Site } \\
\text { structures are not present for shelter and } \\
\text { comfort of the worker. }\end{array}$ \\
\hline $\begin{array}{l}07-09-01 \\
09-09-46 \\
10-09-01 \\
19-09-01 \\
19-09-03 \\
19-09-04 \\
19-25-01 \\
19-99-06 \\
20-09-01 \\
20-09-02 \\
20-09-03 \\
20-09-04 \\
20-09-06 \\
20-09-07 \\
20-09-10 \\
20-25-04 \\
20-25-05\end{array}$ & $\begin{array}{l}\text { Nuclear Test } \\
\text { This area is reserved for dynamic experiments, } \\
\text { hydrodynamic tests, and underground nuclear } \\
\text { weapons and weapons effects tests. This zone } \\
\text { includes compatible defense and nondefense } \\
\text { research, development, and testing activities. }\end{array}$ & $\begin{array}{l}\text { Occasional Use Area } \\
\text { Worker will be exposed to the site occasionally } \\
\text { (up to } 80 \text { hours per year for } 5 \text { years). Site } \\
\text { structures are not present for shelter and } \\
\text { comfort of the worker. }\end{array}$ \\
\hline
\end{tabular}




\section{B.3.0 Step 2 - Identify the Goal of the Study}

Step 2 of the DQO process states how environmental data will be used in meeting objectives and solving the problem, identifies study questions or decision statement(s), and considers alternative outcomes or actions that can occur upon answering the question(s). Figure B.3-1 depicts the sequential flow of questions, answers, and action alternatives required to fulfill the objectives of the SAFER process.

\section{B.3.1 Decision Statements}

The Decision I statement is: “Is any COC present in environmental media within the CAS?” For judgmental sampling design, any analytical result for a COPC above the FAL will result in that COPC being designated as a COC. For probability (random) sampling design, any COPC that has a 95 percent UCL of the average concentration above the FAL will result in that COPC being designated as a COC. A COC may also be defined as a contaminant that, in combination with other like contaminants, is determined to jointly pose an unacceptable risk based on a multiple contaminant analysis (NNSA/NSO, 2006b). If a COC is detected, then Decision II must be resolved.

The Decision II statement is: "If a COC is present, is sufficient information available to meet the closure objectives?” Sufficient information is defined to include:

- Identifying the volume of media containing any COC bounded by analytical sample results in lateral and vertical directions.

- The information needed to characterize remediation wastes and IDW for disposal.

- The information needed to evaluate the feasibility of potential closure options.

The presence of a COC would require a corrective action. A corrective action may also be necessary if there is a potential for wastes that are present at a site to impose COCs into site environmental media if the wastes were to be released. To evaluate the potential for site wastes to result in the introduction of a COC to the surrounding environmental media, the following conservative assumptions were made: 


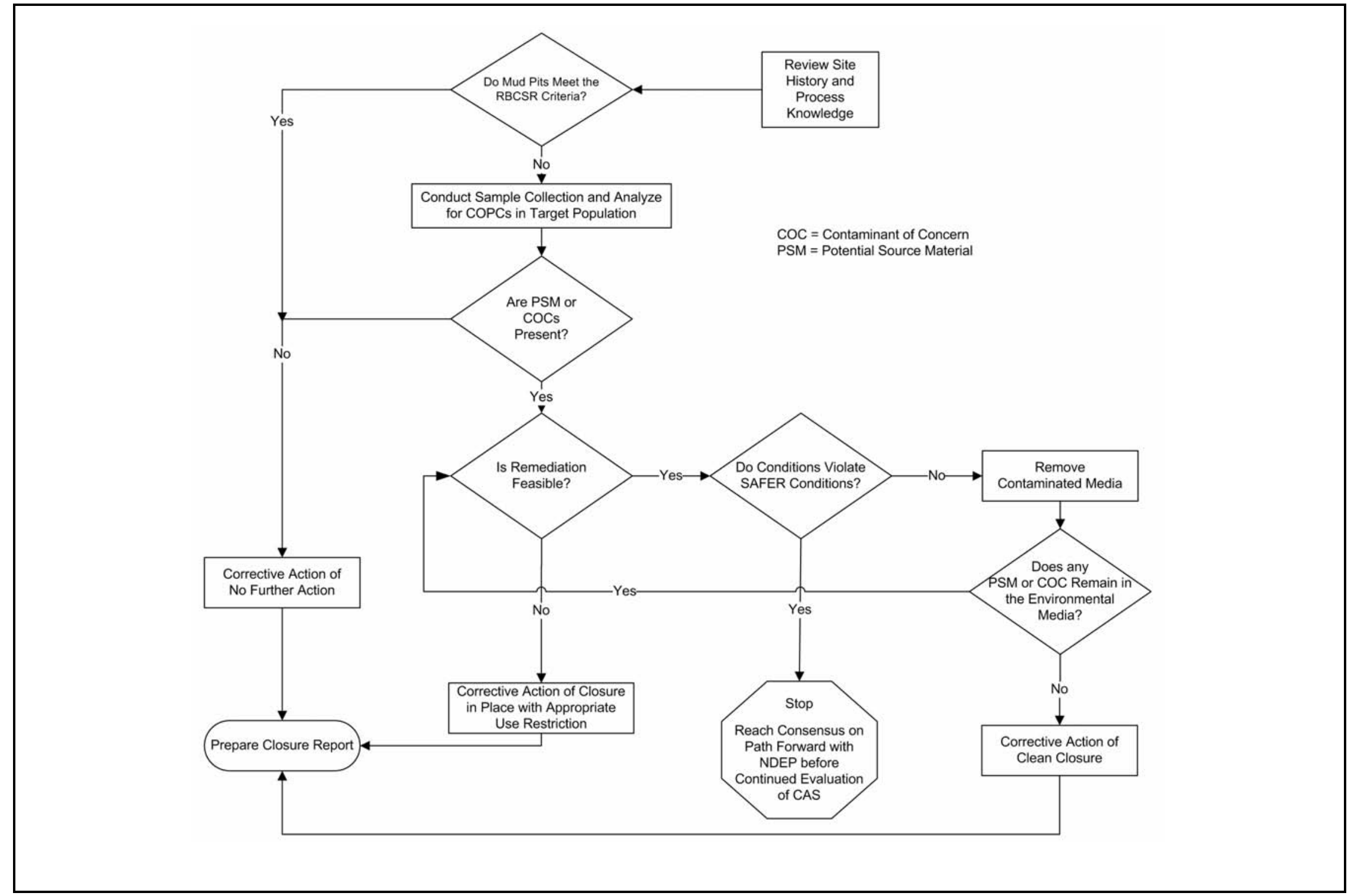

Figure B.3-1

SAFER Closure Decision Process for CAU 544 CASs 
- Any containment of the wastes would fail at some point and the wastes would be released to the surrounding media.

- The resulting concentration of contaminants in the surrounding media would be equal to the concentration of contaminants in the waste.

- For non-liquid wastes, the concentration of any chemical contaminant in soil (following degradation of the waste and release of contaminants into soil) would be equal to the mass of the contaminant in the waste divided by the mass of the waste.

- For liquid wastes, the resulting concentration of contaminants in the surrounding soil would be calculated based on the concentration of contaminants in the wastes and the liquid-holding capacity of the soil.

If sufficient information is not available to meet the closure objectives, then site conditions will be re-evaluated and additional samples will be collected (as long as the scope of the CAI is not exceeded and any CSM assumption has not been shown to be incorrect).

\section{B.3.2 Alternative Actions to the Decisions}

This section identifies actions that may be taken to solve the problem depending on the possible outcomes of the investigation.

\section{B.3.2.1 Alternative Actions to Decision I}

If no COC associated with a release from the CAS is detected, then further assessment of the CAS is not required and the CAA of NFA will be selected. If a COC associated with a release from the CAS is detected, then additional sampling will be conducted to determine the extent of COC contamination.

\section{B.3.2.2 Alternative Actions to Decision II}

If sufficient information is available to define the extent of COC contamination and confirm that closure objectives were met, then further assessment of the CAS is not required. If sufficient information is not available to define the extent of contamination or confirm that closure objectives were met, then additional samples will be collected until the extent is defined. 
If the extent of the contamination is defined and additional remediation can be accomplished, then clean close the site by removing the contaminated media until all contamination has been removed. If the extent of contamination has been determined and additional remediation cannot be accomplished during the SAFER, then the extent of contamination will be defined and the contaminated area will be closed in place with appropriate URs.

If the collection of verification samples confirms that all the contaminated media has been removed, then the clean closure objectives will have been met. If contamination still exists and additional remediation would violate the conditions of the SAFER, then work will stop and a consensus will be reached with NDEP on the path forward before the investigation of the CAS may resume. 


\section{B.4.0 Step 3 - Identify Information Inputs}

Step 3 of the DQO process identifies the information needed, determines sources for information, and identifies sampling and analysis methods that will allow reliable comparisons with FALs.

\section{B.4.1 Information Needs}

To resolve Decision I (determine whether a COC is present at a given CAS), samples need to be collected and analyzed following these two criteria:

- Samples must either (a) be collected in areas most likely to contain a COC (judgmental sampling) or (b) properly represent contamination at the CAS (probabilistic sampling).

- The analytical suite selected must be sufficient to identify any COCs present in the samples.

To resolve Decision II (determine whether sufficient information is available to confirm that closure objectives were met at each CAS), samples must be collected and analyzed to meet the following criteria:

- Samples must be collected in areas contiguous to the contamination but where contaminant concentrations are below FALs.

- Samples of the waste or environmental media must provide sufficient information to characterize remediation wastes or IDW for disposal.

- Samples of the waste must provide sufficient information to determine whether PSM is present.

- The analytical suites selected must be sufficient to detect contaminants at concentrations equal to or less than their corresponding FALs.

\section{B.4.2 Sources of Information}

Information to satisfy Decision I and Decision II will be generated by collecting environmental samples using grab sampling, backhoe excavation, or other appropriate sampling methods. These samples will be submitted to analytical laboratories meeting the quality criteria stipulated in the Industrial Sites QAPP (NNSA/NV, 2002). Only validated data from analytical laboratories will 
be used to make DQO decisions. Sample collection and handling activities will follow standard procedures.

\section{B.4.2.1 Sample Locations}

Design of the sampling approaches for the CAU 544 CASs must ensure that the data collected are sufficient for selection of the CAAs (EPA, 2002b). To meet this objective, the samples collected from each site should be from locations that either (1) most likely contain a COC, if present (judgmental), or (2) properly represent any contamination at the CAS (probabilistic).

A judgmental sampling approach will be implemented for all cellars and oil/waste spills, and for mud pits if biasing factors are identified. Biasing factors (including field screening results [FSRs]) will be used to select the most appropriate samples from a particular location for submittal to the analytical laboratory. Biasing factors to be used for selection of sampling locations are listed in Section B.4.2.1.1. Sample locations may be modified based on site conditions, obvious debris or staining of soils, FSRs, or professional judgment if the modified locations meet the DQO decision needs and criteria stipulated. As biasing factors are identified and used for selection of sampling locations, they will be recorded in the appropriate field documents.

A probabilistic sampling approach will be implemented for the radiologically impacted mud pits. Sample locations at mud pits are specified by the process presented in Appendix C, which reviews the methodology and computational approach for probabilistic sampling and lists the sample size and locations as calculated by the VSP software program (PNNL, 2007).

The following subsections discuss how judgmental and probabilistic approaches are each implemented in selecting sample locations for CAU 544.

\section{B.4.2.1.1 Judgmental Approach for Sample Location Selection}

Decision I sample locations at cellars and oil/waste spills, and where applicable, at mud pits, will be determined based upon the likelihood of the soil containing a COC, if present. These locations will be selected based on field-screening techniques, biasing factors, the CSM, and existing information. Analytical suites for Decision I samples will include all COPCs identified in Table B.2-2. 
Field-screening techniques may be used to select appropriate sampling locations by providing semiquantitative data that can be used to comparatively select samples to be submitted for laboratory analyses from several screening locations. The following field-screening method may be used to select biased sample locations at CAU 544:

- Walkover surface area radiological surveys: A radiological survey instrument may be used as permitted by terrain and field conditions to detect locations of elevated radioactivity.

Biasing factors may also be used to select samples to be submitted for laboratory analyses based on existing site information and site conditions discovered during the investigation. The following biasing factors will be considered in selecting locations for analytical samples at CAU 544:

- Documented process knowledge on source and location of release (e.g., volume of release).

- Stains: Any spot or area on the soil surface.

- Elevated radiation: Any location identified during radiological surveys that had alpha/beta/gamma levels significantly higher than surrounding background soil.

- Geophysical anomalies: Any location identified during geophysical surveys that had results indicating surface or subsurface materials existed, and were not consistent with the natural surroundings (e.g., buried concrete or metal, surface metallic objects).

- Drums, containers, equipment, or debris: Materials that may have contained or come in contact with hazardous or radioactive substances at some point during their use.

- Previous sample results from the site being investigated.

- Visual indicators such as textural discontinuities, disturbance of native soils, or any other indication of potential contamination.

- Other biasing factors: Factors not previously defined for the CAI, but become evident once the investigation of the site is under way.

Decision II sample step-out locations will be selected based on the CSM, biasing factors, and existing data. Analytical suites will include those parameters that exceeded FALs (i.e., COCs) in prior samples. 


\section{B.4.2.1.2 Probabilistic Approach for Sample Location Selection}

Decision I sample locations at radiologically impacted mud pits will be selected using a probabilistic approach. For each mud pit, sample locations will be randomly chosen using the VSP software (PNNL, 2007) based on a random start, triangular pattern (see Figure B.8-2 for an example of this sampling scheme). If sufficient sample material cannot be collected at a specified location (e.g., rock, caliche, or buried concrete), the SS will move the location to the nearest place where a surface sample can be obtained. Any necessary modification of sample locations will be recorded in the sample collection log and reported in the CR.

\section{B.4.2.2 Analytical Methods}

Analytical methods are available to provide the data needed to resolve the decision statements. The analytical methods and laboratory requirements (e.g., detection limits, precision, and accuracy) are provided in Tables 3-5 and B.2-3. 


\section{B.5.0 Step 4 - Define the Boundaries of the Study}

Step 4 of the DQO process defines the target population of interest and its relevant spatial boundaries, specifies temporal and other practical constraints associated with sample/data collection, and defines the sampling units on which decisions or estimates will be made.

\section{B.5.1 Target Populations of Interest}

The population of interest to resolve Decision I ("Is any COC present in environmental media within the CAS?”) is either (a) any location within the site that is contaminated with any contaminant above a FAL (judgmental sampling) or (b) locations representative of total site contamination (probabilistic sampling). The populations of interest to resolve Decision II ("If a COC is present, is sufficient information available to evaluate potential CAAs?”) are:

- Each one of a set of locations bounding contamination in lateral and vertical directions.

- IDW or environmental media that must be characterized for disposal.

Regardless of the sampling design, the population of interest for this investigation is surface soil defined as (a) the residual drilling fluid contained in a mud pit, (b) potentially impacted soil at the base of a cellar, or (c) potentially impacted soil underlying an oil or waste spill. For uncovered mud pits, the surface soil is defined as 0 to 6 in. in depth. For backfilled mud pits and cellars, the soil to be sampled resides within the first 6 in. directly below the fill material. For oil/waste spills, surface soil is defined as 0 to 6 in. in depth.

Following the approved risk-based approach, soil samples from the surface of the residual drilling fluid are considered sufficient to adequately characterize the risk posed by the mud pits. A review of data from previous mud pit investigations conducted under the complex process has demonstrated that TPH-DRO concentrations in surface soils are representative of the TPH-DRO concentrations throughout the depth of the residual drilling fluid (NNSA/NSO, 2004). The same process would apply to radiological constituents suspected to be present in the residual drilling fluid in the mud pits of CAU 544. In addition, considering future land uses, the surface soil is the primary exposure point 
for future workers. Thus, samples collected from subsurface soils would yield no additional information.

\section{B.5.2 Spatial Boundaries}

Spatial boundaries are the maximum lateral and vertical extent of expected contamination at each CAS, as shown in Table B.5-1. Contamination found beyond these boundaries may indicate a flaw in the CSM and may require re-evaluation of the CSM before the investigation could continue. Each CAS is considered geographically independent, and intrusive activities are not intended to extend into the boundaries of neighboring CASs.

Table B.5-1

Spatial Boundaries of CAU 544 CASs

\begin{tabular}{|c|l||}
\hline Feature & \multicolumn{1}{|c|}{ Spatial Boundaries } \\
\hline \hline Mud Pit & $\begin{array}{l}\text { The lateral boundaries are the walls/berms of each mud pit plus a 50-ft lateral buffer. The vertical } \\
\text { boundary is the depth of residual drilling mud in the mud pit, typically 1-3 } \mathrm{ft} .\end{array}$ \\
\hline Cellar & $\begin{array}{l}\text { The lateral boundary is the corrugated metal casing that lines each cellar, typically 10 } \mathrm{ft} \text { in diameter. } \\
\text { The vertical boundary is defined as 15 } \mathrm{ft} \text { below the base of the cellar. }\end{array}$ \\
\hline Oil/Waste Spill & $\begin{array}{l}\text { The lateral boundary is } 50 \mathrm{ft} \text { from release point. The vertical boundary is defined as 10 ft below the } \\
\text { release point. }\end{array}$ \\
\hline
\end{tabular}

\section{B.5.3 Practical Constraints}

Investigation of these CASs may be constrained by a lack of an acceptable stability study for craters, underground utilities, and overhead power lines. Underground utilities will be surveyed at each CAS before starting investigation activities to determine whether utilities exist, and if so, the limit for intrusive activities.

\section{B.5.4 Define the Sampling Units}

The scale of decision making for resolving Decision I and Decision II statements is defined as the individual mud pit, cellar, or spill. This allows for individual mud pits and cellars within a CAS to be closed independent of one another.

For resolving the Decision II statement, the scale of decision making for a cellar or spill is defined as a contiguous area contaminated with any COC likely originating from the cellar or spill. 


\section{B.6.0 Step 5 - Develop the Analytic Approach}

Step 5 of the DQO process specifies appropriate population parameters for making decisions, defines action levels and generates an "If ... then ... else" decision rule that defines the conditions under which possible alternative actions will be chosen. This step also specifies the parameters that characterize the population of interest, specifies the FALs, and confirms that the analytical detection limits are capable of detecting FALs.

\section{B.6.1 Population Parameters}

Population parameters are defined for judgmental and probabilistic sampling designs in the following sections. Population parameters are the values that will be compared to decision criteria in order to resolve the DQO decisions.

\section{B.6.1.1 Judgmental Sampling Design}

For judgmental sampling results, the population parameter is the observed concentration of each contaminant from each individual analytical sample. Each sample result will be compared to the FALs to determine the appropriate resolution to Decision I and Decision II. A single sample result for any contaminant exceeding a FAL would cause a determination that a COC is present within the CAS (for Decision I), or that the COC is not bounded (for Decision II).

\section{B.6.1.2 Probabilistic Sampling Design}

For probabilistic sampling results, the population parameter is the true contaminant concentration of each detected contaminant over the entire contaminant release area. Resolution of DQO decisions associated with the probabilistic sampling design requires determining, with a specified degree of confidence, whether the true contaminant concentration at the site in question exceeds the FAL. Because a measured average contaminant concentration is an estimate of the true (unknown) contaminant concentration, it is uncertain how well the calculated average contaminant concentration represents the true contaminant concentration. If the measured average contaminant concentration were significantly different than the true contaminant concentration, a decision based on the 
measured average contaminant concentration could result in a decision error. To reduce the probability of making a false negative decision error, a conservative estimate of the true contaminant concentration is used to compare to the FAL instead of the measured average contaminant concentration. This conservative estimate (overestimation) of the true contaminant concentration will be calculated as the 95 percent UCL of the average contaminant concentration measurements. By definition, there will be a 95 percent probability that the true contaminant concentration is less than the 95 percent UCL of the measured contaminant concentration.

The computation of appropriate UCLs depends upon the data distribution, the number of samples, the variability of the dataset, and the skewness associated with the dataset. A statistical package will be used to determine the appropriate probability distribution (e.g., normal, lognormal, gamma) and/or a suitable nonparametric distribution-free method and then to compute appropriate UCLs. To ensure that the appropriate UCL computational method is used, the sample data will be tested for goodness-of-fit to all of the parametric and nonparametric UCL computation methods described in Calculating the Upper Confidence Limits for Exposure Point Concentrations at Hazardous Waste Sites (EPA, 2002a).

Computation of an appropriate UCL for each of the calculated contaminant concentration averages requires that:

- A minimum number of samples are collected.

- The data originate from a symmetric, but not necessarily normally distributed, population.

- The estimation of the variability is reasonable and representative of the population being sampled.

- The population values are not spatially correlated.

\section{B.6.2 Action Levels}

The PALs presented in this section are to be used for site screening purposes. They are not necessarily intended to be used as cleanup action levels or FALs. However, they are useful in screening out contaminants that are not present in sufficient concentrations to warrant further 
evaluation and, therefore, streamline the consideration of remedial alternatives. The RBCA process used to establish FALs is described in the Industrial Sites Project Establishment of Final Action Levels (NNSA/NSO, 2006b). This process conforms with NAC Section 445A.227, which lists the requirements for sites with soil contamination (NAC, 2008a). For the evaluation of corrective actions, NAC Section 445A.22705 (NAC, 2008b) requires the use of ASTM Method E1739 (ASTM, 1995) to "conduct an evaluation of the site, based on the risk it poses to public health and the environment, to determine the necessary remediation standards (i.e., FALs) or to establish that corrective action is not necessary.”

This RBCA process defines three tiers (or levels) of evaluation involving increasingly sophisticated analyses:

- Tier 1 evaluation - sample results from source areas (highest concentrations) are compared to action levels based on generic (non-site-specific) conditions (i.e., the PALs established in the SAFER Plan). The FALs may then be established as the Tier 1 action levels or the FALs may be calculated using a Tier 2 evaluation.

- Tier 2 evaluation - conducted by calculating Tier 2 SSTLs using site-specific information as inputs to the same or similar methodology used to calculate Tier 1 action levels. The Tier 2 SSTLs are then compared to individual sample results from reasonable points of exposure (as opposed to the source areas as is done in Tier 1) on a point-by-point basis. Total petroleum hydrocarbon concentrations will not be used for risk-based decisions under Tier 2 or Tier 3. Rather, the individual chemicals of concern will be compared to the SSTLs.

- Tier 3 evaluation - conducted by calculating Tier 3 SSTLs on the basis of more sophisticated risk analyses using methodologies described in Method E1739 that consider site-, pathway-, and receptor-specific parameters.

The comparison of laboratory results to FALs and the evaluation of potential corrective actions will be included in the investigation report. The FALs will be defined (along with the basis for their definition) in the investigation report.

\section{B.6.2.1 Chemical PALs}

Except as noted herein, the chemical PALs are defined as the EPA Regions 3, 6, and 9 RSLs for chemical contaminants in industrial soils (EPA, 2009). Background concentrations for RCRA metals and zinc will be used instead of RSLs when natural background concentrations exceed the RSL, as is 
often the case with arsenic on the NTS. Background is considered the average concentration plus two standard deviations of the average concentration for sediment samples collected by the Nevada Bureau of Mines and Geology throughout the Nevada Test and Training Range (formerly the Nellis Air Force Range) (NBMG, 1998; Moore, 1999). For detected chemical COPCs without established screening levels, the protocol used by the EPA Region 9 in establishing RSLs (or similar) will be used to establish PALs. If used, this process will be documented in the investigation report.

\section{B.6.2.2 Radionuclide PALS}

The PALs for radiological contaminants are based on the screening limits recommended in NCRP Report No. 129 for construction, commercial, and industrial land-use scenarios (NCRP, 1999) scaled to the 25-mrem/yr dose constraint (Murphy, 2004) and the generic guidelines for residual concentration of radionuclides in DOE Order 5400.5 (DOE, 1993). These PALs are based on the construction, commercial, and industrial land-use scenarios provided in the NCRP guidance and are appropriate for the NTS based on future land-use scenarios as presented in Section B.2.2.

\section{B.6.3 Decision Rules}

The decision rules applicable to both Decision I and Decision II are:

- If COC contamination is inconsistent with the CSM or extends beyond the spatial boundaries identified in Section B.5.2, then work will be suspended and the investigation strategy will be reconsidered, else the decision will be to continue sampling to define the extent.

The decision rules for Decision I are:

- If the population parameter of any COPC in the Decision I population of interest (defined in Step 4) exceeds the corresponding FAL, then that contaminant is identified as a COC, the contaminated material will be removed, or Decision II will be resolved.

- If a waste is present that, if released, has the potential to cause the future contamination of site environmental media, then a corrective action will be determined, else no further action will be necessary. 
The decision rules for Decision II are:

- If the population parameter (the observed concentration of any COC) in the Decision II population of interest (defined in Step 4) exceeds the corresponding FAL, then additional samples will be collected to complete the Decision II evaluation. If sufficient information is available to define the extent of COC contamination and confirm that closure objectives were met, then further assessment of the CAS is not required. If sufficient information is not available to define the extent of contamination or confirm that closure objectives were met, then additional samples will be collected until the extent is defined.

- If valid analytical results are available for the waste characterization samples defined in Section B.8.0, then the decision will be that sufficient information exists to characterize wastes and IDW for disposal, else collect additional waste characterization samples. 


\section{B.7.0 Step 6 - Specify Performance or Acceptance Criteria}

Step 6 of the DQO process defines the decision hypotheses, specifies controls against false rejection and false acceptance decision errors, examines consequences of making incorrect decisions from the test, and places acceptable limits on the likelihood of making decision errors.

\section{B.7.1 Decision Hypotheses}

The baseline condition (i.e., null hypothesis) and alternative condition for Decision I are:

- $\quad$ Baseline condition - A COC is present.

- Alternative condition - A COC is not present.

The baseline condition (i.e., null hypothesis) and alternative condition for Decision II are as follows:

- $\quad$ Baseline condition - The extent of a COC has not been defined.

- Alternative condition - The extent of a COC has been defined.

Decisions and/or criteria have false negative or false positive errors associated with their determination. The impact of these decision errors and the methods that will be used to control these errors are discussed in the following subsections. In general terms, confidence in DQO decisions based on judgmental sampling results will be established qualitatively by:

- Developing and achieving concurrence of CSMs (based on process knowledge) by stakeholder participants during the DQO process.

- Conducting validity testing of CSMs based on investigation results.

- $\quad$ Evaluating data quality based on DQI parameters.

\section{B.7.2 False Negative Decision Error}

The false negative decision error would mean deciding that a COC is not present when it actually is (Decision I), or deciding that the extent of a COC has been defined when it has not (Decision II). In both cases the potential consequence is an increased risk to human health and the environment. 


\section{B.7.2.1 False Negative Decision Error for Judgmental Sampling}

In judgmental sampling, the selection of the number and location of samples is based on knowledge of the feature or condition under investigation and on professional judgment (EPA, 2002b).

Judgmental sampling conclusions about the target population depend upon the validity and accuracy of professional judgment.

The false negative decision error (where consequences are more severe) for judgmental sampling designs is controlled by meeting these criteria:

- For Decision I, having a high degree of confidence that the sample locations selected will identify COCs if present anywhere within the CAS. For Decision II, having a high degree of confidence that the sample locations selected will identify the extent of COCs.

- Having a high degree of confidence that analyses conducted will be sufficient to detect any COCs present in the samples.

- Having a high degree of confidence that the dataset is of sufficient quality and completeness.

To satisfy the first criterion, Decision I samples must be collected in areas most likely to be contaminated by COCs (supplemented by random samples where appropriate). Decision II samples must be collected in areas that represent the lateral and vertical extent of contamination (above FALs). The following characteristics must be considered to control decision errors for the first criterion:

- Source and location of release

- Chemical nature and fate properties

- Physical transport pathways and properties

- Hydrologic drivers

These characteristics were considered during the development of the CSMs and selection of sampling locations. The field-screening methods and biasing factors listed in Section B.4.2.1 will be used to further ensure that appropriate sampling locations are selected to meet these criteria. Radiological survey instruments and field-screening equipment will be calibrated and checked in accordance with the manufacturer's instructions and approved procedures. The investigation report will present an 
assessment on the DQI of representativeness that samples were collected from those locations that best represent the populations of interest as defined in Section B.5.1.

To satisfy the second criterion, Decision I samples will be analyzed for the chemical and radiological parameters listed in Section 3.2 of the SAFER Plan. Decision II samples will be analyzed for those chemical and radiological parameters that identified unbounded COCs. The DQI of sensitivity will be assessed for all analytical results to ensure that all sample analyses had measurement sensitivities (detection limits) that were less than or equal to the corresponding FALs. If this criterion is not achieved, the affected data will be assessed (for usability and potential impacts on meeting site characterization objectives) in the investigation report.

To satisfy the third criterion, the entire dataset, as well as individual sample results, will be assessed against the DQIs of precision, accuracy, comparability, and completeness as defined in the Industrial Sites QAPP (NNSA/NV, 2002) and in Section 7.2 of the SAFER Plan. The DQIs of precision and accuracy will be used to assess overall analytical method performance as well as to assess the need to potentially "flag” (qualify) individual contaminant results when corresponding QC sample results are not within the established control limits for precision and accuracy. Data qualified as estimated for reasons of precision or accuracy may be considered to meet the constituent performance criteria based on an assessment of the data. The DQI for completeness will be assessed to ensure that all data needs identified in the DQO have been met. The DQI of comparability will be assessed to ensure that all analytical methods used are equivalent to standard EPA methods so that results will be comparable to regulatory action levels that have been established using those procedures. Strict adherence to established procedures and QA/QC protocol protects against false negatives. Site-specific DQIs are discussed in more detail in Section 7.2 of the SAFER Plan.

To provide information for the assessment of the DQIs of precision and accuracy, the following QC samples will be collected as required by the Industrial Sites QAPP (NNSA/NV, 2002):

- Field duplicates (minimum of 1 per matrix per 20 environmental samples)

- Laboratory QC samples (minimum of 1 per matrix per 20 environmental samples or 1 per CAS per matrix, if less than 20 collected) 


\section{B.7.2.2 False Negative Decision Error for Probabilistic Sampling}

Control of the false negative decision error under a probabilistic sampling design is quantitatively established through the selection of the false negative error rate goal (PNNL, 2007). The false negative error rate goal for all CASs was established by the DQO meeting participants at 0.05 (or 5 percent probability). Upon validation of the analytical results, statistical parameters will be calculated for each significant COPC identified at each site. Maintenance of a false negative error rate of 0.05 is contingent upon:

- Population distribution

- Sample size

- Actual variability

- Measurement error

Control of the false negative decision error, therefore, for probabilistic sampling designs is accomplished by ensuring (for each significant COPC) that:

- The population distributions fit the applied UCL determination method.

- A sufficient sample size was collected.

- The actual standard deviation is calculated.

- Analyses conducted were sufficient to detect any COCs present in samples.

As determination of the minimum sample size cannot be accomplished until after the data have been generated, the sufficiency of the number of samples collected will be evaluated in the investigation report. This will be evaluated based on analytical results of significant contaminants. The required number of samples will be calculated using the statistical protocols described in Data Quality Assessment: Statistical Methods for Practitioners (EPA, 2006a). This determination is based on the type of test to be performed, the distribution of the data, the variability of the data, and the acceptable false positive and false negative error rates.

The input parameters to be used in calculating the minimum sample size are:

- A 95 percent confidence level that a false negative error will not occur.

- An 80 percent confidence level that a false positive error will not occur.

- A gray region width equal to 50 percent of the FAL.

- The standard deviation of the contaminant concentrations at each CAS. 
All calculations for the determination of sample size sufficiency will be provided in the investigation report. If the criteria established in this section result in a determination that the minimum sample size was not met for a plot, one of the following actions may be taken:

- Collect additional composite sample(s).

- Conservatively assume that the contaminant concentration for the plot exceeds the FAL.

If the criteria cannot be met, justifications for using the resulting contaminant concentration without meeting the criteria will be made in the $\mathrm{CR}$.

\section{B.7.3 False Positive Decision Error}

The false positive decision error would mean deciding that a COC is present when it is not, or a COC is unbounded when it is not, resulting in increased costs for unnecessary sampling and analysis.

False positive results are typically attributed to laboratory and/or sampling/handling errors that could cause cross contamination. To control against cross contamination, decontamination of sampling equipment will be conducted according to established and approved procedures and only clean sample containers will be used. To determine whether a false positive analytical result may have occurred, the following QC samples will be collected as required by the Industrial Sites QAPP (NNSA/NV, 2002):

- Trip blanks (one per sample cooler containing VOC environmental samples)

- Equipment blanks (one per sampling event for each type of decontamination procedure)

- Source blanks (one per source lot per sampling event)

- Field duplicates (1 per 20 environmental samples or 1 per CAS per matrix, if less than 20 collected)

- Field blanks (minimum of one per CAS, additional if field conditions change)

- Laboratory QC samples (1 per 20 environmental samples or 1 per CAS per matrix, if less than 20 collected) 
For probabilistic sampling, false positive decision error rate goal was established by the DQO meeting participants at 0.20 (or 20 percent probability). Protection against this decision error is also afforded by the controls listed in Section B.7.2 for probabilistic sampling designs. 


\section{B.8.0 Step 7 - Develop the Plan for Obtaining Data}

Step 7 of the DQO process selects and documents a design that will yield data that will best achieve performance or acceptance criteria. Judgmental and probabilistic sampling schemes will be implemented to select sample locations and evaluate analytical results for CAU 544. Section B.8.1.1 provides the judgmental sampling approach that will be implemented to select sample locations and evaluate analytical results at the cellars. Section B.8.1.2 provides the judgmental sampling approach that will be implemented to select sample locations and evaluate analytical results at the oil and waste spills. Judgmental sampling allows the methodical selection of sample locations that target the populations of interest (defined in Step 4). Section B.8.2.1 provides the probabilistic sampling approach that will be implemented to select sample locations and evaluate analytical results in all mud pits. A summary of the sampling approach and data evaluation for each CAS is presented in Table B.8-1.

Table B.8-1

Summary of Sampling Approach and Data Evaluation (Page 1 of 2)

\begin{tabular}{|c|c|c|c|}
\hline $\begin{array}{c}\text { Feature with } \\
\text { Applicable CASs }\end{array}$ & Description & Sample Locations & Evaluation of Data \\
\hline $\begin{array}{c}\text { Mud Pit } \\
(02-37-09,09-09-46)\end{array}$ & $\begin{array}{l}\text { Probabilistic } \\
\text { Sampling } \\
\text { Approach }\end{array}$ & $\begin{array}{l}\text { - Initial number of locations: } \\
10 \text { random } \\
\text { - Soil profile depth(s): surface } \\
\text { (0-6 in. or first } 6 \text { in. below } \\
\text { cover material if backfilled) }\end{array}$ & $\begin{array}{l}\text { Comparison of the } \\
95 \text { percent UCL of the average } \\
\text { concentration } \\
\text { of each significant contaminant } \\
\text { to the FAL }\end{array}$ \\
\hline $\begin{array}{c}\text { Cellar } \\
(02-37-08,02-37-09)\end{array}$ & $\begin{array}{l}\text { Judgmental } \\
\text { Sampling } \\
\text { Approach }\end{array}$ & $\begin{array}{l}\text { - Initial number of locations: } 2 \\
\text { equally distributed locations } \\
\text { - Soil profile depth(s): surface } \\
\text { (0-6 in. or first } 12 \text { in. below } \\
\text { cover material if backfilled) at } \\
\text { biasing factor or distributed at } \\
\text { the accessible area of the } \\
\text { cellar in the absence of } \\
\text { biasing factors }\end{array}$ & $\begin{array}{l}\text { Point-by-point } \\
\text { comparison of each analytical } \\
\text { result to the FAL }\end{array}$ \\
\hline
\end{tabular}


Table B.8-1

Summary of Sampling Approach and Data Evaluation

(Page 2 of 2)

\begin{tabular}{|c|c|c|c|}
\hline $\begin{array}{c}\text { Feature with } \\
\text { Applicable CASs }\end{array}$ & Description & Sample Locations & Evaluation of Data \\
\hline $\begin{array}{c}\text { Oil/Waste Spill } \\
(19-25-01,19-99-06 \\
20-25-04,20-25-05)\end{array}$ & $\begin{array}{l}\text { Judgmental } \\
\text { Sampling } \\
\text { Approach }\end{array}$ & $\begin{array}{l}\text { Initial number of locations: } 2 \\
\text { (one location from beneath } \\
\text { the heaviest stained soil } \\
\text { within spill area, and one near } \\
\text { the edge of the spill) } \\
\text { - Soil profile depth(s): surface } \\
\text { (0-6 in.) at biasing factor }\end{array}$ & $\begin{array}{c}\text { Point-by-point comparison of } \\
\text { each analytical result } \\
\text { to the FAL }\end{array}$ \\
\hline
\end{tabular}

All sample locations will be selected to satisfy the DQI of representativeness in that samples collected from selected locations will best represent the populations of interest as defined in Section B.5.1.

\section{B.8.1 Judgmental Sampling}

A judgmental sampling design will be implemented at the cellar CASs and the oil/waste spill CASs, and is described in the following sections. To meet the criterion for judgmentally sampled sites, a biased sampling strategy will be used for Decision I samples to target areas with the highest potential to contain a COC, if a COC is present anywhere in the CAS. Sample locations will be determined based on process knowledge, previously acquired data, or the field-screening and biasing factors listed in Section B.4.2.1. If biasing factors are present in soils below locations where Decision I samples were removed, additional Decision I soil samples will be collected at depth intervals selected by the SS based on biasing factors to a depth where the biasing factors are no longer present. The SS has the discretion to modify the sample locations or order additional biased samples to be collected, but only if the new locations meet the decision needs and criteria stipulated in this DQO.

\section{B.8.1.1 Cellar Sampling Design}

The cellars will be investigated based on the potential for chemical and radioactive contamination of surface soil at the cellar base. Judgmental samples will be collected at the first 6 in. of soil directly beneath the cover material in the backfilled cellars based on biasing factors. Samples will be submitted for analysis in accordance with the analytical program listed in Table 3-1. 
Based on the sampling design from CAU 177, Mud Pits and Cellars, a minimum of four samples, two surface and two subsurface, would be sufficient to determine whether contamination exists (NNSA/NSO, 2006c). The subsurface samples will be collected to avoid complications with accessing cellar samples at a later time. The subsurface samples may also provide potential information on vertical migration of contaminants, if any. The locations of the surface samples will be restricted to within the boundaries of the cellar casing because contamination is not expected to have migrated laterally out of this boundary. The presence and orientation (i.e., direction and angle of installation) of drill stemming left within the cellar cavity may laterally and vertically restrict access to surface and subsurface sample locations. The common post-test drilling situation was to drill at an angle to access the zone of rock affected by the test associated with post-test drilling (LLNL, 1984). With this information, it is possible to determine the direction at which the drill stemming trends below the ground surface. Sample locations may therefore vary and will be dependent on the following criteria:

- For the two backfilled cellars, biasing factors are not expected to be apparent. In the expected absence of obvious biasing factors, planned sample locations will be either (a) equally distributed on each side of the drill stemming if the entire cellar area is accessible (Figure B.8-1, item [a]), or (b) equally distributed on the side of the cellar that will be accessible for the appropriate sample collection method (Figure B.8-1, item [b]). It will be assumed that drill stemming has been left in place for backfilled cellars in order to avoid contact with the stemming during excavation and sample collection. Access restrictions related to the presence of drill stemming will also be considered when selecting sample locations in backfilled cellars.

Samples will be obtained through either excavation or other appropriate method. For the backfilled cellars, the cover material/surface soil interface is expected to be encountered near a depth of 10 to $12 \mathrm{ft}$ bgs (Figure B.8-1) based on the assumption that this is the typical depth to the base of a cellar as determined from the sampling that occurred during the CAU 177 investigation (NNSA/NSO, 2007). However, this transition horizon between cover material and the underlying surface soil may not be distinguishable. The following lists the procedure for obtaining samples from the potentially impacted subsurface soil in the cellars:

- Soil will be monitored for lithology changes during excavation to determine the cover material/surface soil interface. 
(a)

Plan View

Full Access

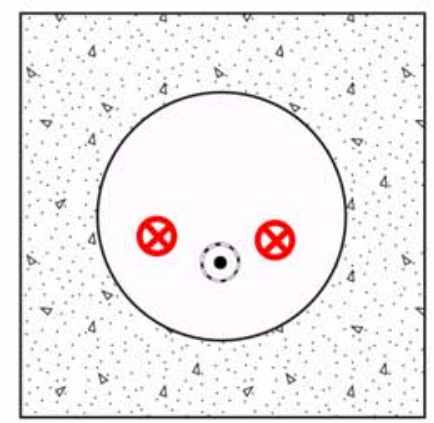

(b)

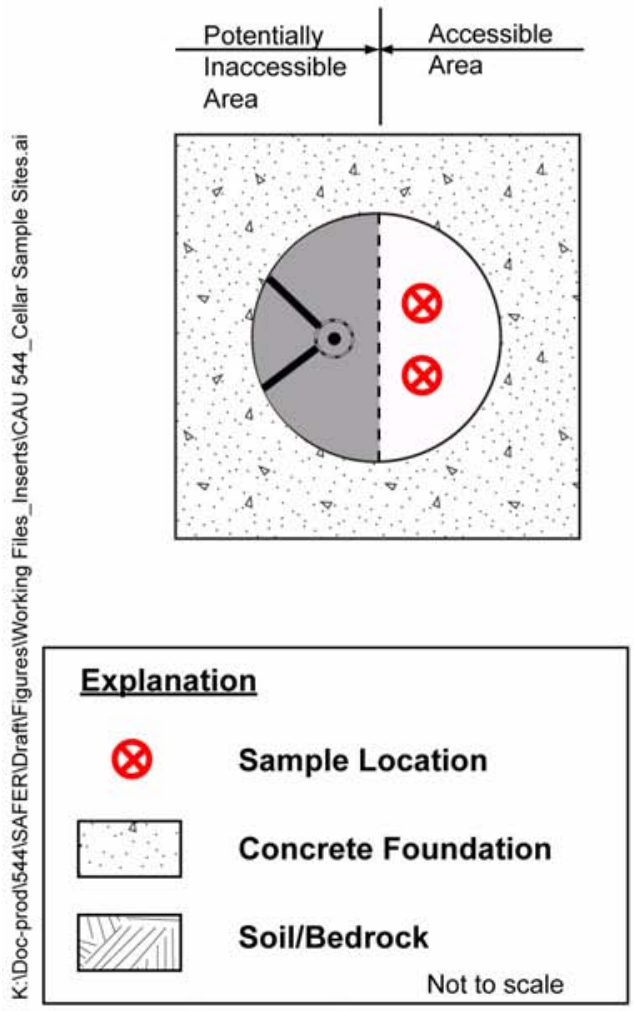

\section{Cross-Section View}

Full Access

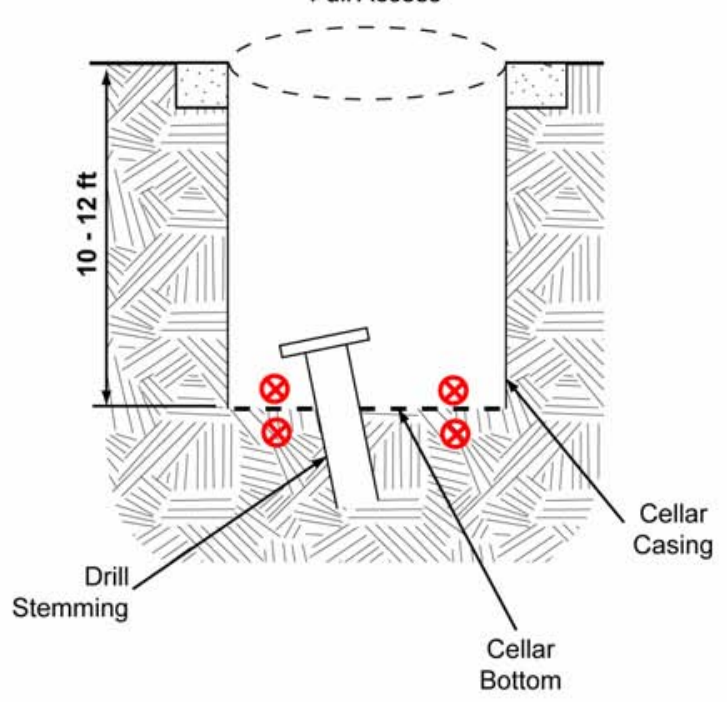

Cross-Section View

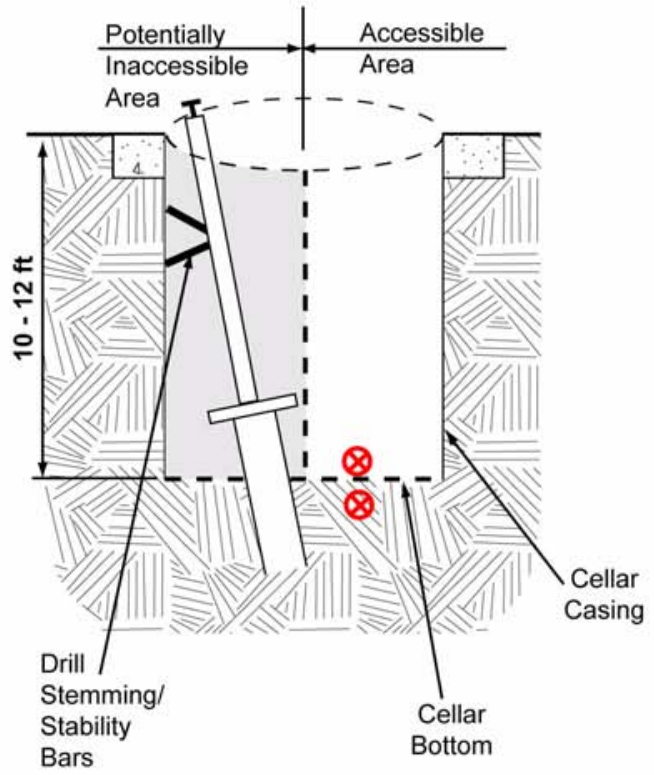

Figure B.8-1

Proposed Sample Locations at Cellars 
- If the interface is recognizable, then a sample will be collected from the first 6 in. of soil directly below the interface.

- If the interface is not recognizable, then a sample will be collected at the depth where the potentially impacted surface soil is expected to be located (i.e., 10 to $12 \mathrm{ft}$ bgs) based on the observations from open cellars.

- If the interface has not been identified and a layer of caliche or a cement bottom is encountered, then a sample will be collected directly above that layer.

The SS will use professional judgment to determine whether biasing factors (e.g., stains, elevated screening levels) are found that might indicate the need to take additional depth samples.

\section{B.8.1.2 OilMaste Spill Sampling Design}

The Decision I sampling approach at the oil and waste spills will be based on a typical CSM for a surface spill. The oil and waste spills will be investigated based on the potential for chemical contamination of surface soil. A total of two judgmental samples will be collected from surface soil (0 to 6 in. bgs) at the spills based on biasing factors (visual observations and FSRs). The samples will be collected from areas of suspected highest contaminant concentrations. Samples will be submitted for analysis in accordance with the analytical program listed in Table 3-1.

The SS will use professional judgment to determine whether biasing factors (e.g., stains, elevated screening levels) are found that might indicate the need to take additional depth samples.

\section{B.8.2 Probabilistic Sampling Design}

A probabilistic sampling scheme will be implemented to select sample locations and evaluate analytical results for radiologically impacted mud pits. For probabilistically sampled sites, randomly selected sample locations will be chosen, with locations specified by the VSP software (PNNL, 2007). If a location contains a shallow, hard object (e.g., rock, caliche, or buried concrete), or is located on the mud pit berm, the SS will establish the location at the nearest place that a surface sample can be obtained. 
Statistical methods that generate site characteristics will be used at the mud pits CASs. The information provided from probabilistic sampling allows for establishing contaminant concentrations that represent the site as a whole.

\section{B.8.2.1 Mud Pit Sampling Design}

The mud pits will be investigated based on the potential for radiological contamination of the residual drilling mud contained within the mud pit. A total of 10 samples per mud pit will be collected from the surface (0 to 6 in. bgs) of the residual drilling mud, or 0 to 6 in. below cover material or at the expected depth of mud for backfilled mud pits. The number of samples has been estimated to sufficiently satisfy the criteria of establishing the 95 percent UCL of the average COPC concentration. Appendix C reviews the methodology and computational approach of the VSP software program for determining the sample size and locations for probabilistic sampling (PNNL, 2007). The samples will be configured in a triangular pattern to ensure that all areas of the pit are represented. The initial sample location will be randomly chosen and will serve as the basis for the triangular grid that is established by VSP. Figure B.8-2 shows the predetermined layout of surface sample locations to be collected at a mud pit.

Samples to be collected at open mud pits will be obtained through hand scoop, backhoe excavation, or other appropriate method. Samples to be collected at backfilled mud pits will be obtained through backhoe excavation or other appropriate method. For backfilled mud pits, the cover material/residual mud interface is expected to be easily recognized and encountered at a depth typical of other NTS excavated mud pits (4 to $5 \mathrm{ft}$ bgs based on observations from previous mud pit investigations). Although the cover material/residual mud interface was well recognized at most previously investigated backfilled mud pits, the transition between these layers may not be distinguishable for reasons such as (a) the mud pit was not used or only partially used; and (b) because boundaries of backfilled mud pits are approximated, some unbiased samples may be located in the former mud pit berm. The following, therefore, lists a procedure for obtaining samples from residual mud:

- Soil will be monitored for lithology changes during excavation to identify the cover material/residual mud interface. 


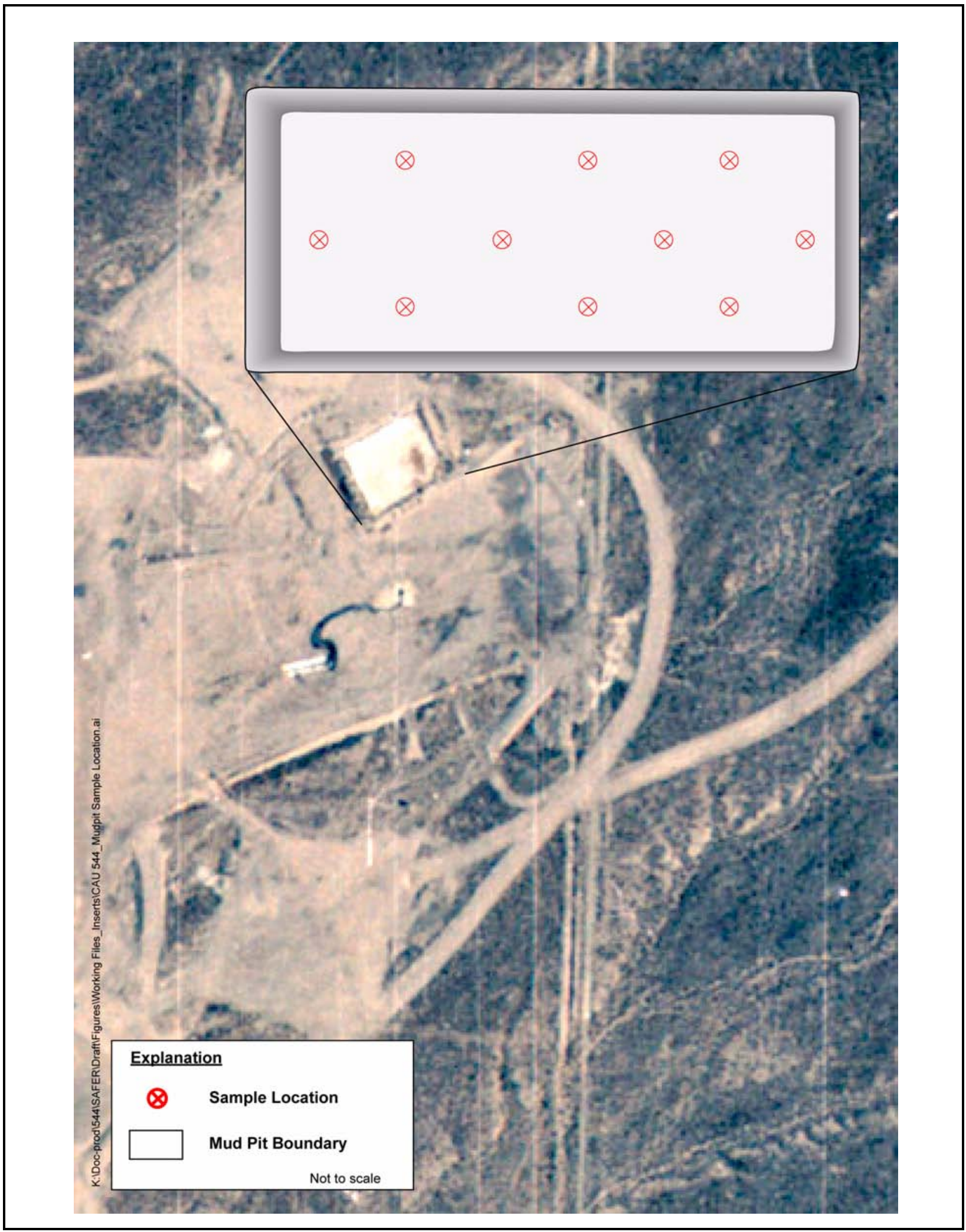

Figure B.8-2

Proposed Sample Locations at Mud Pits 
- If the interface is recognizable, then a sample will be collected from the first 6 in. of mud/cuttings directly below the interface.

- If the interface is not recognizable, then a sample will be collected at the depth where the residual mud is expected to be located based on the observations from other mud pits.

- If the interface has not been identified and a layer of caliche is encountered, then a sample will be collected directly above the caliche.

In addition to the 10 unbiased samples to be collected from each mud pit, additional biased samples may be collected in areas of obvious spills or staining located either within or adjacent to the mud pit. The SS has the discretion to modify the sample locations or order additional biased samples to be collected, but only if the new locations meet the decision needs and criteria stipulated in this DQO. The SS will use professional judgment to determine whether biasing factors (e.g., stains, elevated screening levels) are found that might indicate the need to take additional depth samples. Samples will be submitted for analysis in accordance with the analytical program listed in Table 3-1.

\section{B.8.3 Decision II Sampling}

To meet the DQI of representativeness for Decision II samples (that Decision II sample locations represent the population of interest as defined in Section B.5.1), judgmental sampling locations will be selected based on the outer boundary sample locations where COCs were detected, the CSM, and other field-screening and biasing factors listed in Section B.4.2. In general, sample locations will be arranged in a triangular pattern around the Decision I location or area at distances based on site conditions, process knowledge, and biasing factors. If COCs extend beyond the initial step-outs, Decision II samples will be collected from incremental step-outs. Initial step-outs will be at least as deep as the vertical extent of contamination defined at the Decision I location, and the depth of the incremental step-outs will be based on the deepest contamination observed at all locations. A clean sample (i.e., COCs less than FALs) collected from each step-out direction (lateral or vertical) will define the extent of contamination in that direction. The number, location, and spacing of step-outs may be modified by the SS, as warranted by site conditions. 
For cellars, Decision II step-out samples will be collected only in the vertical direction because the lateral migration is restricted to inside the cellar casing. If a concrete bottom is encountered, then Decision II step-out samples in the vertical direction may not be collected. 


\section{B.9.0 References}

ASTM, see American Society for Testing and Materials.

American Society for Testing and Materials. 1995 (reapproved 2002). Standard Guide for Risk-Based Corrective Action Applied at Petroleum Release Sites, ASTM E1739 - 96(2002).

Philadelphia, PA.

DOE, see U.S. Department of Energy.

DOE/NV, see U.S. Department of Energy, Nevada Operations Office.

EPA, see U.S. Environmental Protection Agency.

LLNL, see Lawrence Livermore National Laboratory.

Lawrence Livermore National Laboratory. 1984. Postshot Drilling Handbook, January. Livermore, CA.

Moore, J., Science Applications International Corporation. 1999. Memorandum to M Todd (SAIC) titled "Background Concentrations for NTS and TTR Soil Samples," 3 February.

Las Vegas, NV: IT Corporation.

Murphy, T., Bureau of Federal Facilities. 2004. Letter to R. Bangerter (NNSA/NSO) titled "Review of Industrial Sites Project Document Guidance for Calculating Industrial Sites Project

Remediation Goals for Radionuclides in Soil Using the Residual Radiation (RESRAD) Computer Code,” 19 November. Las Vegas, NV.

NAC, see Nevada Administrative Code.

NBMG, see Nevada Bureau of Mines and Geology.

NCRP, see National Council on Radiation Protection and Measurements.

NNSA/NSO, see U.S. Department of Energy, National Nuclear Security Administration Nevada Site Office.

NNSA/NV, see U.S. Department of Energy, National Nuclear Security Administration Nevada Operations Office.

National Council on Radiation Protection and Measurements. 1999. Recommended Screening Limits for Contaminated Surface Soil and Review of Factors Relevant to Site-Specific Studies, NCRP Report No. 129. Bethesda, MD. 
Nevada Administrative Code. 2008a. NAC 445A.227, “Contamination of Soil: Order by Director for Corrective Action; Factors To Be Considered in Determining Whether Corrective Action Required.” As accessed at http://www.leg.state.nv.us/nac 3 March 2010.

Nevada Administrative Code. 2008b. NAC 445A.22705, “Contamination of Soil: Evaluation of Site by Owner or Operator; Review of Evaluation by Division.” As accessed at http://www.leg.state.nv.us/nac 3 March 2010.

Nevada Bureau of Mines and Geology. 1998. Mineral and Energy Resource Assessment of the Nellis Air Force Range, Open-File Report 98-1. Reno, NV.

PNNL, see Pacific Northwest National Laboratory.

Pacific Northwest National Laboratory. 2007. Visual Sample Plan, Version 5.0 User's Guide, PNNL-16939. Richland, WA.

Shott, G.J., V. Yucel, M.J. Sully, L.E. Barker, S.E. Rawlinson, and B.A. Moore. 1997. Performance Assessment/Composite Analysis for the Area 3 Radioactive Waste Management Site at the Nevada Test Site, Nye County, Nevada, Rev. 2.0. Las Vegas, NV.

USGS and DOE, see U.S. Geological Survey and U.S. Department of Energy.

U.S. Department of Energy. 1993. Radiation Protection of the Public and the Environment, DOE Order 5400.5, Change 2. Washington, DC: U.S. Government Printing Office.

U.S. Department of Energy, National Nuclear Security Administration Nevada Operations Office. 2002. Industrial Sites Quality Assurance Project Plan, Nevada Test Site, Nevada, Rev. 3, DOE/NV--372. Las Vegas, NV.

U.S. Department of Energy, National Nuclear Security Administration Nevada Site Office. 2004. Mud Pit Risk-Based Closure Strategy Report, Nevada Test Site, Nevada, DOE/NV--991. Las Vegas, NV.

U.S. Department of Energy, National Nuclear Security Administration Nevada Site Office. 2005. Streamlined Approach for Environmental Restoration Plan for Corrective Action Units 530, 531, 532, 533, 534, and 535, Nevada Test Site Mud Pits, Nevada Test Site, Nevada, DOE/NV--1057. Las Vegas, NV.

U.S. Department of Energy, National Nuclear Security Administration Nevada Site Office. 2006a. Closure Report for Corrective Action Units 530, 531, 532, 533, 534, 535: NTS Mud Pits, Nevada Test Site, Nevada, DOE/NV--1131. Las Vegas, NV.

U.S. Department of Energy, National Nuclear Security Administration Nevada Site Office. 2006b. Industrial Sites Project Establishment of Final Action Levels, DOE/NV--1107, Rev. 0. Las Vegas, NV. 
U.S. Department of Energy, National Nuclear Security Administration Nevada Site Office. 2006c. Streamlined Approach for Environmental Restoration Plan for Corrective Action Unit 177: Mud Pits and Cellars, Nevada Test Site, Nevada, DOE/NV--1126. Las Vegas, NV.

U.S. Department of Energy, National Nuclear Security Administration Nevada Site Office. 2007. Closure Report for Corrective Action Unit 177: Mud Pits and Cellars, Nevada Test Site, Nevada, DOE/NV--1186. Las Vegas, NV.

U.S. Department of Energy, Nevada Operations Office. 1992. Remedial Investigation and Feasibility Study for the Plutonium Contaminated Soils at Nevada Test Site, Nellis Air Force Range and Tonopah Test Range. April. Las Vegas, NV.

U.S. Department of Energy, Nevada Operations Office. 1998. Nevada Test Site Resource Management Plan, DOE/NV--518. Las Vegas, NV.

U.S. Department of Energy, Nevada Operations Office. 2001. Mud Pit Strategy, Nevada Test Site, Nevada, DOE/NV-684. Las Vegas, NV.

U.S. Environmental Protection Agency. 2002a. Calculating the Upper Confidence Limits for Exposure Point Concentrations at Hazardous Waste Sites, OSWER 9285.6-10. Washington, DC: Office of Emergency and Remedial Response.

U.S. Environmental Protection Agency. 2002b. Guidance for Quality Assurance Project Plans, EPA QA/G5, EPA/240/R-02/009. Washington, DC.

U.S. Environmental Protection Agency. 2006a. Data Quality Assessment: Statistical Methods for Practitioners, EPA QA/G-9S, EPA/240/B-06/003. Washington, DC.

U.S. Environmental Protection Agency. 2006b. EPA Guidance on Systematic Planning Using the Data Quality Objectives Process, EPA QA/G-4. Washington, DC.

U.S. Environmental Protection Agency. 2009. Regions 3, 6, and 9 Regional Screening Levels for Chemical Contaminants at Superfund Sites. As accessed at http://www.epa.gov/region09/superfund/prg/index.html on 3 March 2010.

U.S. Geological Survey and U.S. Department of Energy. 2009. "USGS/USDOE Cooperative Studies in Nevada; Water-Level Wells, Nevada Test Site.” As accessed at http://nevada.usgs.gov/doe_nv/ntsmap.htm on 25 February 2010.

Winograd, I.J., and W. Thordarson. 1975. Hydrogeologic and Hydrochemical Framework, South-Central Great Basin, Nevada-California, with Special Reference to the Nevada Test Site, USGS Professional Paper 712-C. Denver, CO. 


\section{Appendix C}

\section{Probabilistic Sampling Plan}




\section{C.1.0 Probabilistic Sampling Plan}

\section{C.1.1 Purpose}

A probabilistic (random) sampling design was specified by the DQO meeting participants for sampling of the radiologically impacted mud pits of CAU 544. This approach will allow for the mud pits to be characterized by evaluating contamination as a whole rather than individual locations within the mud pit. Following this approach, a proposed initial number of 10 sample locations for each mud pit in CAU 544 was agreed upon by decision makers during the April 27, 2010, DQO meeting.

This appendix provides the methodology used to design the probabilistic sampling plan that will be used to characterize mud pits, the specific number and locations of samples to be collected, and the statistical tests to be applied to the data upon completion of the investigation.

\section{C.1.2 Methodology}

For probabilistic sampling results, the population parameter is the true contaminant concentration of each detected contaminant over the entire contaminant release area. Resolution of DQO decisions associated with the probabilistic sampling design requires determining, with a specified degree of confidence, whether the true contaminant concentration at the site in question exceeds the FAL. Because a measured average contaminant concentration is an estimate of the true (unknown) contaminant concentration, it is uncertain how well the calculated average contaminant concentration represents the true contaminant concentration. If the measured average contaminant concentration were significantly different than the true contaminant concentration, a decision based on the measured average contaminant concentration could result in a decision error. To reduce the probability of making a false negative decision error, a conservative estimate of the true contaminant concentration is used to compare to the FAL instead of the measured average contaminant concentration. This conservative estimate (overestimation) of the true contaminant concentration will be calculated as the 95 percent UCL of the average contaminant concentration measurements. By definition, there will be a 95 percent probability that the true contaminant concentration is less than the 95 percent UCL of the measured contaminant concentration. 


\section{C.1.2.1 Computation of the Upper Confidence Limit}

The computation of appropriate UCLs depends upon the data distribution, the number of samples, the variability of the dataset, and the skewness associated with the dataset. A statistical package will be used to determine the appropriate probability distribution (e.g., normal, lognormal, gamma) and/or a suitable nonparametric distribution-free method and then to compute appropriate UCLs. To ensure that the appropriate UCL computational method is used, the sample data will be tested for goodness-of-fit to all of the parametric and nonparametric UCL computation methods described in the EPA guidance document on the calculation of upper confidence limits for exposure point concentrations at hazardous waste sites (EPA, 2002).

A UCL will be calculated for each COPC that is detected in any sample at a concentration greater than the PAL. Computation of an appropriate UCL requires that a minimum number of samples be collected from random locations at each site. It also requires the following assumptions:

- The data originate from a symmetric, but not necessarily normally distributed, population.

- The estimation of the variability is reasonable and representative of the population being sampled.

- The population values are not temporally or spatially correlated.

\section{C.1.2.2 Sample Size}

A minimum number of samples is required to compute a UCL. As determination of the minimum sample size cannot be accomplished until after the data have been generated, the sufficiency of the number of samples collected will be evaluated in the investigation report. This will be evaluated based on analytical results of significant contaminants. The required number of samples will be calculated using the statistical protocols described in Data Quality Assessment: Statistical Methods for Practitioners (EPA, 2006). This determination is based on the type of test to be performed, the distribution of the data, the variability of the data, and the acceptable false positive and false negative error rates. 
The input parameters to be used in calculating the minimum sample size are:

- A 95 percent confidence level that a false negative error will not occur.

- An 80 percent confidence level that a false positive error will not occur.

- A gray region width equal to 50 percent of the FAL.

- The standard deviation of the contaminant concentrations at each CAS.

All calculations for the determination of sample size sufficiency will be provided in the investigation report. If the criteria established in this section result in a determination that the minimum sample size was not met for a plot, one of the following actions may be taken:

- Collect additional composite sample(s).

- Conservatively assume that the contaminant concentration for the plot exceeds the FAL.

If the criteria cannot be met, justifications for using the resulting contaminant concentration without meeting the criteria will be made in the CR.

\section{C.1.2.3 Sample Location Selection}

The locations of the 10 initial samples will be determined in VSP using a triangular grid pattern that is based on a randomly selected start location and the mud pit perimeters that were obtained using GPS collection methods. Figures C.1-1 through C.1-2 show the VSP-generated locations and coordinates of each sample within the spatial boundaries of the radiologically impacted mud pits (02-37-09 and 09-09-46). In the event that unforeseen site-specific conditions at other CASs will require the VSP software to regenerate sample locations, the new layout will also be documented in the field activity daily log and CR, but an ROTC will not be generated for this SAFER Plan. If it is determined that additional samples need to be collected based on the determination of minimum sample size using actual sample results, additional sample locations will be determined using the same methodology (for five or more samples) or by randomly selecting each sample location (for less than five samples). 


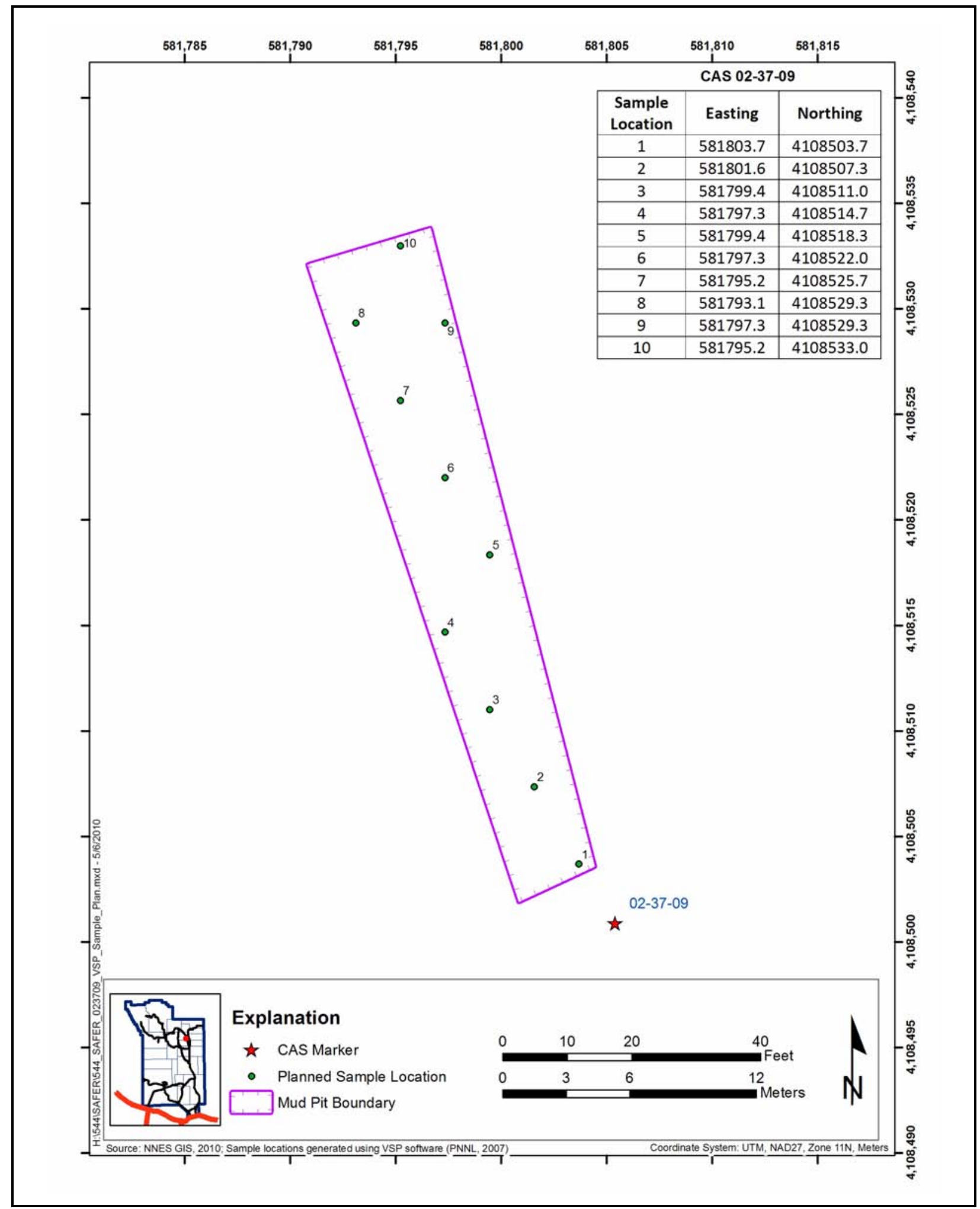

Figure C.1-1

CAS 02-37-09, Sample Locations and Coordinates 


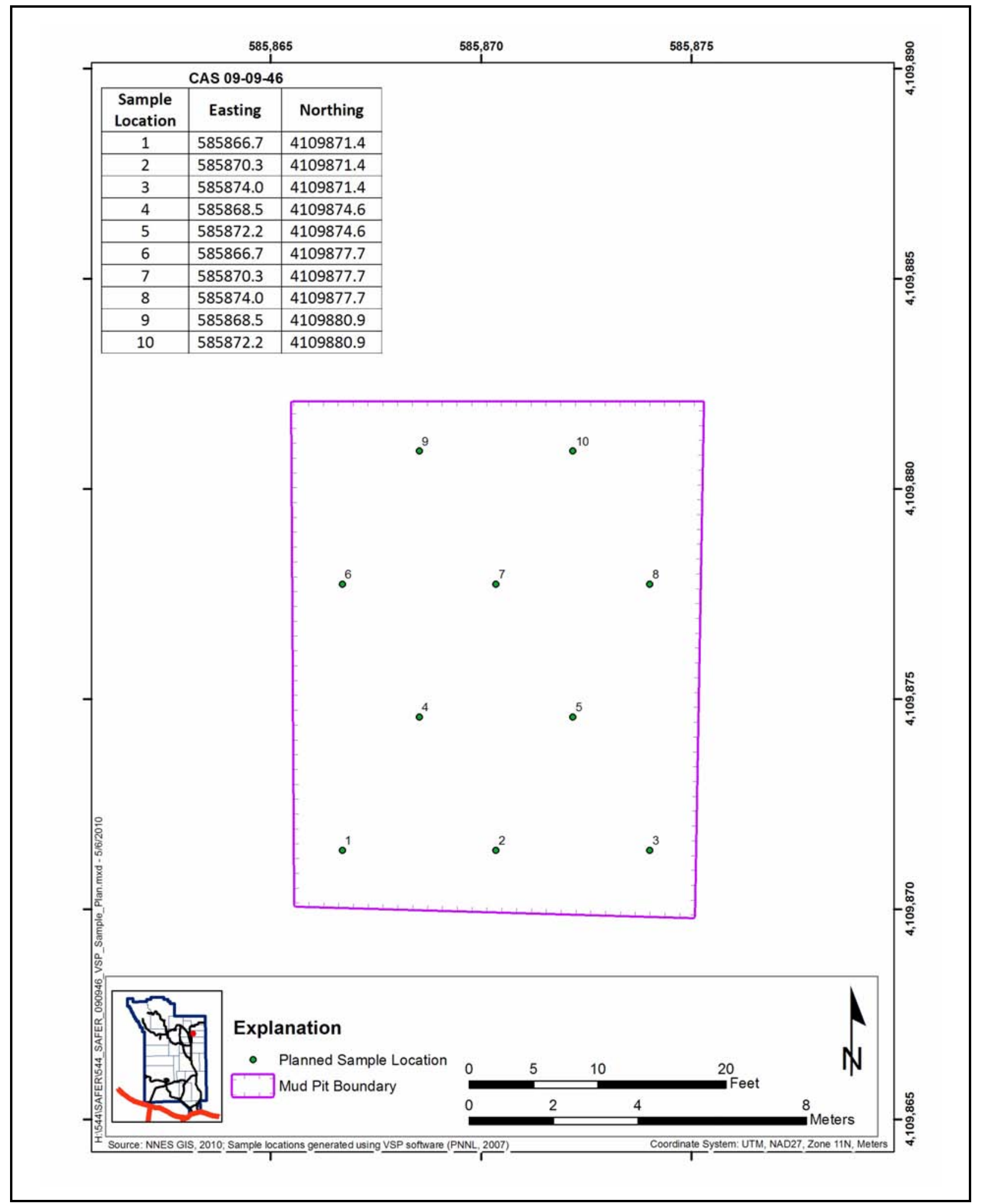

Figure C.1-2

CAS 09-09-46, Sample Locations and Coordinates 


\section{C.2.0 References}

EPA, see U.S. Environmental Protection Agency.

NNES GIS, see Navarro Nevada Environmental Services Geographic Information Systems.

Navarro Nevada Environmental Services Geographic Information Systems. 2010.

ESRI ArcGIS Software.

PNNL, see Pacific Northwest National Laboratory.

Pacific Northwest National Laboratory. 2007. Visual Sampling Plan Version 5.0, User's Guide PNNL-16939. Richland, WA.

U.S. Environmental Protection Agency. 2002. Calculating the Upper Confidence Limits for Exposure Point Concentrations at Hazardous Waste Sites. OSWER 9285.6-10. Washington, DC: Office of Emergency and Remedial Response.

U.S. Environmental Protection Agency. 2006. Data Quality Assessment: Statistical Methods for Practitioners, EPA QA/G-9S, EPA/240/B-06/003. Washington, DC. 


\title{
Appendix D
}

\section{Nevada Division of Environmental Protection Comments}

\author{
(2 Pages)
}




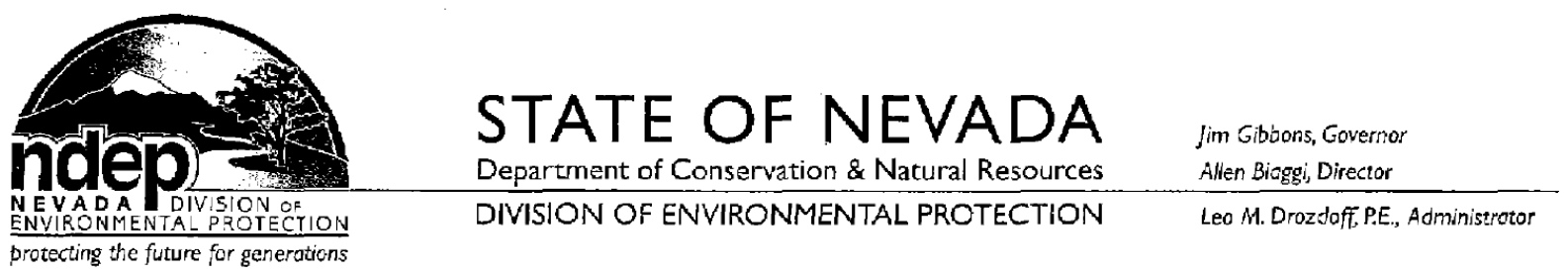

May 26, 2010

Robert F. Boehlecke

Federal Project Director

Environmental Restoration Project

National Nuclear Security Administration

Nevada Site Office

P. O. Box 98518

Las Vegas, NV $89193-8518$

RE: Review of the draft Streamlined Approach for Environmental Restoration (SAFER)

Corrective Action Unit (CAU) 544: Cellars, Mud Pits, and Oil Spills, Nevada Test Site, Nevada, Revision 0, May 2010

Federal Facility Agreement and Consent Order

Dear Mr. Boehlecke:

The Nevada Division of Environmental Protection, Bureau of Federal Facilities (NDEP) staff has received and reviewed the draft Streamlined Approach for Environmental Restoration (SAFER) for Corrective Action Unit (CAU) 544: Cellars, Mud Pits, and Oil Spills, Nevada Test Site, Nevada. NDEP's review of this document did not indicate any deficiencies.

Address any questions regarding this matter to Ted Zaferatos at (702) 486-2850, ext. 234, or myself at (702) 486-2850, ext. 233.

Sincerely,

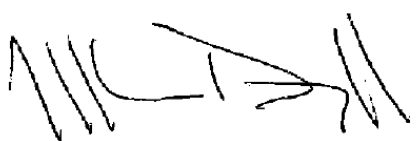

Jeff MacDougall, Ph.D., C.P.M.

Supervisor

Bureau of Federal Facilities

JJM/TZ:tz

2030 E.Flamingo Road, Suite 230 • Las Vegas, Nevada 89I19 • p: 702.486.2850 • f: 702.486.2863 • www.ndep.nv.gov prined on recreles poper 
Robert F. Boehlecke

Page 2

May 26, 2010

cc: $\quad$ K. J. Cabble, ERP, NNSA/NSO, Las Vegas, NV E.F. DiSanza, WMP, NNSA/NSO, Las Vegas, NV FFACO Group, PSG, NNSA/NSO, Las Vegas, NV Jeffrey Fraher, DTRA/CXTS, Kirtland AFB, NM

T. A. Thiele, NSTec, Las Vegas, NV

N.Y. Carson, NNES, Las Vegas, NV

$M$. Krauss, NNES, Las Vegas, NV

T.D. Taylor, NNES, Las Vegas, NV

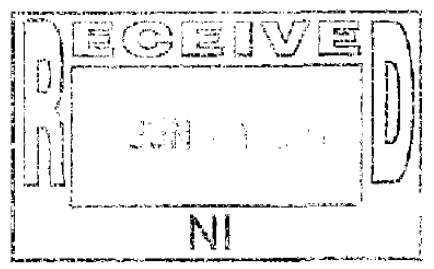




\title{
Library Distribution List
}

\author{
$\underline{\text { Copies }}$ \\ U.S. Department of Energy \\ 1 (Uncontrolled, electronic copy) \\ National Nuclear Security Administration \\ Nevada Site Office \\ Technical Library \\ P.O. Box 98518, M/S 505 \\ Las Vegas, NV 89193-8518 \\ U.S. Department of Energy \\ 1 (Uncontrolled, electronic copy) \\ Office of Scientific and Technical Information \\ 1 (Uncontroller \\ P.O. Box 62 \\ Oak Ridge, TN 37831-0062 \\ Southern Nevada Public Reading Facility \\ 2 (Uncontrolled, electronic copies) \\ c/o Nuclear Testing Archive \\ P.O. Box 98521, M/S 400 \\ Las Vegas, NV 89193-8521 \\ Manager, Northern Nevada FFACO \\ 1 (Uncontrolled, electronic copy) \\ Public Reading Facility \\ c/o Nevada State Library \& Archives \\ 100 N Stewart Street \\ Carson City, NV 89701-4285
}

